\author{
UNIVERSIDADE DE SÃO PAULO \\ INSTITUTO DE FÍSICA DE SÃO CARLOS
}

\title{
AUTOMAÇÃO DO PROCESSO DE ESTEREOLITOGRAFIA
}

ore

José Pott

USP/IFSC/SBI

||||||||||||||||||||||

8-2-001205

Dissertação apresentada ao Instituto de Física de São

Carlos, da Universidade de São Paulo, para obtenção Do título de Mestre em Ciências: Física Aplicada

Orientador: Prof. Dr. Valentin Obac Roda

São Carlos

1998 
Pott, José

Automação do Processo de Estereolitografia: Integração/ José Pott - São Carlos, 1988.

$89 p$.

Dissertação (Mestrado) - Instituto de Física de São Carlos, 1998.

Orientador: Prof. Dr. Valentin Obac Roda

1 - Estereolitografia. 2 - Prototipagem Rápida por Extrusão. 3 - Varredura a Laser. 
MEMBROS DA COMISSÃO JULGADORA DA DISSERTAÇÃO DE MESTRADO DE JOSÉ POTT APRESENTADA AO INSTITUTO DE FISICA DE SÃO CARLOS, DA UNIVERSIDADE DE SÃO PAULO, EM O9 DE MARC̣O DE 1998.

COMISSÃO JULGADORA:

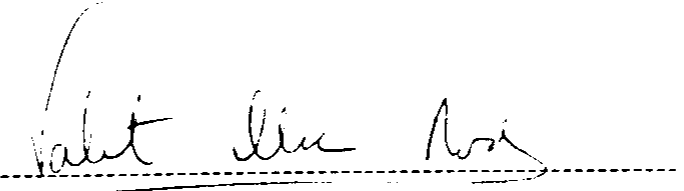

Prof. Dr. Valentin Obac Roda/IFSC-USP

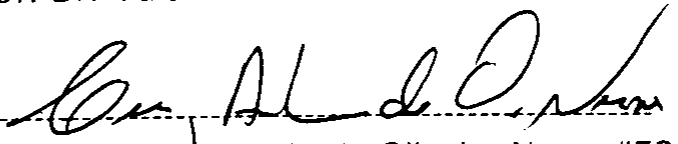

Prof. Dr. Luiz Antonio de Oliveira Nunes/IFSC-USP

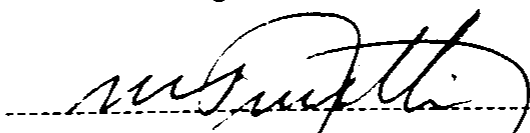

Prof. Dr. Mário Pinotti Júnior/EtSSC-USP 


\section{AGRADECIMENTOS}

Agradeço ao Prof. Dr. Valentin pela orientação, ao Luis Antônio, ao Rafael, ao Edésio, ao pessoal do grupo, à oficina de ótica, à oficina mecânica, e a tantos outros que tornaram possível a realização deste trabalho. 


\section{ÍNDICE}

Resumo

Abstract

Lista de Tabelas

1. INTRODUÇÃO

1.1. Construção de protótipos ................................................................................

1.2. Tecnologias de Prototipagem Rápida ............................................................

1.3. Estereolitografia com Resina Plástica Polimerizavel ...........................................

1.4. Processos de Exposição em Estereolitografia ......................................................10

1.5. Automação do Processo de Estereolitografia ......................................................12

2. CONSIDERAÇÕES GERAIS SOBRE O PROCESSO DE ESTEROLITOGRAFIA

2.1. Introdução

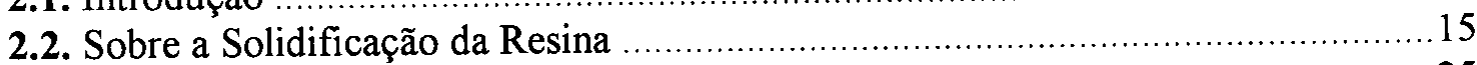

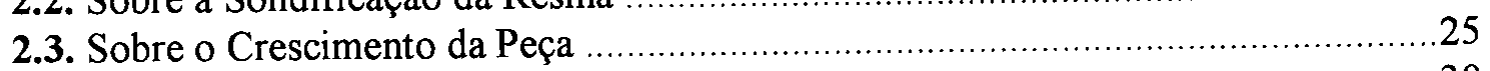

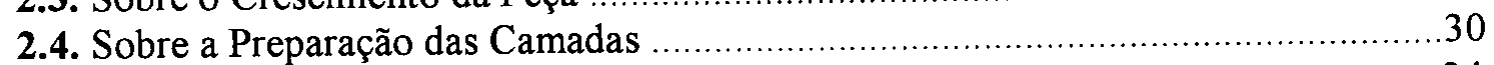

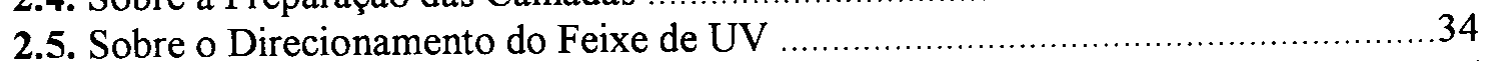

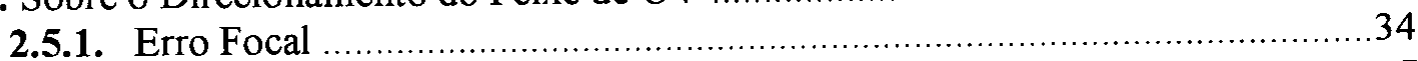

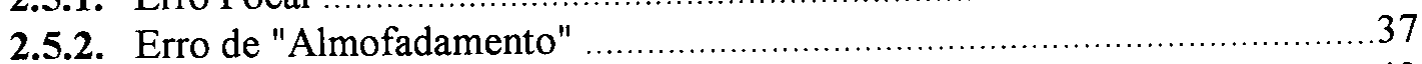

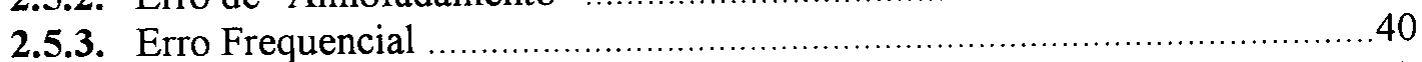

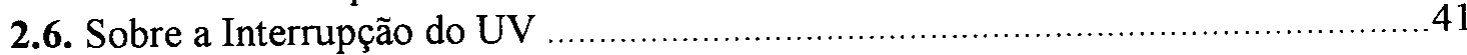

3. AUTOMAÇÃO DO PROCESSO DE ESTEREOLITOGRAFIA

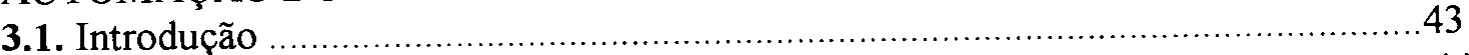

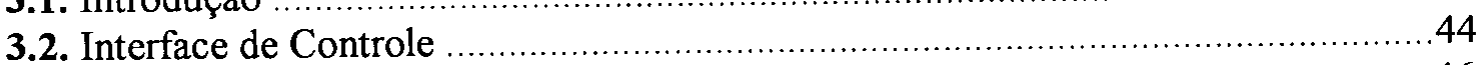

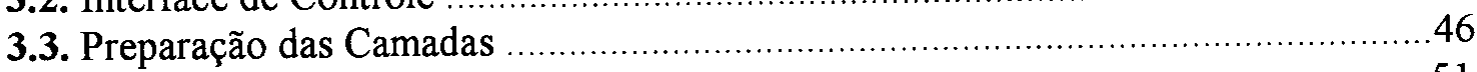

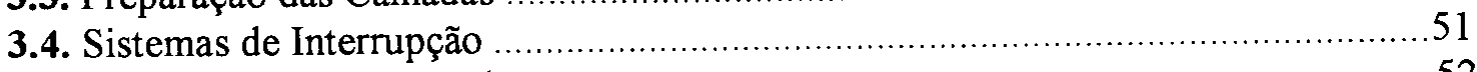

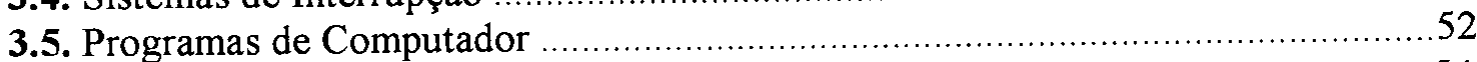

3.6. Sistema de Exposição por Projeção .............................................................. 54

3.6.1. Resultados de Construção por Superfície Livre .....................................57

3.6.2. Resultados de Construção por Superficie Fixada .....................................59

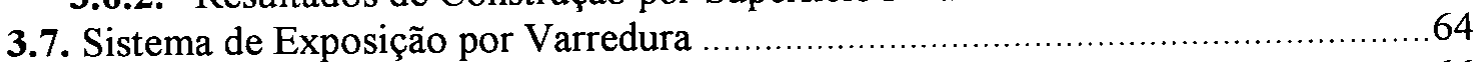

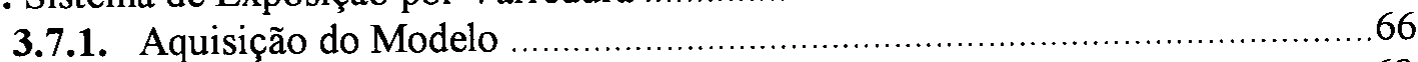

3.7.1.1. Extração de Bordas de uma Figura 3D ...........................................68

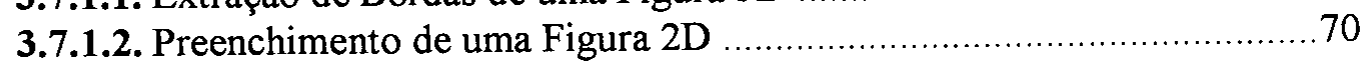

3.7.1.3. Varredura de Saída ............................................................. 75

4. ANÁLISE DOS RESULTADOS

5. CONCLUSÕES E SUGESTÕES PARA CONTINUIDADE $\ldots \ldots \ldots \ldots \ldots \ldots \ldots \ldots \ldots \ldots \ldots$

Bibliografia

Bibliografia Complementar

Apêndice A - Circuito Elétrico da Interface

Apêndice B - Programa de Controle em VisualBasic

Apêndice C - Programa de Extração de Bordas 3D em AutoLisp

Apêndice D - Programa de Controle em $\mathrm{C}^{++}$ 


\section{RESUMO}

Os processos tradicionais de construção de protótipos são caros, demorados e necessitam de profissionais altamente qualificados. Devido à grande importância de protótipos nas mais diversas áreas, há mais de uma década empresas e instituições de vários países vêm desenvolvendo diversas técnicas de prototipagem rápida.

A estereolitografia é um processo de prototipagem rápida que permite construir protótipos sólidos tridimensionais em pouco tempo a um custo relativamente baixo.

A estereolitografia é um processo no qual o protótipo é formado pela sobreposição de camadas sólidas extremamente finas formadas à partir de uma resina líquida fotopolimerizavel com luz ultra violeta. Devido à necessidade de um grande número de camadas para se conseguir uma boa resolução e, pela abrangência e complexidade envolvida, torna-se necessária a integração do sistema pela automação do processo.

Neste trabalho apresentamos a automação de um sistema de estereolitografia que realiza a construção de peças pela projeção das camadas a serem litografadas. Desenvolvemos também o suporte para a automação de um processo de estereolitografia por varredura de laser de ultra violeta que permite a construção de peças mais complexas projetadas por computador. Este último processo não foi implementado pela não disponibilidade do laser de ultra violeta e da ótica associada. 


\begin{abstract}
Traditional prototype construction processes are expensive, slow and require highly qualified professionals. Due to the great importance of prototypes in the many areas, for more than one decade companies and institutions of many countries have been developing rapid prototyping techniques.

Stereolithography is a rapid prototyping technique for low time, low cost, construction of three-dimentional solid prototypes.

In stereolithography the prototype is formed by the fusion and adherence of extremely fine solid layers made of a liquid resin, fotopolimerized by ultra violet light. Because the method requires a great number of layers to obtain a good resolution and due to its associated complexity, automation is necessary to integrate the varios parts of the stereolithography system.

In this work we present the automation of a stereolithography system that accomplishes the construction of prototyping using a projection of the layers to be lithographed. We also developed the support for the automation of a stereolithography process using laser scanning which allows the construction of more complex computer aided designed prototypes. This laser scanning process was not implemented due to the non availability of the ultra violet laser and associated optics.
\end{abstract}




\section{LISTA DE FIGURAS}

Figura 1.1 - (Exemplo de um modelo de peça 3D ) ....................................

Figura 1.2 - ( Representação do modelo 3D por camadas ) ................................. 8

Figura1.3 - (Estereolitografia pelo Método Bifotônico ) ...................................9

Figura 1.4 - ( Fluxograma do Processo de Estereolitografia ) .............................. 10

Figura 1.5 - ( Projeção de uma Imagem com Fotomáscara ) ................................ 11

Figura 1.6 - ( Sistema de Varredura com Laser ) ........................................ 12

Figura 2.1 - ( Trajetória Randônica de um Foton ao Penetrar na Resina )...............17

Figura 2.2 - ( Valores teóricos para a "Célula Solidificada") ................................ 17

Figura 2.3 - ( Variação da Largura da Pista com a Velocidade de Varredura) ............19

Figura 2.4 - ( Variação da Profundidade da Pista com a Velocidade de

Varredura ).

Figura 2.5 - ( Relação entre espessura solidificada e quantidade de radiação para a resina OKM-2 em atmosfera de Ar e Hélio )

Figura 2.6 - ( Relação entre espessura solidificada e quantidade de radiação para a resina TGM-3 em atmosfera de Ar e Hélio ) .....................22

Figura 2.7 - ( Disposição Normal de "Células Solidificadas") .................................25

Figura 2.8 - ( Disposição Justaposta de "Células Solidificadas")...........................26

Figura 2.9 - ( Disposição Extraposta de “Células Solidificadas”) ............................26

Figura 2.10 - ( Efeito Escada formado pela sobreposição de Camadas ) ..................27

Figura 2.11 - (Falta de Monotonicidade numa orientação errônea do

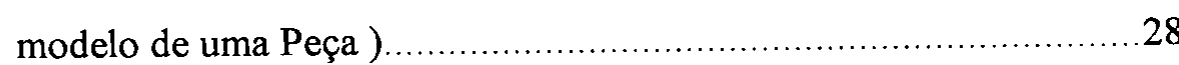

Figura 2.12 - ( Mesmo Modelo orientado corretamente com o sentido de crescimento da Peça )......

Figura 2.13 - (Exemplo de uma Peça que não possui nenhum sentido de Monotonicidade ).............................................29

Figura 2.14 - ( Divisão da Peça em partes apropriadas para a construção ) ..............29

Figura 2.15 - ( Formação de uma Camada pela descida da Plataforma )..................30

Figura 2.16 - ( Formação de uma Camada com a Janela Instalada ) ..........................31 
Figura 2.17 - ( Variante do Crescimento da Peça com uma Plataforma Móvel ).......32

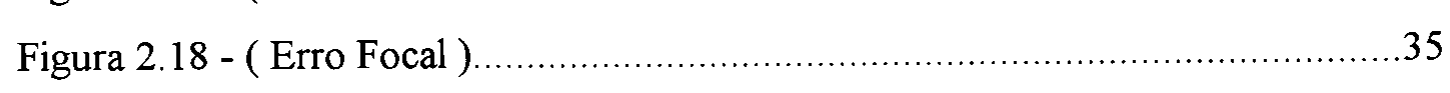

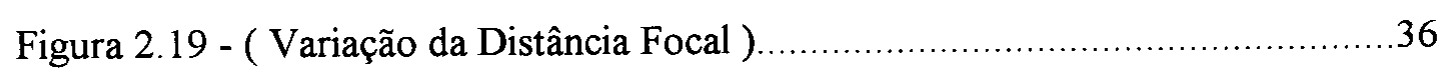

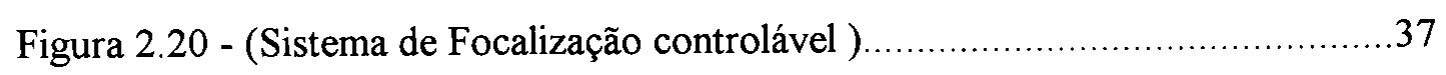

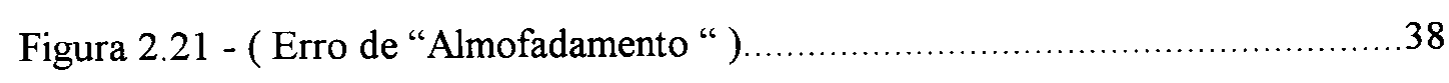

Figura 2.22 - ( Geometria Auxiliar do erro de "Almofadamento" ).........................38

Figura 2.23 - ( Distorção Frequencial causada por velocidade de varredura alta )...40

Figura 2.24 - ( Filetes gravados indevidamente devido a falta de sincronismo entre os processos de Interrupção e Varredura )...........................44

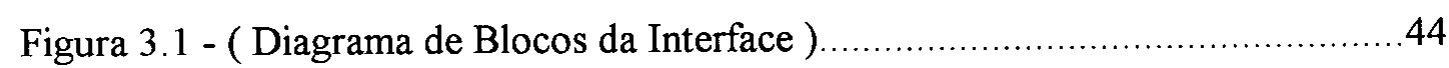

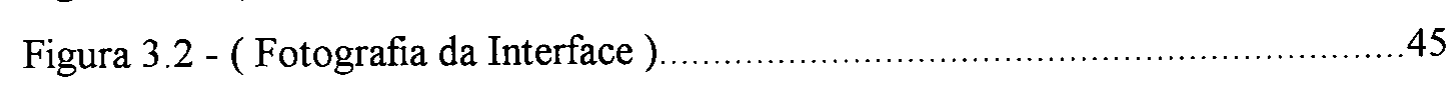

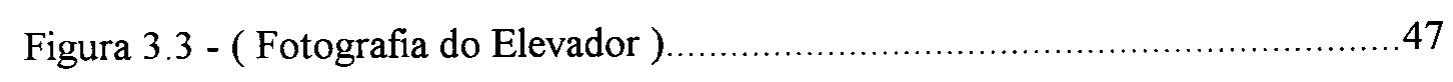

Figura 3.4 - ( Desgrudamento da Peça com o uso da folha de Celofane ) .................48

Figura 3.5 - ( Ciclo completo do Processo de Estereolitografia )..........................49

Figura 3.6 - ( Fluxograma de formação de camada ) ...........................................50

Figura 3.7 - ( Sistema de Interrupção na Exposição por Projeção ) ..........................51

Figura 3.8 - (Sistema de Interrupção na Exposição por Varredura ) .........................51

Figura 3.9 - ( Tela do Programa de Controle em VisualBasic ) .................................53

Figura 3.10 - ( Fotografia do Autocolimador Ótico ) ...........................................54

Figura 3.11 - ( Sistema de Construção por Superficie Livre ) ..............................55

Figura 3.12 - (Fotografia do Sistema de Construção por Projeção ) ........................56

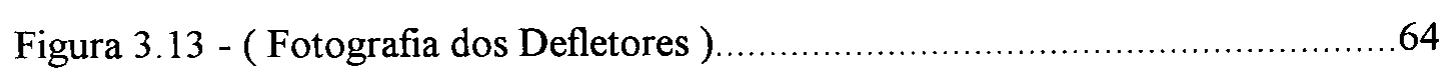

Figura 3.14 - ( Posicionamento do Modelo 3D para a Extração dos Pontos )...........67

Figura 3.15 - ( Representação das principais Entidades do AutoCad )....................69

Figura 3.16 - ( Comandos para a Extração de Bordas de uma Figura 3D )..............69

Figura 3.17 - (Exemplo da Matriz com Elementos de Borda ) .............................. 70

Figura 3.18 - (Elementos utilizados para testes de Borda ) .............................. 71

Figura 3.19 - ( Possíveis Bordas que podem ser encontradas ) ...........................72

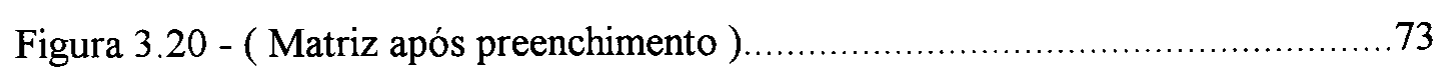

Figura 3.21 - ( Fluxograma de Preenchimento de uma Figura 2D )...................... 74

Figura 3.22 - ( Sentido de Varredura do feixe de luz UV ) ..............................75 
Figura 3.23 - ( Fluxograma da Varredura de Saída )

Figuras rl a r3 - ( Protótipos construídos por Superficie Livre ). .58

Figuras r4 a r14 - ( Protótipos construídos por Superficie Fixada ). $60-62$

Figura r15 - ( Fotomáscaras utilizadas na Projeção ) 


\section{LISTA DE TABELAS}

Tabela 1.1 - ( Empresas e Instituições que Desenvolvem Sistemas de

Prototipagem Rápida ).

Tabela 2.1 - ( Legenda das Resinas em Função da Densidade de Corantes )............. 18

Tabela 2.2 - ( Quantidade de Radiação para a Polimerização da Resina OKM-2 )...23

Tabela 2.3 - ( Quantidade de Radiação para a Polimerização da Resina TGM-3 )....23

Tabela 3.1 - ( Condições de Exposição por Superficie Livre ) ...............................57

Tabela 3.2 - ( Condições de Exposição por Superfície Fixada )...............................59

Tabela 3.3 - ( Formato do Arquivo resultante da Aquisição do Modelo ) ................66

Tabela 3.4 - ( Sentidos Possíveis de Deslocamento entre Elementos Vizinhos ).......76

Tabela 3.5 - ( Posicionamento da Máscara para os Sentidos de Deslocamento ).......77

Tabela 3.6 - ( Curvaturas em Inclinação Reta ) ............................................. 80

Tabela 3.7 - ( Curvaturas em Inclinação Obliqua ) .......................................... 81 


\section{INTRODUÇÃO}

\subsection{Construção de protótipos}

A construção de protótipos é uma etapa intermediária no desenvolvimento de um produto, sendo geralmente usada para avaliações do desempenho futuro de um produto a ser manufaturado. As avaliações utilizando protótipos são úteis em diversas áreas de desenvolvimento e aplicação como industriais, de pesquisa, médicas, engenharia civil e arquitetura entre outras.

Em se tratando de protótipos sólidos 3D, a visualização é um forte item de análise. $\mathrm{Na}$ indústria, através da análise do protótipo são feitas as correções necessárias antes de se colocar o produto na linha de produção. $\mathrm{Na}$ pesquisa, a necessidade constante de peças muito particulares, não convencionais, acaba tornando o protótipo o produto final para os pesquisadores. $\mathrm{Na}$ área médica, a partir de imagens conseguidas por Ressonância Magnética, Raios X e outras técnicas, pode-se construir protótipos de orgãos do corpo todo e especialmente de ossos quando da necessidade de um implante, onde o protótipo é de grande valia. $\mathrm{Na}$ arquitetura em geral, se estendendo à engenharia civil, basta mencionar que uma maquete é um protótipo que mostra a forma final de uma edificação. 
Entretanto a construção de um protótipo 3D pelos métodos tradicionais é um processo caro e demorado que necessita de uma infra-estrutura adequada e de profissionais altamente qualificados para a realização do serviço. A necessidade de construção rápida de protótipos levou, há mais de uma década, pesquisadores e instituições de diversos países a desenvolverem métodos mais eficientes para construção destes protótipos que são chamados de tecnologias de prototipagem rápida.

\subsection{Tecnologias de prototipagem rápida}

A seguir, na tabela 1.1 apresentamos diversas empresas e instituições com suas respectivas tecnologias empregadas para a construção rápida de protótipos [1] e uma descrição das tecnologias existentes incluindo uma noção de custo e resolução dos equipamentos.

Tabela 1.1: Empresas e Instituições que desenvolvem sistemas de prototipagem rápida.

\begin{tabular}{|l|l|}
\hline \multicolumn{1}{|c|}{ INSTITUIC̃̃̃O / EMPRESA } & \multicolumn{1}{c|}{ TECNOLOGIA } \\
\hline 3D Systems & Estereolitografia \\
\hline Quadrax Laser Technologies & Estereolitografia \\
\hline JSR / Sony & Estereolitografia \\
\hline Mitsubishi & Estereolitografia \\
\hline Electro Optical Systems & Estereolitografia \\
\hline Mitsui & Estereolitografia \\
\hline DTM Co. & Sinterização Seletiva por Laser \\
\hline Helisys & Laminação \\
\hline Sparx AB & Laminação \\
\hline Light Sculpting & Fotosolidificação \\
\hline Stratasys & Modelamento por Fusão e Deposição \\
\hline MIT & Jato de Tinta \\
\hline Texas Instruments & Jato de Tinta \\
\hline Perception Systems & Confecção Balística por Partículas \\
\hline
\end{tabular}

Os sistemas de prototipagem rápida mencionados utilizam processo de construção de múltiplas camadas, sendo que os formatos das camadas resultam de um

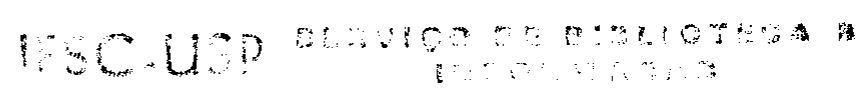


processo de seccionamento transversal (horizontal) do modelo $3 \mathrm{D}$ segundo o qual será construído o protótipo.

A empresa $3 D$ Systems foi a pioneira em equipamentos de prototipagem rápida por estereolitografia com resina líquida fotopolimerizavel, tendo desenvolvido o processo em 1987. A empresa desenvolveu três modelos que possuem diferenças em relação às dimensões das peças que podem ser construídas, à velocidade de construção e ao preço.

O modelo SLA-190 possibilita a construção de peças de até $190 \mathrm{~mm}$ X 190mm X $250 \mathrm{~mm}$, usa laser de $\mathrm{HeCd}$, a velocidade de deslocamento do laser é de $38 \mathrm{~cm}$ por segundo e custa US\$95.000.

O modelo SLA-250 permite a construção de peças de até $254 \mathrm{~mm}$ X $254 \mathrm{~mm} \mathrm{X}$ $254 \mathrm{~mm}$, também usa laser de $\mathrm{HeCd}$, tem velocidade de deslocamento de $38 \mathrm{~cm}$ por segundo e custa US\$187.000.

E o modelo SLA-500 permite a construção de peças de até $508 \mathrm{~mm}$ X $508 \mathrm{~mm}$ X 610mm, usa laser de Íon-Argônio e por ísso pode se deslocar a uma velocidade de $254 \mathrm{~cm}$ por segundo e custa US\$385.000.

A velocidade de deslocamento se refere à velocidade com que o feixe percorre a camada de resina solidificando-a de acordo com a secção correspondente ao modelo. Os três modelos da $3 D$ Systems operam com diâmetro de feixe do laser igual a $0,25 \mathrm{~mm}$ e possibilitam a criação de camadas com espessura entre $0,0254 \mathrm{~mm}$ e $0,254 \mathrm{~mm}$

A empresa Quadrax Laser Technologies desenvolveu um sistema de estereolitografia com resina líquida fotopolimerizavel chamado Mark 1000. Esse 
equipamento opera com comprimento de luz visível de laser de Íon-Argônio e possui a capacidade de variar o diâmetro do feixe de laser incidente. $O$ preço do equipamento é US\$230.000.

As empresas japonesas Sony e JSR desenvolveram o sistema SCS (Solid Creation System) similar ao SLA-500 usando também laser de Íon-Argônio, porém com capacidade de construção de peças de até um metro cúbico. O preço do SCS é US\$500.000.

A também japonesa Mitsubishi, desenvolveu um sistema chamado SOUP (Solid Object Ultraviolet Laser Plotter), similar aos modelos SLA da 3D System.

A empresa Electro Optical Sistems, da Alemanha, desenvolveu um sistema de estereolitografia também similar aos SLA. O sistema foi chamado de ESTEREOS 400 e apresenta duas versões. A menor possibilita a construção de peças de até $40,64 \mathrm{~cm}$ $\mathrm{X} 40,64 \mathrm{~cm} \mathrm{X} 25,4 \mathrm{~cm}$ e usa laser de $\mathrm{HeCd}$ de $25 \mathrm{~W}$. O sistema de maior porte permite a construção de peças de até $40,64 \mathrm{~cm}$ X 40,64cm X $60,96 \mathrm{~cm}$ e usa laser de ÍonArgônio de 300mW.

A empresa americana DTM desenvolveu um sistema que utiliza um processo chamado SLS (Selective Laser Sintering), que também opera camada por camada, mas ao invés de usar resina líquida fotopolimerizavel, usa pó de policarbonatos, nylon ou metais para serem sinterizados com laser de gás carbônico $\left(\mathrm{CO}_{2}\right)$ que eleva a temperatura dos grãos ao ponto de fusão, fundindo-os sem derretê-los efetivamente A precisão do sistema, segundo a $D T M$, é de $0,127 \mathrm{~mm}$.

A empresa canadense Helisys desenvolveu equipamentos de prototipagem rápida utilizando a técnica LOM (Laminated Object Manufacturing). Nesse processo de laminação o material usado para constituir as camadas é papel (em folhas ou 
lâminas), com espessura entre $0,051 \mathrm{~mm}$ e $0,254 \mathrm{~mm}$, o qual é recortado à laser de $\mathrm{CO}_{2}$ de acordo com o formato da camada em questão. Quando uma nova folha de papel é colocada sobre a anterior, um rolo quente pressiona ao longo de toda a folha e a faz colar-se na anterior; podendo então começar a recortá-la também. O modelo LOM-1015 usa laser de de $\mathrm{CO}_{2}$ de $25 \mathrm{~W}$ recortando a folha de papel a uma velocidade de $381 \mathrm{~mm}$ por segundo e custa US\$85.000. O modelo LOM-2030 usa laser de $\mathrm{CO}_{2}$ de $50 \mathrm{~W}$ atingindo velocidade de corte de $610 \mathrm{~mm}$ por segundo e custa US\$140.000. Ambos os modelos oferecem precisão de $0,127 \mathrm{~mm}$

A empresa suiça Sparx $A B$ desenvolveu um processo de laminação chamado Hot Plot, que cola lâminas de Poliestileno de $1 \mathrm{~mm}$ de espessura e realiza os cortes com um posicionador mecânico (Plotter) equipado com um eletrodo quente. A operação de posicionamento das lâminas é manual, e o equipamento custa US\$12.900

A empresa americana Light Sculpting desenvolveu um processo chamado DesCAF (Design-Controled Automated Fabrication). Esse sistema também usa resina líquida fotopolimerizavel para formar as camadas. A cura da camada, de acordo com a respectiva secção do modelo $3 \mathrm{D}$ é feita pela projeção dessa secção com fotomáscara e lâmpada de UV. As máscaras devem ser trocadas manualmente. O modelo LSI-0609MA constrói peças de até 152,4mm X 152,4mm X 229mm com resolução de $0,00636 \mathrm{~mm}$, precisão de $0,0381 \mathrm{~mm}$ e espessura das camadas entre $0,0254 \mathrm{~mm}$ e $1,27 \mathrm{~mm}$. O tempo de solidificação da camada está abaixo de um minuto, e o preço do equipamento é US\$99.600. Segundo o presidente da empresa o sistema é de 10-100 vezes mais rápido do que dos sistemas à laser, e tem resolução 60 vezes melhor. 
A empresa Stratasys Inc. desenvolveu um processo de prototipagem rápida por deposição de material fundido, FDM (Fused Deposition Modeling). Nesse sistema, um carretel contém um fio termoplástico que será extrudado através de um bico quente. Nessa passagem a temperatura do termoplástico é elevada a um ponto um pouco acima de seu ponto de fusão, derretendo-o e depositando-o em seguida na superficie em construção onde solidifica-se rapidamente. O modelo 3D- Modeler pode construir peças de até $30,5 \mathrm{~cm} \times 30,5 \mathrm{~cm} \times 30,5 \mathrm{~cm}$. A precisão dos deslocamentos do bico é de $0,0254 \mathrm{~mm}$, a espessura das camadas está entre $0,0254 \mathrm{~mm}$ e $1,27 \mathrm{~mm}$, a velocidade de deslocamento do bico é de $38,1 \mathrm{~cm}$ por segundo e o preço do equipamento é US\$178.000.

O Instituto Tecnológico de Massachusetts (MIT) desenvolveu um sistema de prototipagem rápida também multicamadas usando tecnologia de jato de tinta (ink jet). O material a constituir as camadas são dois: cerâmica em pó e cerâmica pastosa. O sistema deposita uma fina camada da cerâmica em pó sobre uma plataforma através de um sistema de pulverização. Em seguida, a cabeça impressora do jato deposita a cerâmica pastosa nos pontos desejados de acordo com a respectiva secção do modelo, concretizando a formação da camada. A cerâmica em pó usada é de óxido de alumínio, e a pastosa é sílica coloidal. O sistema desenvolvido pelo MIT possibilita a construção de peças de até $30,5 \mathrm{~cm} \times 30,5 \mathrm{~cm} \times 61 \mathrm{~cm}$, numa taxa de crescimento vertical de $6,35 \mathrm{~cm}$ por hora, com espessura de camada igual a $0,127 \mathrm{~mm}$.

A Texas Instruments também desenvolveu um sistema usando jato de tinta. $\mathrm{O}$ sistema, chamado de PCT (Printed Computer Tomograph) possibilita a construção de peças de até $30,5 \mathrm{~cm} \times 30,5 \mathrm{~cm}$ X $30,5 \mathrm{~cm}$ com resolução de $0,1 \mathrm{~mm}$. 
A empresa americana Perception Systems desenvolveu um sistema parecido com o do MIT e o da Texas, usando também tecnologia de jato de tinta. A cabeça do jato de tinta usado possui um mecanismo piezoelétrico para a ejeção do material formador da peça, por isso esse sistema foi chamado de BPM (Ballistic Particle Manufacuring). O segundo material utilizado pelo BPM, o que é ejetado, é o Polietileno Glicol. A precisão do equipamento é de $0,102 \mathrm{~mm}$ e o preço está em torno de US\$50.000.

\subsection{Estereolitografia com resina plástica polimerizável}

A estereolitografia é um processo de sobreposição de camadas litografadas, ou seja, camadas com espessura relevante, podendo ser chamadas de camadas de alto relevo. A sobreposição de muitas camadas de alto relevo forma uma peça sólida 3D Através do modelo de uma peça podemos construí-la desde a base até o topo sobrepondo as camadas correspondentes às seções transversais do modelo. Na figura 1.1 vemos um exemplo de um modelo $3 \mathrm{D}$ desenhado no computador e na figura 1.2 vemos esse modelo representado por camadas.

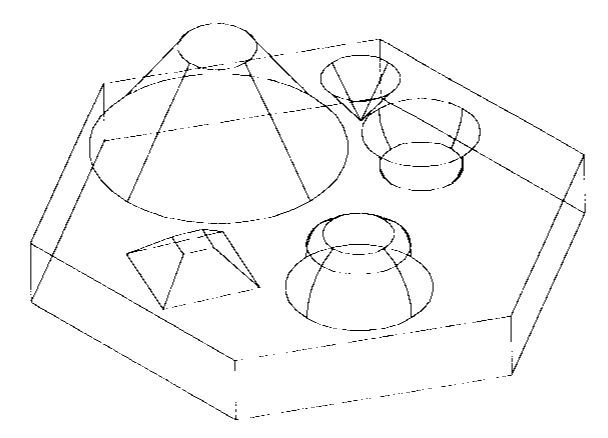

Figura 1.1 : Exemplo de um modelo 3D original. 


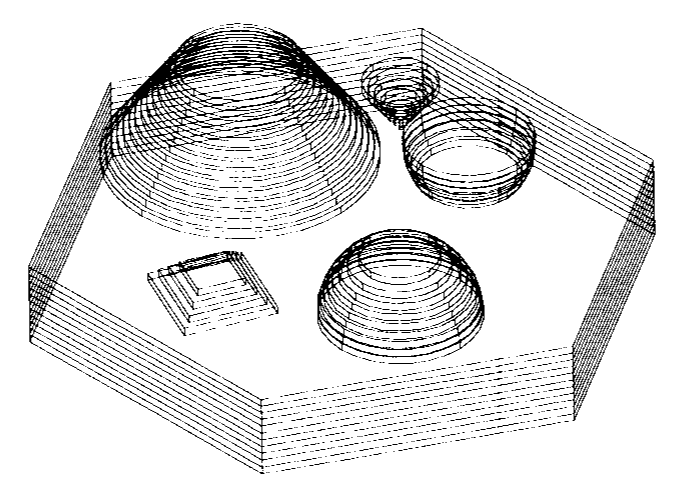

Figura 1.2 : Representação do modelo 3D por camadas.

A estereolitografia pode ser realizada usando-se como material constituinte das camadas resina plástica líquida fotopolimerizavel. A cura (endurecimento) da resina ocorre pela incidência de luz Ultra Violeta (UV) proveniente de fontes como laser de Íon-Argônio, Hélio-Cadmio ( $\mathrm{HeCd})$, Xenônio $(\mathrm{XeCl}), \mathrm{KrCl}$, e também de lâmpadas de Xenônio e Mercúrio.

A camada deve ser preparada com a resina (em estado líquido) e em seguida faz-se a incidência da luz UV nos pontos desejados de acordo com o formato da secção, curando a resina nesses pontos (estado sólido), efetivando a litografia da camada. A preparação das camadas é feita normalmente por um elevador cuja plataforma submerge num reservatório que contém a resina. Com a submersão controlada, forma-se uma camada de resina líquida com a espessura desejada acima da plataforma.

A incidência de luz UV é feita geralmente por varredura, "desenhando-se" a secção, ponto a ponto, com o feixe de laser. Outra alternativa para curar a resina é pela projeção da imagem da secção através de fotomáscaras e lâmpadas de UV. 
Outra variação do processo de estereolitografia com resina líquida fotopolimerizavel utiliza duas fontes de luz de comprimento de onda diferentes para a polimerização da resina, sendo conhecido por processo bifotônico [2]. Nesse caso, o endurecimento da resina acontece nas regiões onde se cruzam os raios de luz das duas fontes. Esse processo torna desnecessária a plataforma de crescimento, sendo que a peça é construída de maneira "suspensa" na resina dentro do reservatório, não precisando de sustentação mecânica. Na figura 1.3 vemos um esquema da técnica de estereolitografia pelo processo bifotônico.

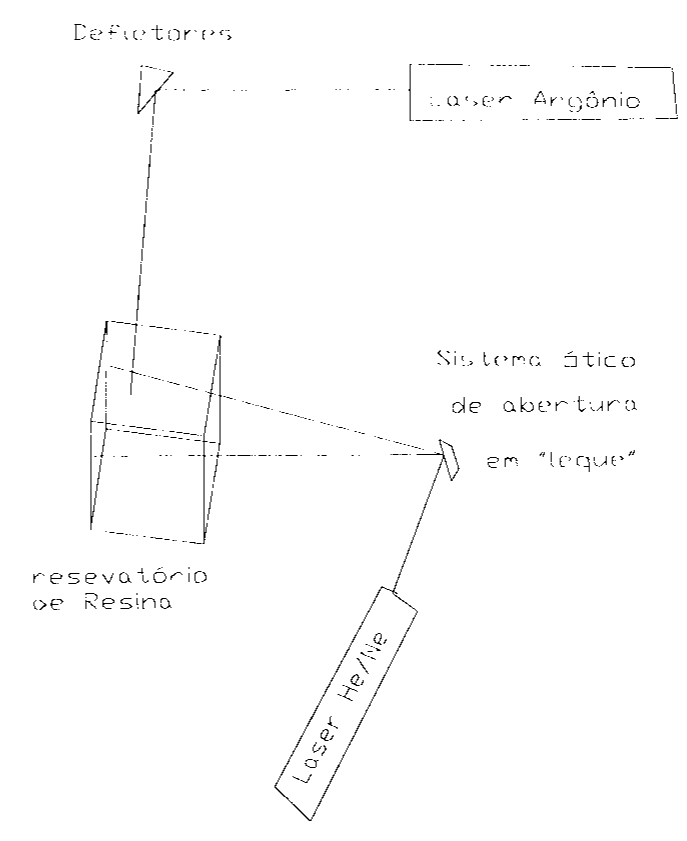

Figura 1.3 : Estereolitografia pelo processo Bifotônico.

O elevador nesse processo, responsável pelo eixo $z$, transporta uma das fontes de luz, nesse caso o laser de $\mathrm{He} / \mathrm{Ne}$, e o plano XY recebe a incidência do laser de Argônio. Como podemos observar na figura acima, o laser de $\mathrm{He} / \mathrm{Ne}$ é aberto em 
"leque" por dispositivos óticos, sendo que na intersecção desses dois comprimentos de onda ocorre a polimerização da resina.

No processo de estereolitografia, a primeira etapa para a construção de um protótipo é a aquisição do modelo, depois o processo torna-se uma sequência repetitiva dos dois eventos principais que compõem a técnica:

1 - Preparação das camadas.

2 - Exposição do modelo com luz UV.

A figura 1.4 mostra o diagrama do processo de estereolitografia

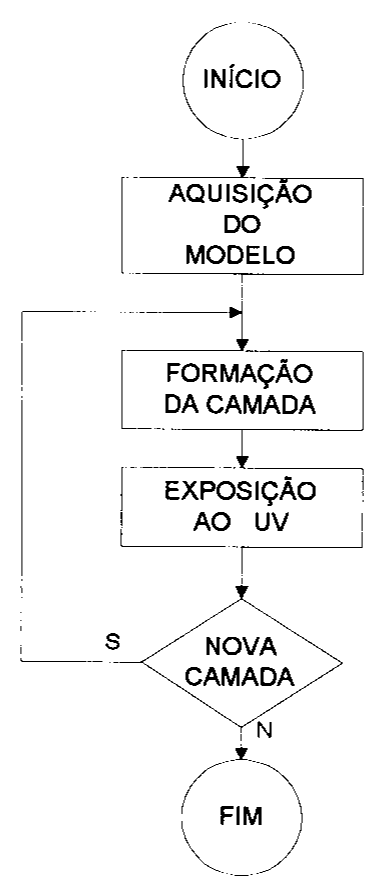

Figura 1.4 : Diagrama do Processo de Estereolitografia

\subsection{Processos de exposição em estereolitografia}

A exposição em estereolitografia pode ser realizada por dois processos distintos que diferem muito quanto a complexidade e principalmente quanto ao alcance de aplicabilidade da técnica. Os dois processos são: 
1 - Por Projeção.

2 - Por Varredura.

$\mathrm{Na}$ exposição ao UV por projeção todos os pontos pertencentes à secção (pontos de borda e pontos internos) são expostos simultaneamente pela imagem projetada da secção, projeção essa feita com fotomáscaras que podem ser conseguidas por métodos fotográficos comuns. Toda vez que uma dada secção diferir da anterior deve ocorrer a troca da fotomáscara. Na figura 1.5 vemos um desenho da projeção de uma imagem com uma fotomáscara.

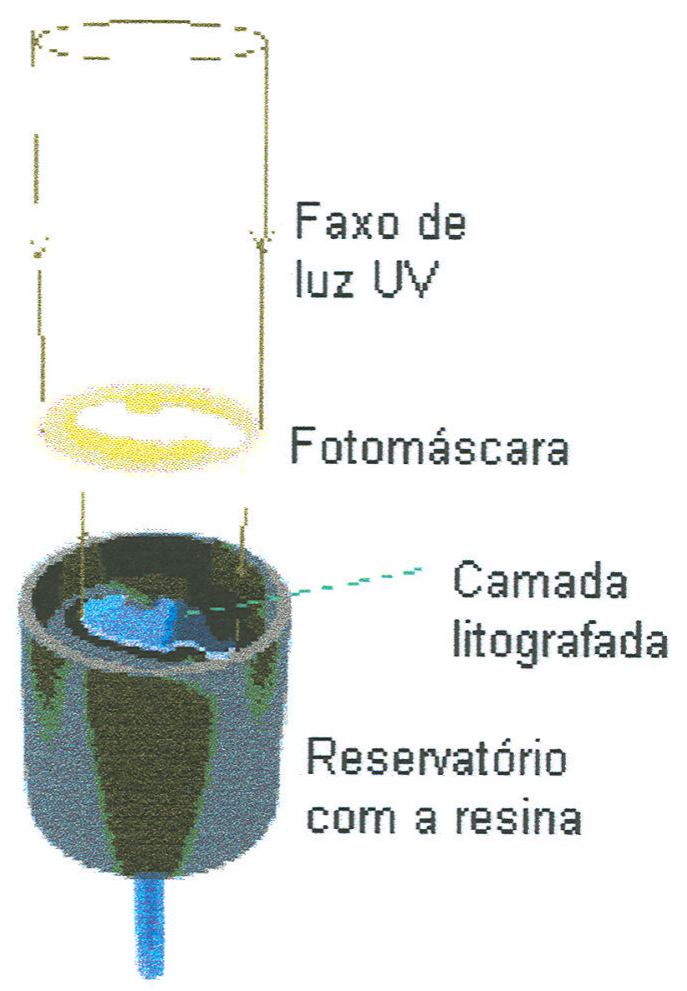

Figura 1.5 : Projeção de uma Imagem por uma Fotomáscara.

A exposição por varredura é um processo em que os pontos pertencentes a uma dada secção do modelo 3D são litografados um a um pelo feixe de luz UV. Cada camada a ser litografada corresponde a uma respectiva secção do modelo $3 \mathrm{D}$, sendo 
que cada secção é uma figura 2D cujos pontos serão usados para direcionar o feixe de UV e concretizar a solidificação da mesma. Na figura 1.6 vemos o esquema de varredura de uma camada de resina por um feixe de laser.

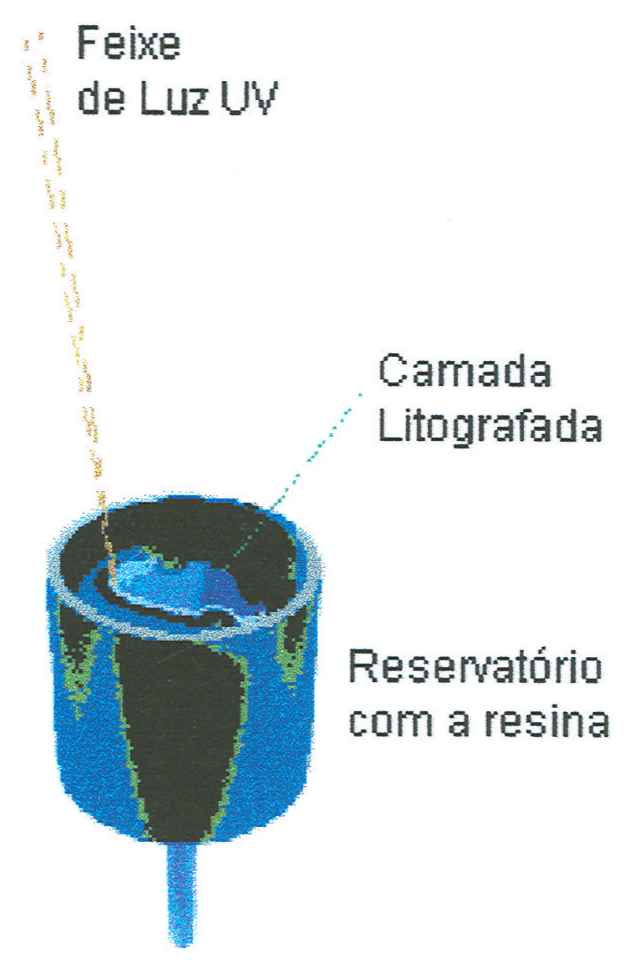

Figura 1.6 : Sistema de Varredura por Laser.

\subsection{Automação do processo de estereolitografia}

Neste trabalho foi desenvolvida a automação utilizando microcomputador para o processo de estereolitografia com resina polimerizavel. A automação foi utilizada para um método de preparação de camadas e para dois métodos de exposição ao UV.

O sistema desenvolvido permite a construção de protótipos de até $40 \mathrm{~mm}$ de altura por $40 \mathrm{~mm}$ de diâmetro, com espessura mínima de camada, resolução em relação ao eixo z, de $0,01 \mathrm{~mm}$. Na exposição por projeção o equipamento permite o uso de apenas uma fotomáscara, resultando em peças extrudadas. 
Por varredura é possível a construção de peças mais complexas, bastando que o modelo possa ser acessado pelo AutoCad-Release 13. Serão descritos os sistemas desenvolvidos para a Aquisição do Modelo, de Preparação de Camadas e da Exposição ao UV. Será mostrada a instrumentação utilizada e desenvolvida: mecânica, ótica e eletrônica, bem como os programas computacionais necessários: de controle geral, de aquisição do modelo e de direcionamento do feixe de UV. 


\section{CONSIDERAÇÕES GERAIS SOBRE O PROCESSO DE ESTEREOLITOGRAFIA}

\subsection{Introdução}

Um sistema automatizado de estereolitografia com resina líquida fotopolimerizavel é um processo multidisciplinar que abrange áreas do conhecimento da química, ótica, mecânica, eletrônica e informática. Para a integração do sistema devemos adquirir um conhecimento suficiente dos aspectos relevantes de cada área considerando as possibilidades operacionais e de infra-estrutura necessárias para a implementação de um sistema cujo desempenho está diretamente relacionado com a profundidade e aplicabilidade dessas pesquisas.

Neste capítulo apresentamos alguns aspectos e considerações de maneira a fornecer um suporte necessário para a automação do processo de estereolitografia. 


\subsection{Sobre a Solidificação da Resina}

Fotopolimerização é a utilização de luz como fonte de energia para a polimerização de monômeros e oligômeros funcionais de uma resina, podendo dessa maneira solidificá-la. Para tanto, é necessário que o sistema absorva a energia luminosa e a utilize para promover novas ligações químicas resultando no estado físico sólido.

A absorção da energia luminosa pode ser feita através de fotoiniciadores que, sendo agentes químicos capazes de absorver luz UV e proximidades do visível numa faixa espectral entre $250-450 \mathrm{~nm}$, convertem essa energia luminosa em energia química gerando subprodutos reativos intermediários como radicais livres e cátions reativos, que subsequentemente iniciarão a polimerização dos monômeros e oligômeros funcionais, efetivando a cura da resina.

Quandn um fóton da luz UV atinge uma molécula do fotoiniciador FI, este permanece num estado eletronicamente excitado $\mathrm{FI}^{*}$ como mostrado na equação 1.

$$
\mathrm{FI}+\mathrm{luz} \rightarrow \mathrm{FI}^{*}
$$

A molécula do fotoiniciador permanece excitada por um tempo menor que $10^{-6} \mathrm{~s}$, sendo esse o tempo disponível para a produção dos subprodutos intermediários I (ou I ${ }^{+}$) antes que ocorra o decaimento expontâneo, e consequentemente o retorno a FI com a liberação da energia em forma de luz ou calor. 


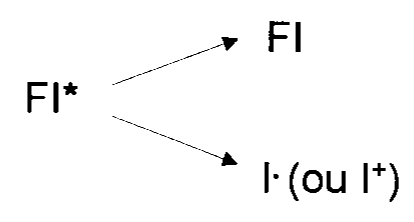

$\mathrm{O}$ agente intermediário $\mathrm{I}$ pode combinar-se com outro radical $\mathrm{R}$ ou iniciar a polimerização de um monômero M. [3]

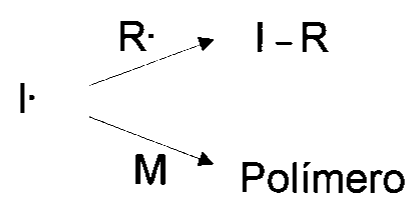

A incidência de um feixe de luz UV sobre a resina provoca a solidificação de uma unidade de construção chamada "Célula Solidificada" [4] cuja estrutura possui formato e tamanho que determinarão a precisão final do trabalho, uma vez que este é composto por células ao lado de células e sobre células.

Quando os fotons do feixe de UV penetram na resina eles descrevem trajetórias aleatórias devido a dispersões ocorridas pelos choques com as moléculas presentes até encontrar um fotoiniciador, quando então são absorvidos. A figura 2.1 mostra a trajetória de um foton ao penetrar na resina através de uma janela do reservatório. 


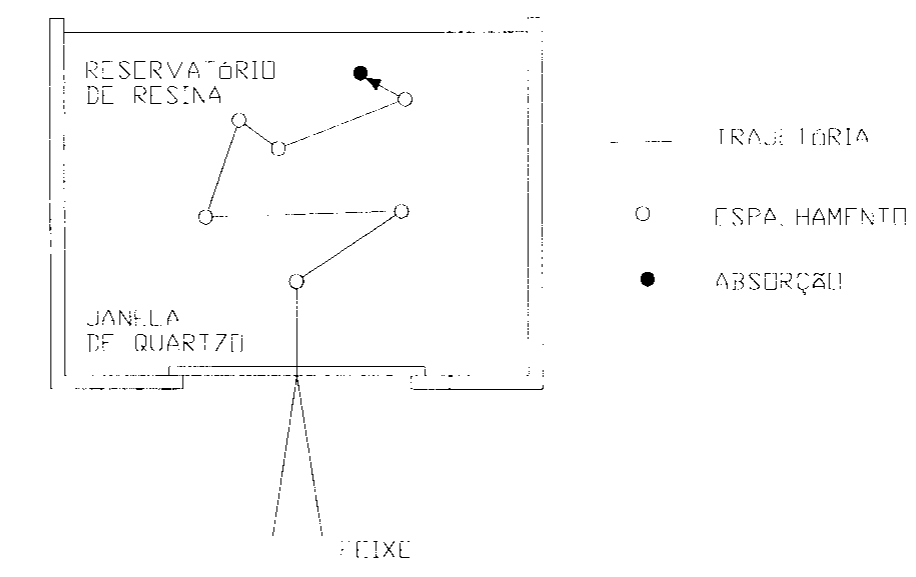

Figura 2.1 Trajetória aleatórias de um foton ao penetrar na resina.

$\mathrm{Na}$ figura 2.2 temos o resultado de uma simulação computacional da probabilidade de absorção do foton numa dispersão aleatória, determinando o formato da célula em função da quantidade de UV na exposição, onde p é a probabilidade de absorção de um foton num pequeno volume unitário ao redor do ponto [4].

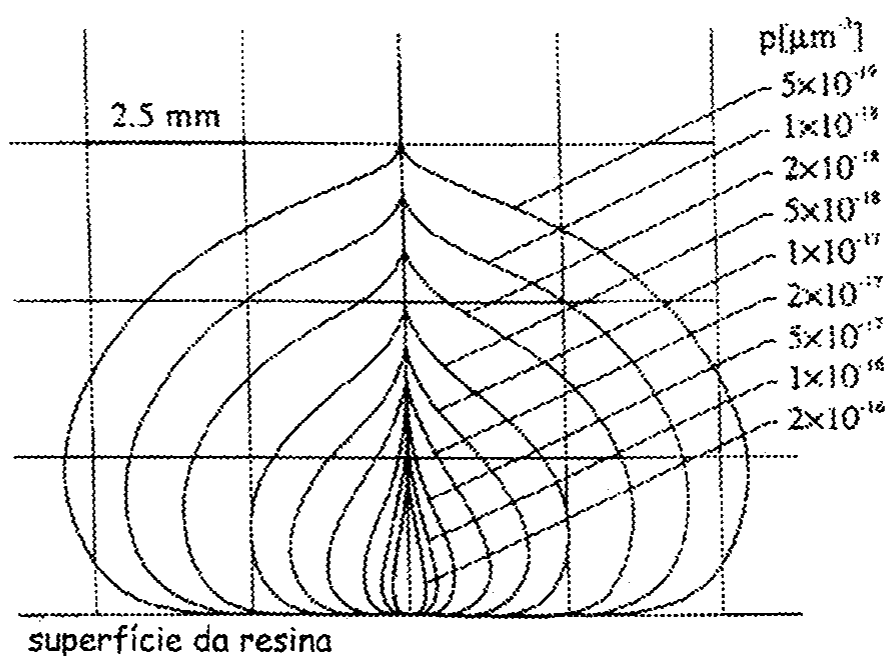

Figura 2.2 :Valores teóricos para a célula solidificada. 
Quando se faz uma varredura com um feixe de UV sobre a resina com um deslocamento bem menor que o diâmetro do feixe, pode-se considerar tal varredura como sendo contínua do ponto de vista macroscópico para fins de estudo. O resultado dessa varredura será uma pista litografada cujas dimensões, largura e profundidade, dependem do diâmetro do feixe incidente e da velocidade de varredura. Certamente, a resina e as condições de exposição como por exemplo a atmosfera de Ar ou de $\mathrm{He}$ [5], influem nessas dimensões, entretanto o comportamento é similar se mantidas as mesmas condições e a mesma resina, bem como do feixe de UV (diâmetro, intensidade e comprimento de onda).

A dependência do formato e dimensões das pistas solidificadas com a quantidade de luz recebida pode ser observado nos resultados mostrados nas figuras 2.3 e 2.4. Essas figuras mostram respectivamente a largura e a profundidade da pista em função do inverso da velocidade de varredura do feixe, expresso em segundos por metro percorrido. Podemos observar nos gráficos dessas figuras que a medida em que o tempo de exposição aumenta, ou seja, a velocidade de varredura diminui, tanto a largura quanto a profundidade aumentam devido a maior quantidade de energia recebida. $\mathrm{O}$ diâmetro do feixe utilizado foi de $0,4 \mathrm{~mm}$, e as diversas curvas referem-se a diferentes densidades de corantes na resina [5], conforme consta na tabela 2.1.

Tabela 2.1 : Legenda das Resinas em função da Densidade de Corante empregada.

\begin{tabular}{|c|c|}
\hline RESINA & DENSIDADE DE CORANTE \\
\hline 1 & $0,0 \%$ \\
\hline 2 & $0,4 \%$ \\
\hline 3 & $0,8 \%$ \\
\hline 4 & $4,0 \%$ \\
\hline 5 & $8,0 \%$ \\
\hline
\end{tabular}




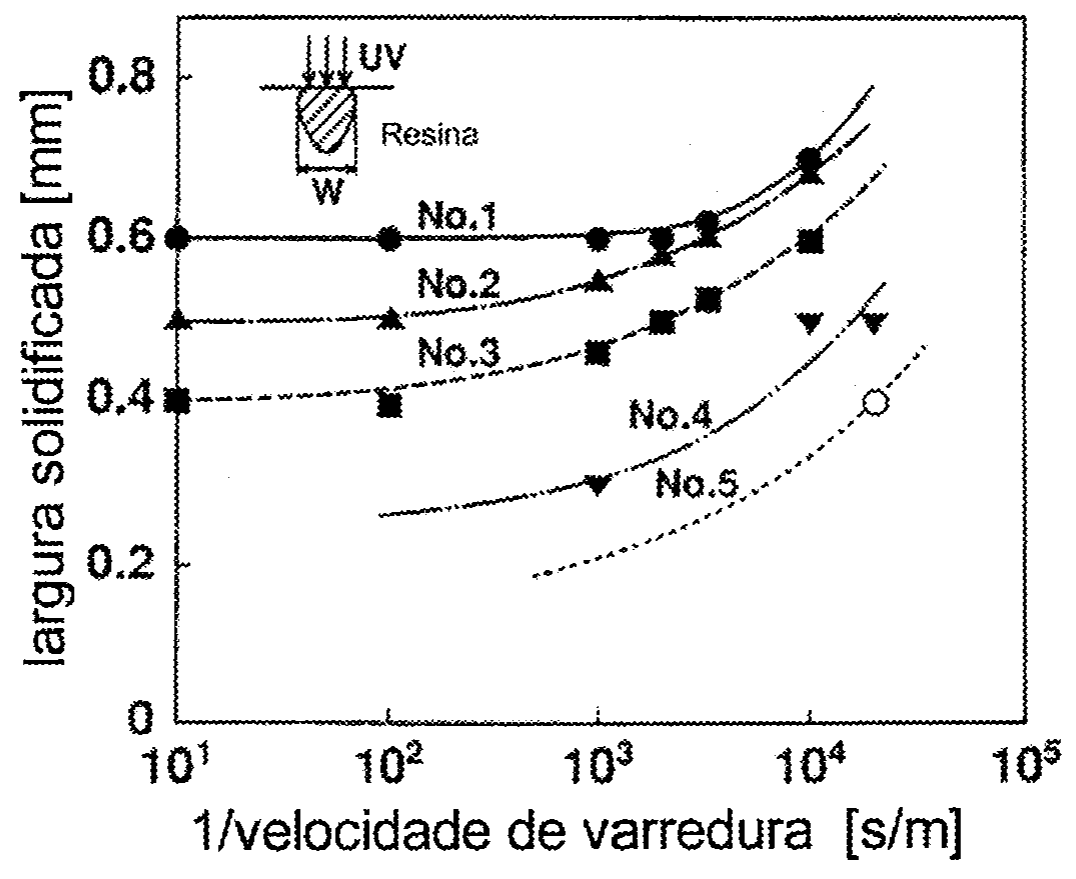

Figura 2.3 : Variação da largura da Pista em função da velocidade de varredura.

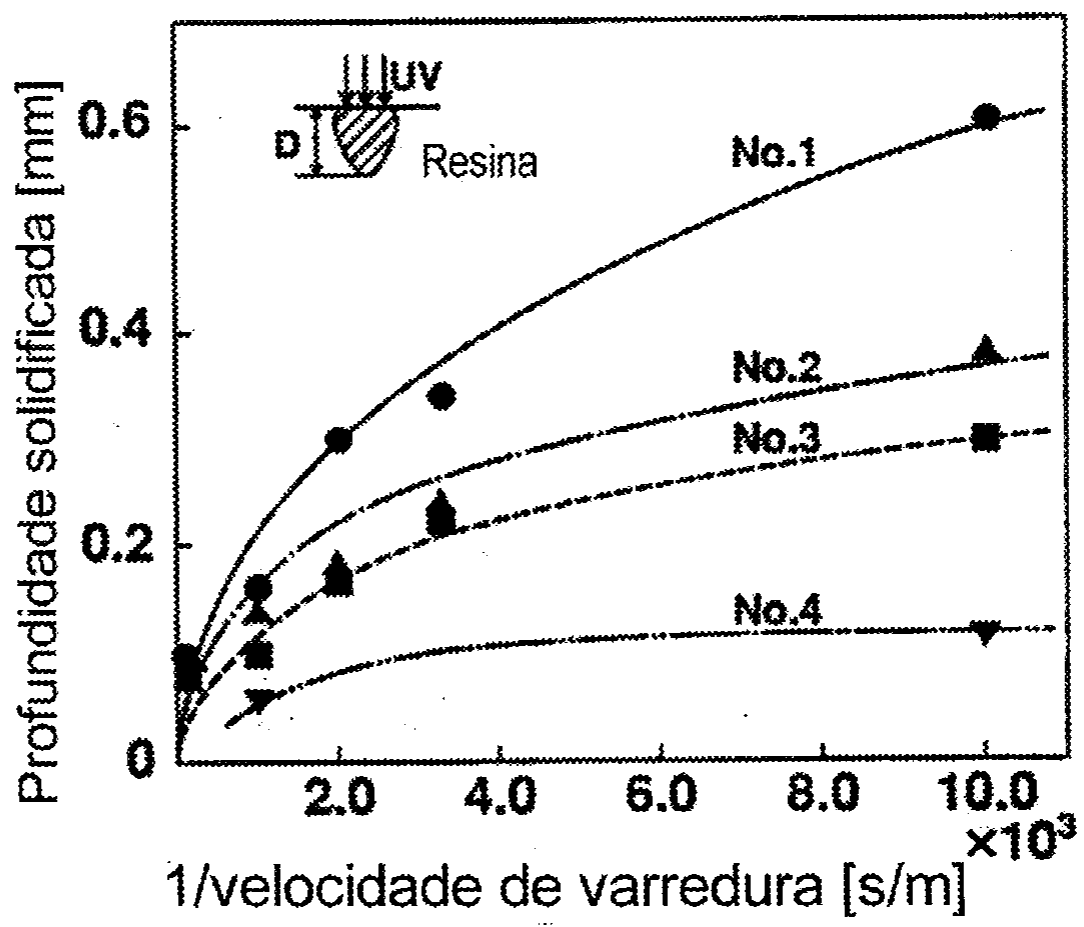

Figura 2.4 :Variação da profundidade da Pista em função da velocidade de varredura. 
Os gráficos acima mostram a dependência das dimensões das partes solidificadas em função da densidade de coloração da resina, ou melhor, mostram a relação entre as partes solidificadas (dimensões desta) em função da absorção ótica. A possibilidade de controle dessas dimensões pela coloração favorece, dentro de certos limites, a construção de "células solidificadas" com valores desejados, contribuindo para a determinação da resolução no plano XY e no eixo z. Entretanto, como em ambos os gráficos as dimensões, profundidade e largura, estão em função da velocidade de varredura, não é possível controlá-las de maneira independente, ou melhor, não é possível fixar-se uma das dimensões e passar a controlar a outra apenas pela velocidade de varredura. Esse controle, pela velocidade de varredura, é possível numa faixa que compreende o intervalo entre $10^{1} \mathrm{~s} / \mathrm{m}$ e $10^{3} \mathrm{~s} / \mathrm{m}$ no gráfico da figura 2.3. Nessa faixa a largura mantém-se aproximadamente constante para a resina 1 , sendo que a profundidade será definida através do gráfico da figura 2.4 pelo controle da velocidade dentro do intervalo definido. Para a resina número 1 a largura dentro desse intervalo é de $0,6 \mathrm{~mm}$, e a profundidade pode então ser controlada para no máximo (aproximadamente) $0,25 \mathrm{~mm}$.

Diversas variáveis estão envolvidas na solidificação da resina. A própria resina (sua natureza (acrílica, epoxi-acrílica, ...)), concentração de coloração, concentração de fotoiniciador, espessura da camada, tempo de exposição (velocidade de varredura), diâmetro do feixe incidente, seu comprimento de onda e sua potência, e também da atmosfera presente na superficie da resina onde ocorre a incidência do feixe de UV.

Nos gráficos das figuras 2.5 e 2.6 abaixo vemos a relação entre a espessura de uma camada solidificada em função da quantidade de radiação para duas resinas diferentes e para duas atmosferas diferentes [6]. A resina OKM-2 é composta de 
diacrilatos de $\alpha, \omega$-(methacryloyloxyethyleneoxycarbonyloxyethylene)oxyl, e o fotoiniciador usado foi o benzoin numa concentração de $0,06 \mathrm{~mol} / \mathrm{dm}^{3}$. A resina TGM-3 é composta de $\alpha, \omega$-(methacryloyloxyethyleneoxy)ethylene, também utilizando benzoin como fotoiniciador numa concentração de $0,12 \mathrm{~mol} / \mathrm{dm}^{3}$.

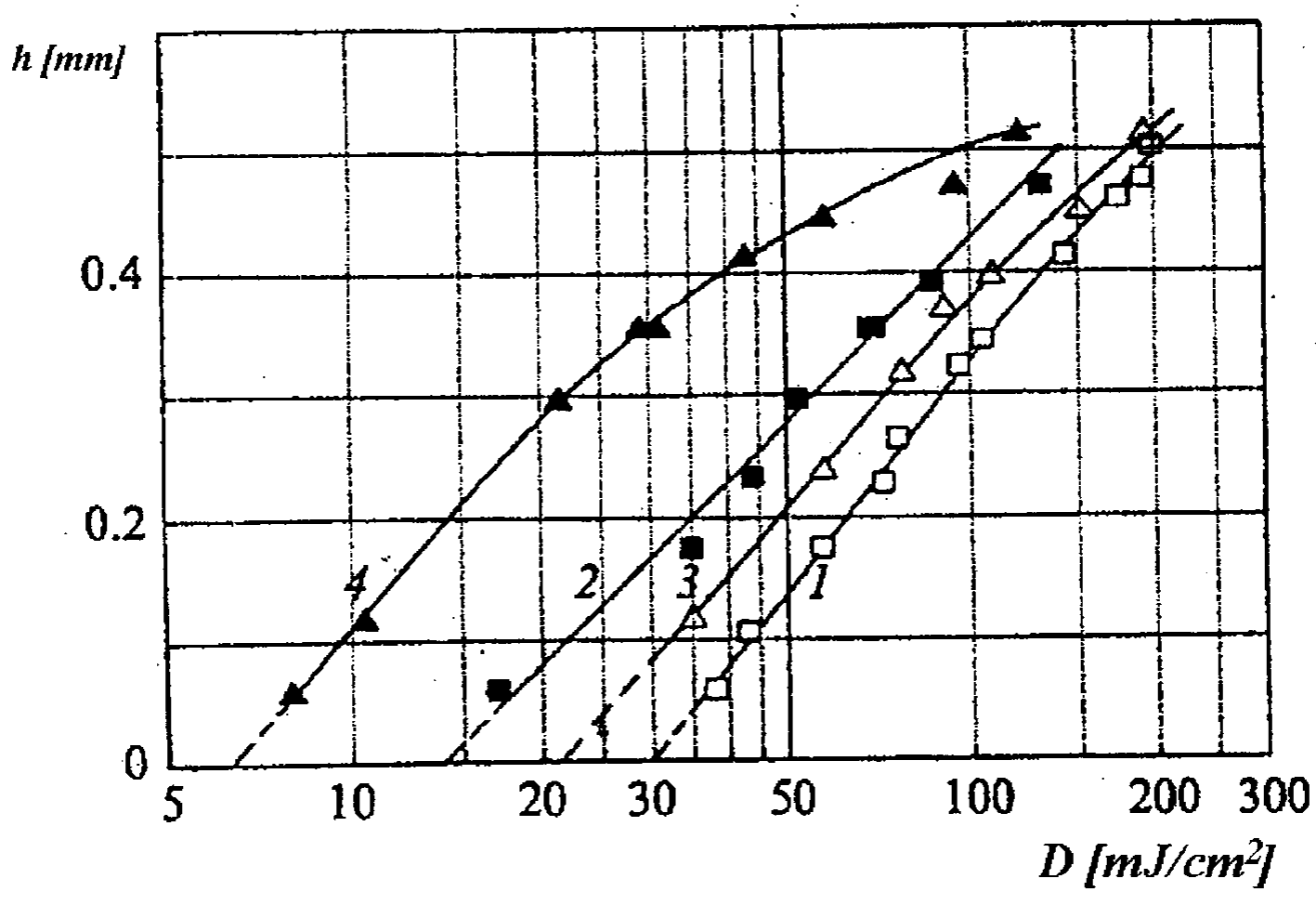

Figura 2.5 : Dependência entre a espessura solidificada em função da quantidade de radiação para a resina OKM-2 em atmosfera de Ar e Hélio.

As curvas 1 e 3 referem-se à polimerização em atmosfera de Ar e as curvas 2 e 4 referem-se à atmosfera de Hélio. As curvas 1 e 2 foram levantadas com uma densidade de energia de radiação $\phi=1 \mathrm{~mJ} / \mathrm{cm}^{2}$, e as curvas 3 e 4 com densidade de energia de radiação $\phi=0,2 \mathrm{~mJ} / \mathrm{cm}^{2}$. 


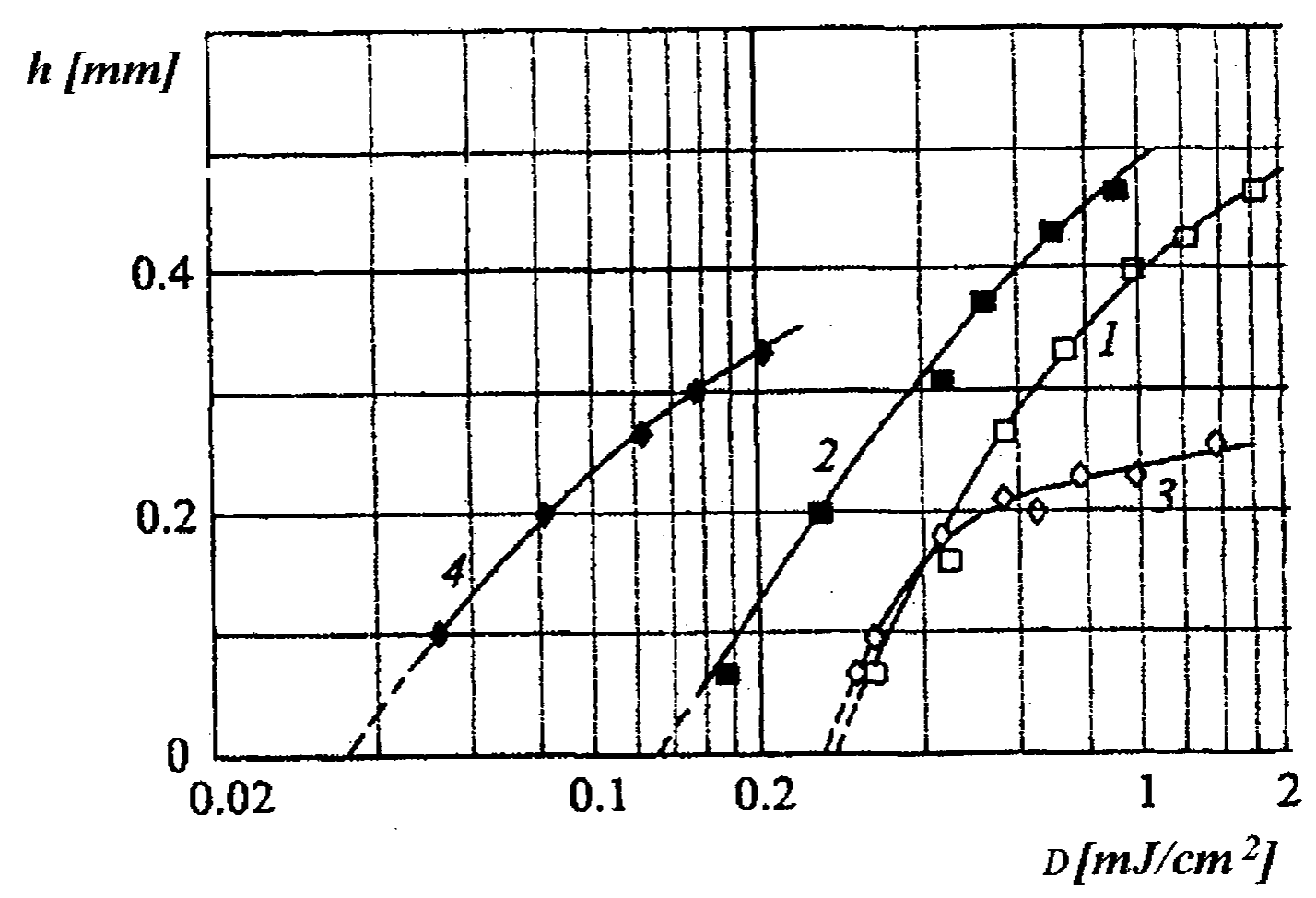

Figura 2.6 : Dependência entre a espessura solidificada em função da quantidade de radiação para a resina TGM-3 em atmosfera de Ar e Hélio.

As curvas 1 e 3 referem-se à polimerização em atmosfera de Ar e as curvas 2 e 4 referem-se à atmosfera de Hélio. As curvas 1 e 2 foram levantadas com uma densidade de energia de radiação $\phi=9 \mathrm{~mJ} / \mathrm{cm}^{2}$, e as curvas 3 e 4 com densidade de energia de radiação $\phi=1 \mathrm{~mJ} / \mathrm{cm}^{2}$.

A quantidade de radiação necessária para promover uma solidificação de determinada espessura $h$, é $D=\phi N$, onde $N$ é o número de pulsos do laser. A frequência de repetição dos pulsos em todos os resultados dos gráficos foi de $2 \mathrm{~Hz}$.

Para a curva número 4 da resina OKM-2, por exemplo, para solidificarmos uma espessura $h=0,1 \mathrm{~mm}$, é necessária uma quantidade de energia $D=8 \mathrm{~mJ} / \mathrm{cm}^{2}$. Como $\phi=0,2 \mathrm{~mJ} / \mathrm{cm}^{2}$, são necessários 4 pulsos de laser $(N=4)$. E como a frequência é de $2 \mathrm{~Hz}$, o tempo necessário para a solidificação é de 2 s. 
Em relação à concentração $C$ de fotoiniciador, podemos ver sua influência nas tabelas 2.2 e 2.3 abaixo. Essas tabelas mostram a quantidade energia de radiação necessária para a polimerização de camadas de $0,1 \mathrm{~mm}$ e de $0,2 \mathrm{~mm}$ em função da densidade de energia $\phi$ do laser, da concentração $C$ de fotoiniciador e da atmosfera (Ar e Helio).

Tabela 2.2 : Quantidade de radiação necessária para a polimerização da resina OKM-2 para as espessuras de $0,1 \mathrm{~mm}$ e $0,2 \mathrm{~mm}$ com laser de $\mathrm{XeCl}$ numa frequência de $2 \mathrm{~Hz}$.

\begin{tabular}{|c|c|c|c|c|}
\hline$\phi\left[\mathrm{mJ} / \mathrm{cm}^{2}\right]$ & $C\left[\mathrm{~mol} / \mathrm{dm}^{3}\right]$ & Atmosfera & \multicolumn{2}{|c|}{$D\left[\mathrm{~mJ} / \mathrm{cm}^{2}\right]$} \\
\hline & & & $h=0,1 \mathrm{~mm}$ & $h=0,2 \mathrm{~mm}$ \\
\hline 0,2 & 0,036 & $\mathrm{Ar}$ & 50 & 75 \\
\hline 0,2 & 0,06 & $\mathrm{Ar}$ & 35 & 60 \\
\hline 0,2 & 0,06 & Hélio & 10 & 15 \\
\hline 1,0 & 0,036 & $\mathrm{Ar}$ & 25 & 30 \\
\hline 1,0 & 0,06 & $\mathrm{Ar}$ & 33 & 50 \\
\hline 1,0 & 0,06 & Hélio & 15 & 25 \\
\hline 9 & 0,036 & $\mathrm{Ar}$ & 27 & 45 \\
\hline 9 & 0,06 & $\mathrm{Ar}$ & 45 & 72 \\
\hline 9 & 0,06 & Hélio & 27 & 45 \\
\hline
\end{tabular}

Tabela 2.3 :Quantidade de radiação necessária para a polimerização da resina TGM-3 para as espessuras de $0,1 \mathrm{~mm}$ e $0,2 \mathrm{~mm}$ com laser de $\mathrm{XeCl}$ numa frequência de $2 \mathrm{~Hz}$.

\begin{tabular}{|c|c|c|c|c|}
\hline$\phi\left[\mathrm{mJ} / \mathrm{cm}^{2}\right]$ & $C\left[\mathrm{~mol} / \mathrm{dm}^{3}\right]$ & Atmosfera & \multicolumn{2}{|c|}{$D\left[\mathrm{~m} J / \mathrm{cm}^{2}\right]$} \\
\hline & & & $h=0,1 \mathrm{~mm}$ & $h=0,2 \mathrm{~mm}$ \\
\hline 0,2 & 0,08 & $\mathrm{Ar}$ & 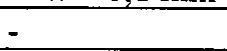 & 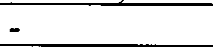 \\
\hline 0,2 & 0,08 & Hélio & 30 & 50 \\
\hline 0,2 & 0,12 & $\mathrm{Ar}$ & - & - \\
\hline 0,2 & 0,12 & Hélio & 23 & 35 \\
\hline 1,0 & 0,08 & $\mathrm{Ar}$ & 380 & 1100 \\
\hline 1,0 & 0,08 & Hélio & 50 & 80 \\
\hline 1,0 & 0,12 & $\mathrm{Ar}$ & 350 & 1000 \\
\hline 1,0 & 0,12 & Hélio & 60 & 110 \\
\hline 9 & 0,08 & $\mathrm{Ar}$ & 350 & 600 \\
\hline 9 & 0,08 & Hélio & 180 & 330 \\
\hline 9 & 0,12 & $\mathrm{Ar}$ & 400 & 550 \\
\hline 9 & 0,12 & Hélio & 200 & 310 \\
\hline
\end{tabular}

Para a resina TGM-3, por exemplo, para solidificarmos uma camada com espessura de 0,1 mm em atmosfera de Hélio, com concentração de fotoiniciador de $0,08 \mathrm{~mol} / \mathrm{dm}^{3}$ e laser com densidade de energia de $0,2 \mathrm{~mJ} / \mathrm{cm}^{2}$ pulsando numa 
frequência de $2 \mathrm{~Hz}$, é necessária uma quantidade de energia de $30 \mathrm{~mJ} / \mathrm{cm}^{2}$. Para tanto são necessários 150 pulsos, consumindo $75 \mathrm{~s}$ aproximadamente

Todos os dados e relações teóricas, referentes à figura 2.2, e experimentais, referentes às demais, foram extraídos de polimerizações de camadas de resina suficientemente grandes a ponto de a luz UV não alcançar um anteparo, que no caso seria a camada inferior. Sem uma camada inferior que sirva de anteparo para a luz, as figuras 2.3 e 2.4 mostram a dificuldade de se conseguir, por exemplo, uma célula solidificada cujo diâmetro seja igual à profundidade, como de $0,1 \mathrm{~mm}$ por exemplo. $\mathrm{Na}$ construção de uma peça, a existência de uma camada inferior delimita a profundidade da camada solidificada, sendo que o diâmetro desta (ou largura da pista) poderá ser mais facilmente controlável pelas outras variáveis como o diâmetro do feixe de laser, o tempo de exposição (ou velocidade de varredura), densidade de coloração, ou concentração de fotoiniciadores. 


\subsection{Sobre o Crescimento da Peça}

A precisão do formato de uma secção litografada e consequentemente do trabalho todo depende em princípio da "Célula Solidificada" da resina. Considerando as células solidificadas como sendo cilíndricas, para facilitar, o próprio diâmetro da célula será a resolução do sistema em relação ao plano XY. O formato ótimo das células deve ter suas dimensões aproximadamente as mesmas ao longo dos três eixos, ou seja, essa dimensão deve ser a mesma do deslocamento entre células vizinhas e da espessura da camada [4].

Se a célula for muito maior que o deslocamento haverá uma perda de precisão pelo próprio "desperdício" dela, e se ela for menor que o deslocamento ficarão espaços entre elas tornando impossível a construção de uma peça. Um deslocamento $\Delta_{\mathrm{xy}}\left(\Delta_{\mathrm{x}}\right.$ ou $\Delta_{\mathrm{y}}$ dependendo da direção) de valor aproximado ao diâmetro da célula resulta numa disposição de células que pode ser dita como Disposição Normal. Na figura 2.7 abaixo vemos uma Disposição Normal de células.

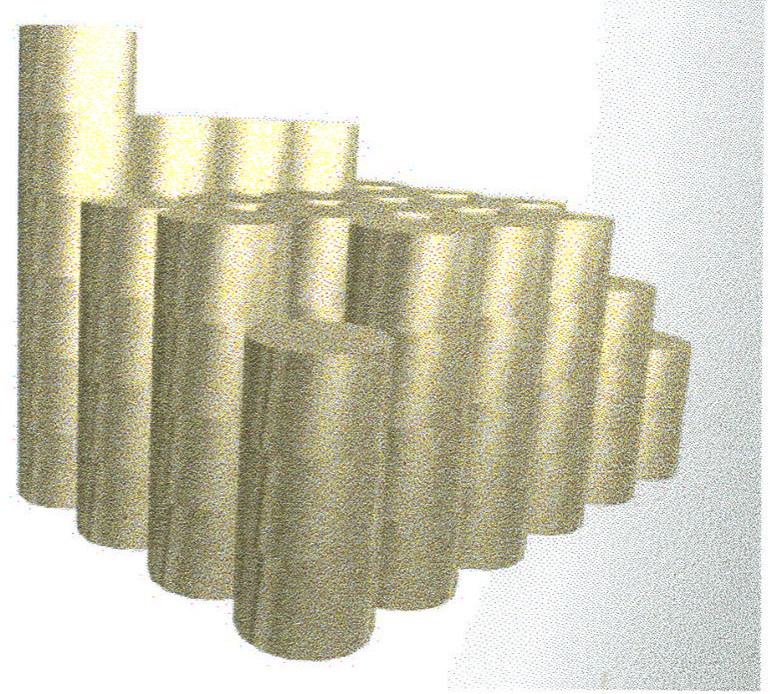

Figura 2.7 : Disposição Normal de Células Solidificadas. 
Se $\Delta_{\mathrm{xy}}$ for menor que o diâmetro da célula, podemos dizer que ocorrerá uma Disposição Justaposta das células conforme podemos ver na figura 2.8 .

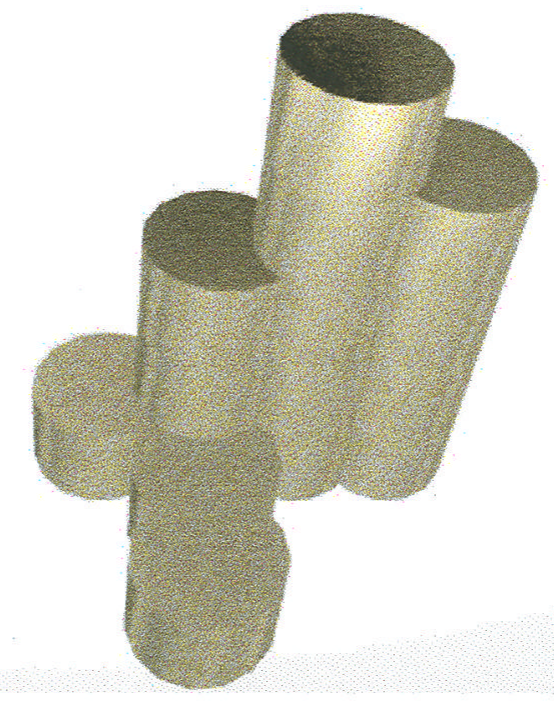

Figura 2.8 : Disposição Justaposta de Células Solidificadas.

Se $\quad \Delta_{\mathrm{xy}}$ for maior que o diâmetro da célula ocorrerá uma Disposição Extraposta das células, tornando inadequada a sobreposição de camadas e o consequente crescimento da peça resultando na inviabilização da técnica. Na figura 2.9 vemos essa disposição.

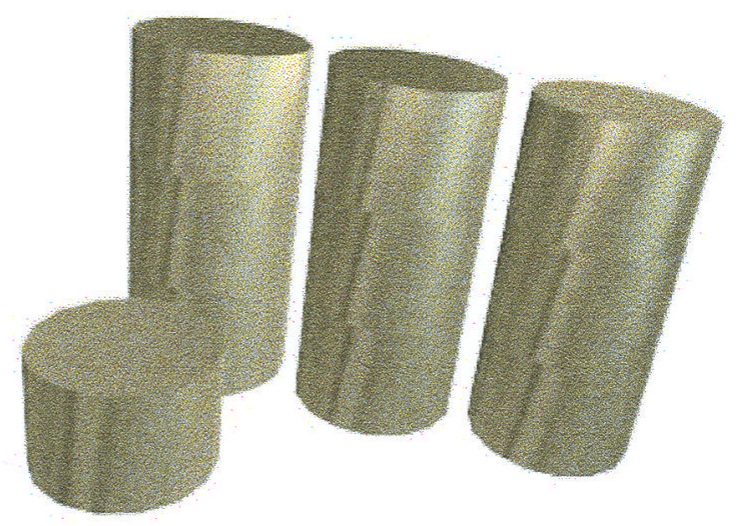

Figura 2.9: Disposição Extraposta de Células Solidificadas. 
A sobreposição de camadas implica numa discretização ao longo do eixo z causando um efeito escada cujo degrau corresponde à espessura d da camada. Na figura 2.10 vemos o resultado da discretização por camadas ao longo do eixo $\mathrm{z}$ de uma figura formada por curvas contínuas.

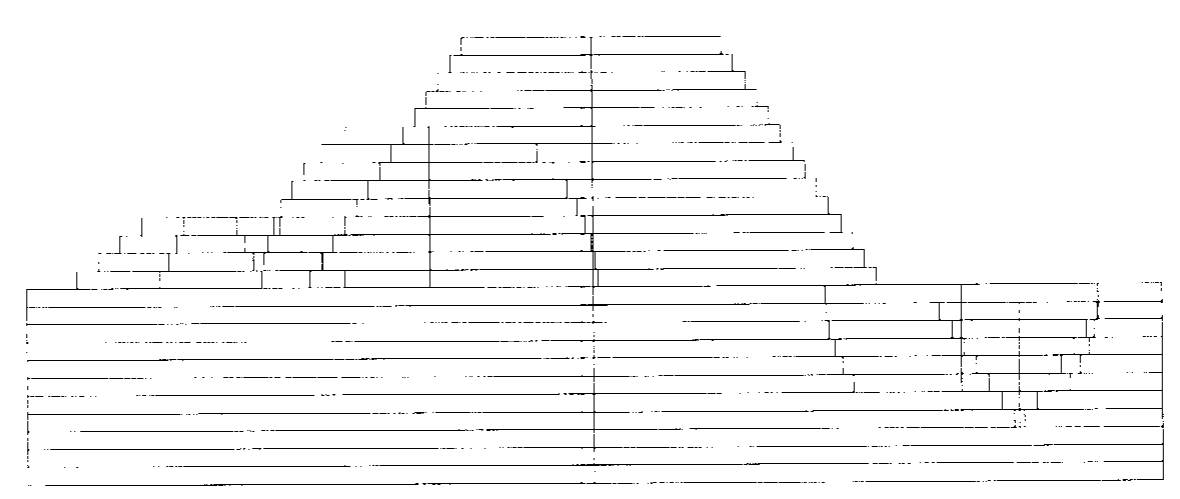

Figura 2.10 : Efeito Escada formado pela sobreposição de camadas.

O efeito escada é um problema inerente ao processo sendo um fator limitante, pois para obtermos uma suavidade muito grande dos contornos seria necessário uma quantidade muito grande de camadas muito finas, o que entra em desacordo com a dimensão do diâmetro do feixe que por sua vez teria que ser diminuido proporcionalmente assim como a distância entre os deslocamentos para que não se perca precisão. O "degrau" da escada é a própria resolução em relação ao eixo $z$.

Outro problema inerente ao processo de sobreposição de camadas é a sustentação. Inicialmente a primeira camada adere-se, e portanto sustenta-se, na plataforma de crescimento; entretanto as secções subsequentes não possuem essa base, podendo fixar-se somente na camada anterior. Se uma seção litografada ocorrer 
sem que haja sustentação, essa secção ficará "flutuando" e se deslocará pelo movimento da resina quando da formação da próxima camada. Assim, essa necessidade de sustentação força a uma ligação física entre camadas de maneira que haja um caminho contínuo e monotônico de ligação de qualquer camada com a plataforma de crescimento. Para que um protótipo possa ser construído pela sobreposição de camadas é necessário que haja pelo menos um sentido de monotonicidade, o qual dará a orientação do sentido de construção. Na figura 2.11 vemos exemplificado uma peça que não apresenta monotonicidade em relação ao sentido de crescimento da peça. Na figura 2.12 vemos a mesma peça orientada corretamente para a construção.
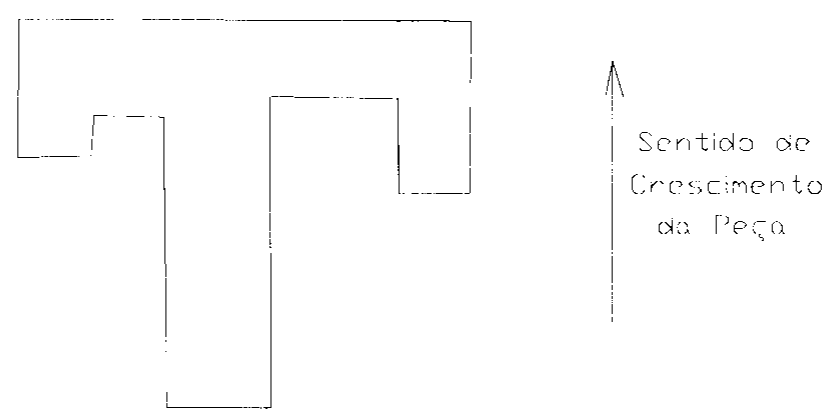

Figura 2.11 : Falta de monotonicidade numa orientação errônea do modelo de uma peça

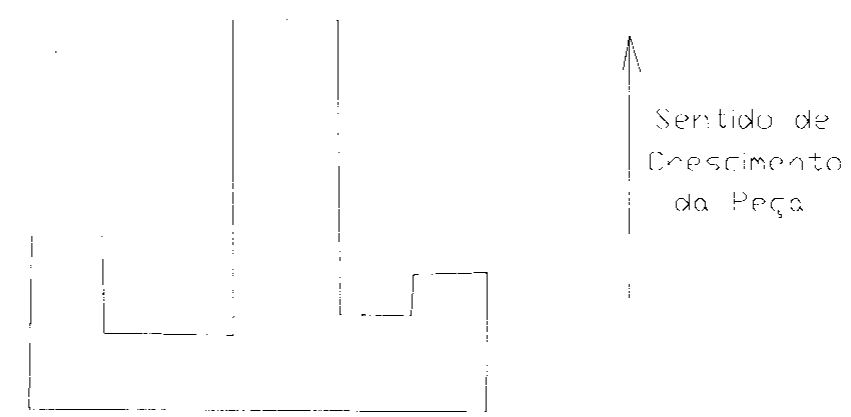

Figura 2.12: Mesmo modelo orientado corretamente com o sentido de crescimento da peça 
Existem modelos de peças que não possuem nenhum sentido de monotonicidade mas que podem ser divididos em partes monotônicas e depois juntados; mas também existem modelos que precisariam ser divididos em muitas partes, complicando sua montagem principalmente se as dimensões forem muito reduzidas. A figura 2.13 mostra o modelo de uma peça que não possui nenhum sentido de monotonicidade, e a figura 2.14 mostra uma sugestão de divisão em partes apropriadas para a construção da peça.

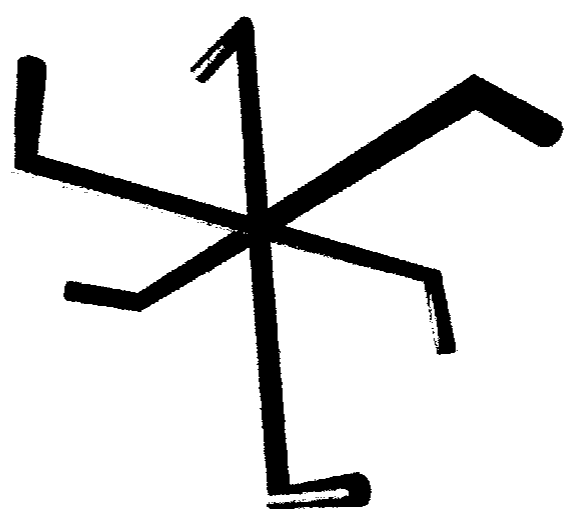

Figura 2.13 : Exemplo de uma peça que não possui nenhum sentido de monotonicidade.

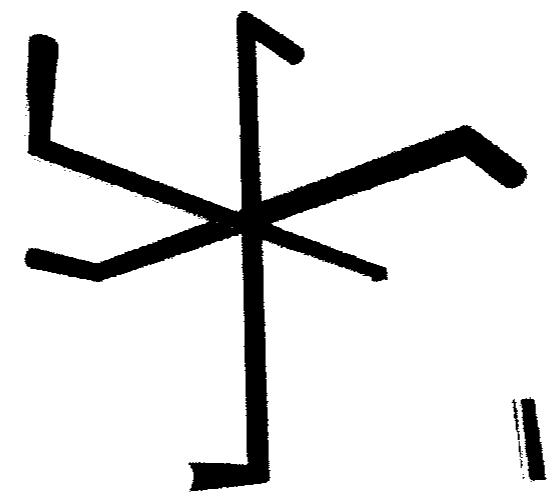

Figura 2.14 : Divisão da peça em partes apropriadas para a construção. 


\subsection{Sobre a Preparação das Camadas}

A preparação das camadas pode ser feita por um elevador cuja plataforma submerge num reservatório que contém a resina [5][6]. Na figura 2.15 podemos observar a espessura d num momento qualquer de descida da plataforma.

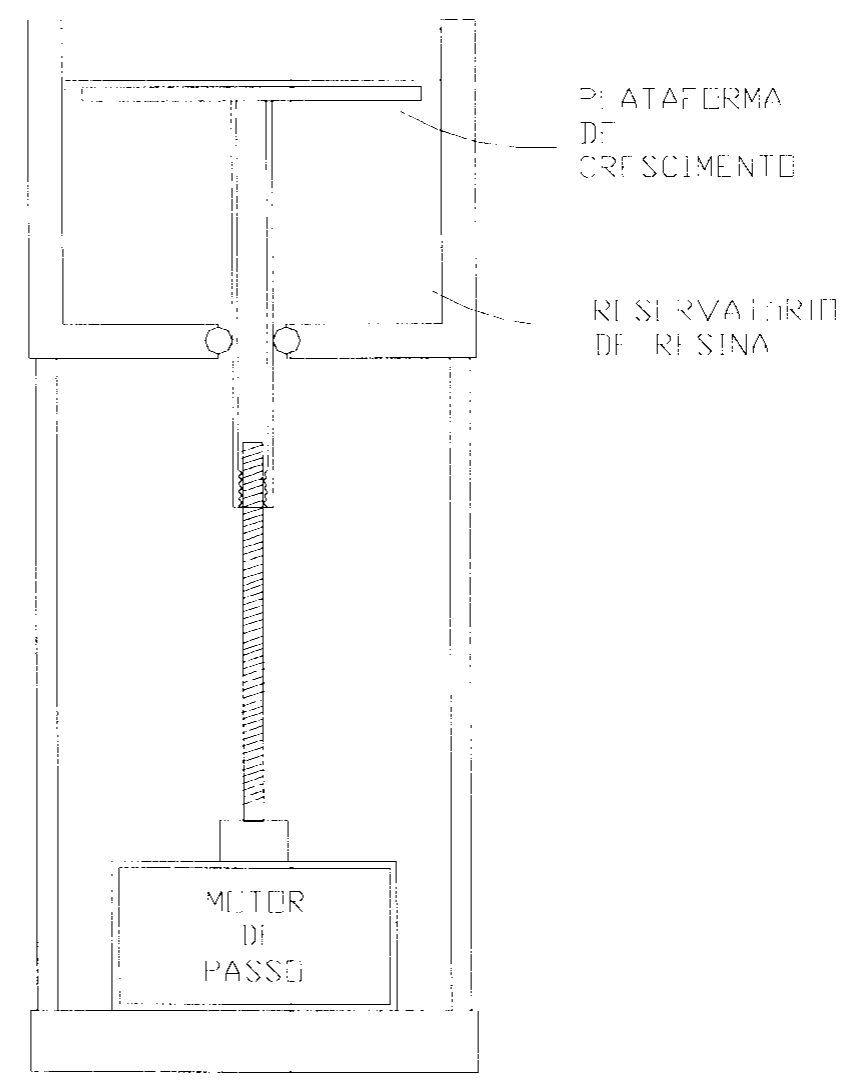

Figura 2.15 : Formação de camada pela descida da plataforma.

Esta técnica de preparação de camadas apresenta a princípio uma forte limitação quanto à espessura mínima que se pode conseguir, limitação essa devida à tensão superficial e a viscosidade da resina. A tensão superficial presente nas interfaces fluido/fluido (resina líquida/ar) e fluido/sólido (resina líquida/plataforma de aço inoxidável ou resina líquida/resina sólida) impede que a resina (líquida) flua 
naturalmente devido ao próprio peso por espaços menores que um certo valor, o qual depende dos fluidos e dos sólidos em contato.

O problema da espessura mínima pode ser solucionado instalando-se no sistema uma janela (preferencialmente de quartzo) de maneira a fazer interface com a superfície da resina. Assim, à medida em que a plataforma vai descendo cria-se uma pressão negativa entre a plataforma e a janela forçando um fluxo de resina das vizinhanças externas para o centro, vencendo a tensão superficial e a viscosidade. $\mathrm{Na}$ figura 2.16 vemos o sistema com a janela instalada.

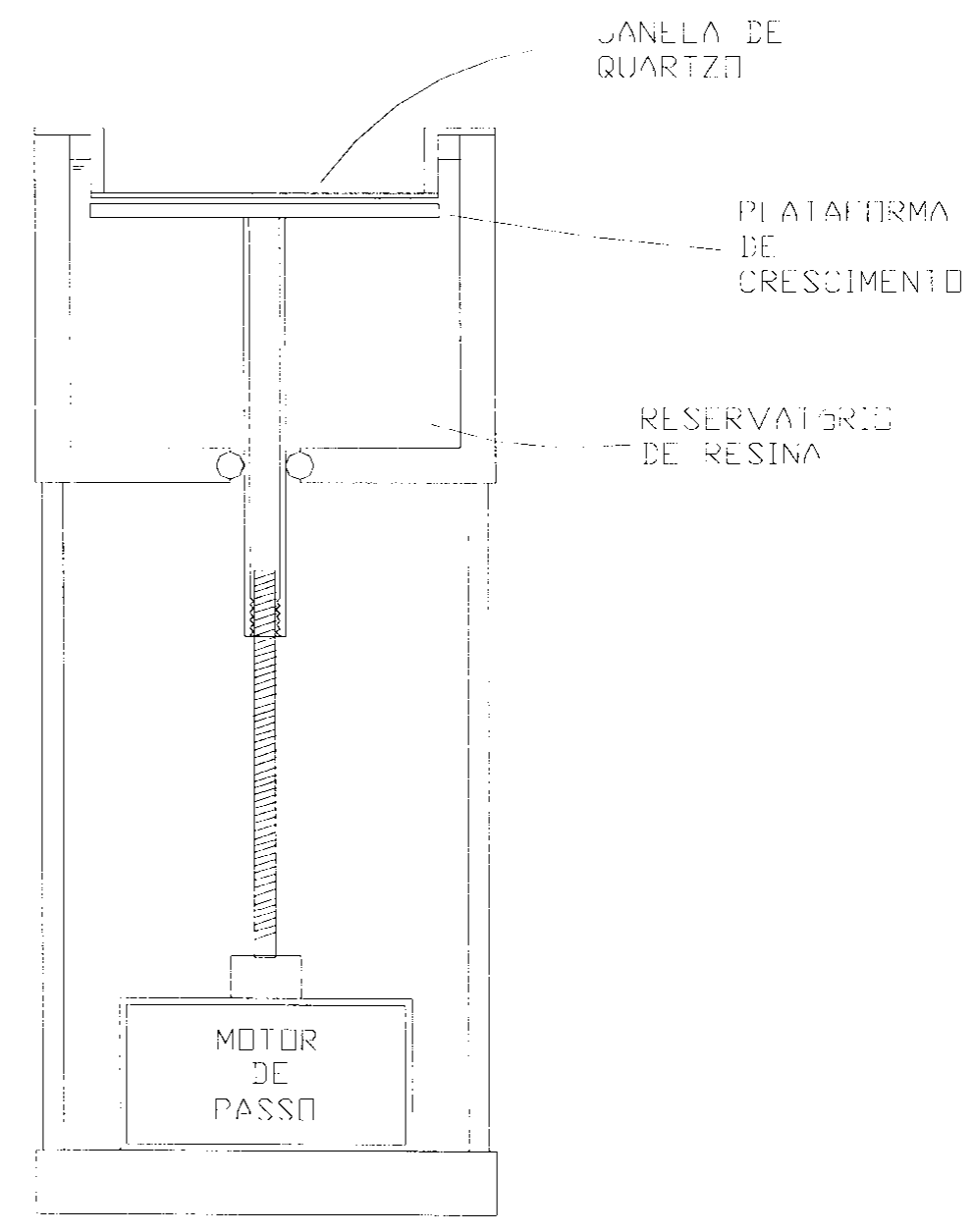

Figura 2.16 : Formação de camada com a janela instalada. 
O uso da janela apresenta prós e contras em relação ao tempo de cura da resina. O quartzo é o material mais adequado para o caso pois ele absorve um quantidade insignificante de UV e, o fato de não mais haver $\mathrm{O}_{2}$ (do ar) em contato com a resina no local de incidência de UV favorece a uma diminuição do tempo de cura [3], suplantando facilmente as perdas pelo quartzo.

A construção de uma peça sem o uso da janela é dita Construção por Superficie Livre, e com o uso da janela é dita Construção por Superficie Fixada [4].

Uma variação possível de preparação das camadas e consequentemente de crescimento da peça pode ser conseguida pela elevação da plataforma ao invés da submersão [5]. Na figura 2.17 abaixo podemos ver que a peça será formada de maneira invertida em relação à orientação do modelo.

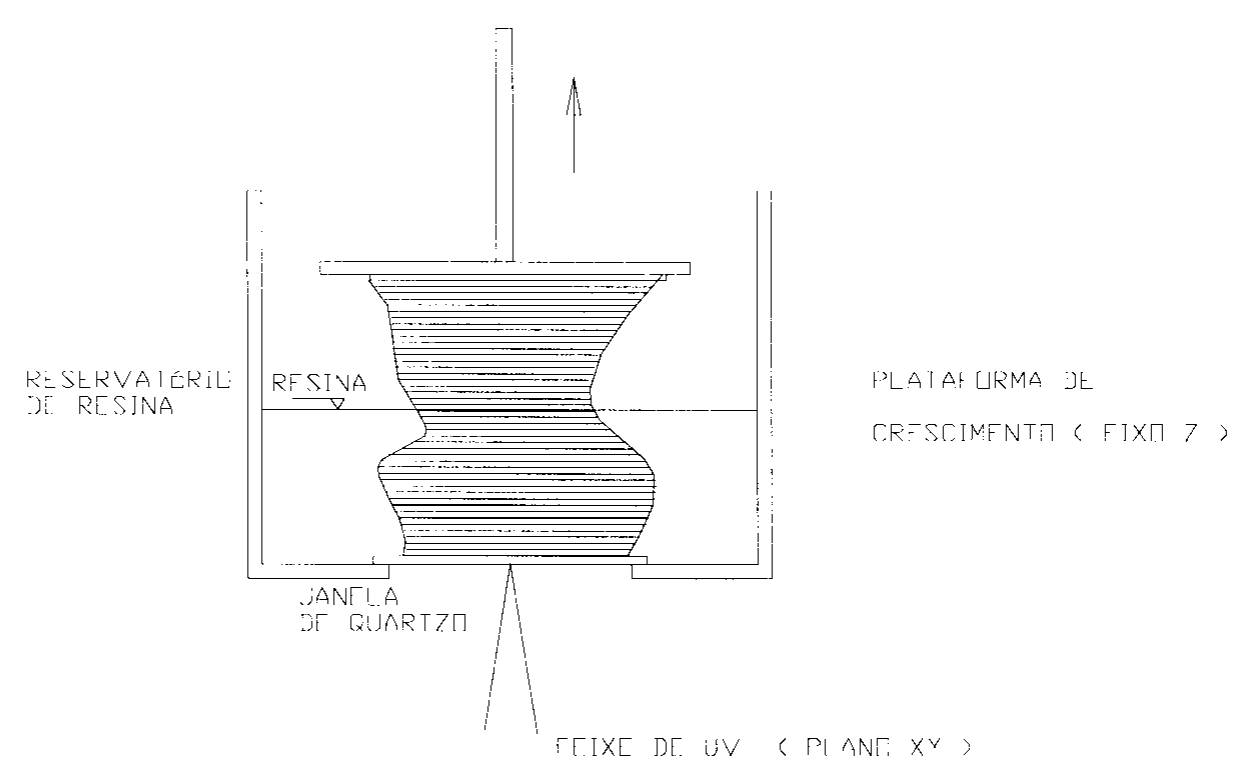

Figura 2.17: Variante do Crescimento da Peça com uma Plataforma Móvel. 
Nesse caso, uma pequena vantagem em relação à plataforma de submersão é que, ao término do trabalho a peça já estará praticamente fora do reservatório; e este por sua vez pode ter uma altura relativamente baixa. Uma das desvantagens dessa variante de formação de camadas é a focalização do feixe de UV numa posição de dificil visualização humana. Outro inconveniente do uso de uma janela na parte inferior do reservatório é a necessidade de seu esvaziamento quando da aderência de resina solidificada na janela. 


\subsection{Sobre o Direcionamento do Feixe de UV}

A litografia por varredura com um feixe de laser UV pode ser feita com o uso de defletores de espelho eletromecânicos dispostos ortogonalmente entre si, tornando possível a varredura num plano XY. O controle dos defletores é feito por potenciais elétricos analógicos $v_{x}$ e $v_{y}$ que determinarão os ângulos de deflexão $\theta_{x}$ e $\theta_{y}$.

O uso de direcionadores de um feixe de luz desse tipo gera problemas de posicionamento de um ponto $\mathrm{P}(\mathrm{x}, \mathrm{y})$ no plano. Os erros de natureza geométrica que tal arranjo produz devem ser corrigidos para se eliminar distorções do protótipo em relação ao modelo. Três tipos de erro foram abordados em relação a esse tipo de direcionamento:

1- Erro Focal.

2- Erro de "Almofadamento".

3- Erro Frequencial.

\subsubsection{Erro Focal}

Um dos problemas de varredura de um feixe de laser num plano é o erro de foco. O diâmetro do feixe incidente depende do sistema ótico de focalização, o qual deverá focalizar no plano a imagem da secção do feixe de acordo com as dimensões desejadas. Se o sistema ótico operar com distância focal fixa, o feixe sairá de foco de acordo com a magnitude $\mathrm{V}$ do vetor formado pelas coordenadas do ponto. Na figura 
2.18 abaixo vemos a superficie formada pelos pontos equifocais e o consequente aparecimento de um erro focal no plano XY.

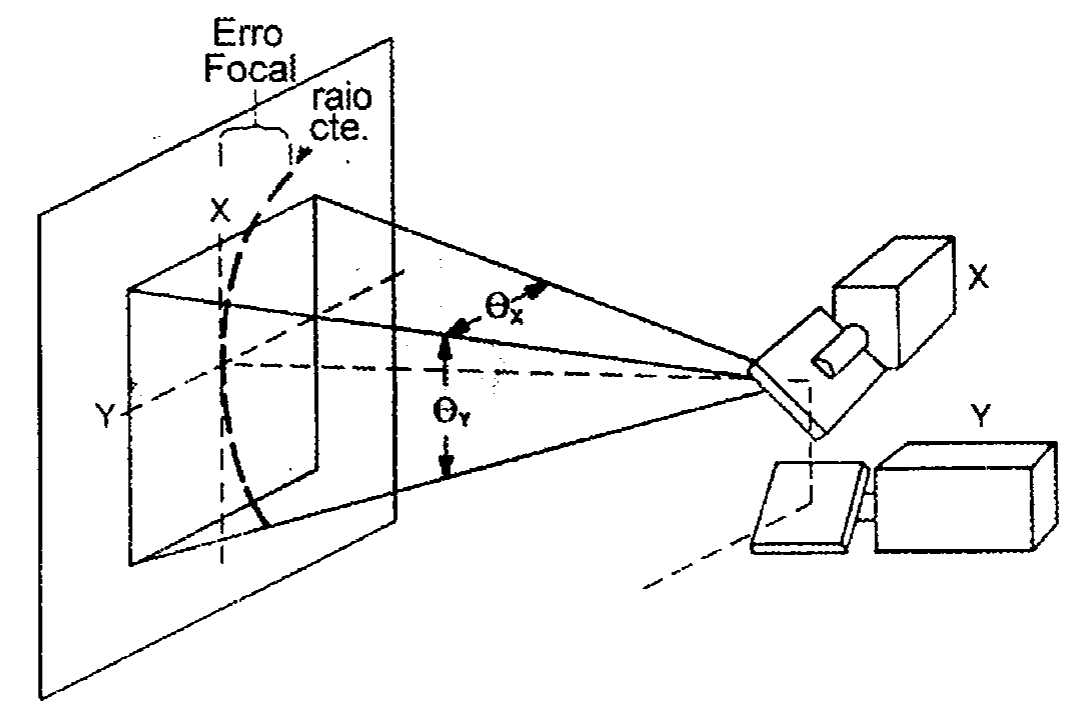

Figura 2.18 : Erro Focal devido a um Sistema Ótico que Opera com Distância Focal Fixa.

Para um controle dinâmico de foco, devemos aplicar um fator de correção à distância focal do sistema ótico de maneira a compensar o erro e eliminar esse tipo de distorção. Considerando uma distância focal inicial $\mathrm{f}_{0}$ ajustada como origem em $(\mathrm{x}, \mathrm{y})$ $=(0,0)$, quando outros pontos do plano forem atingidos pelo laser, a distância percorrida pelo feixe é diferente (maior) que $f_{0}$ como podemos observar na figura 2.19 abaixo. 


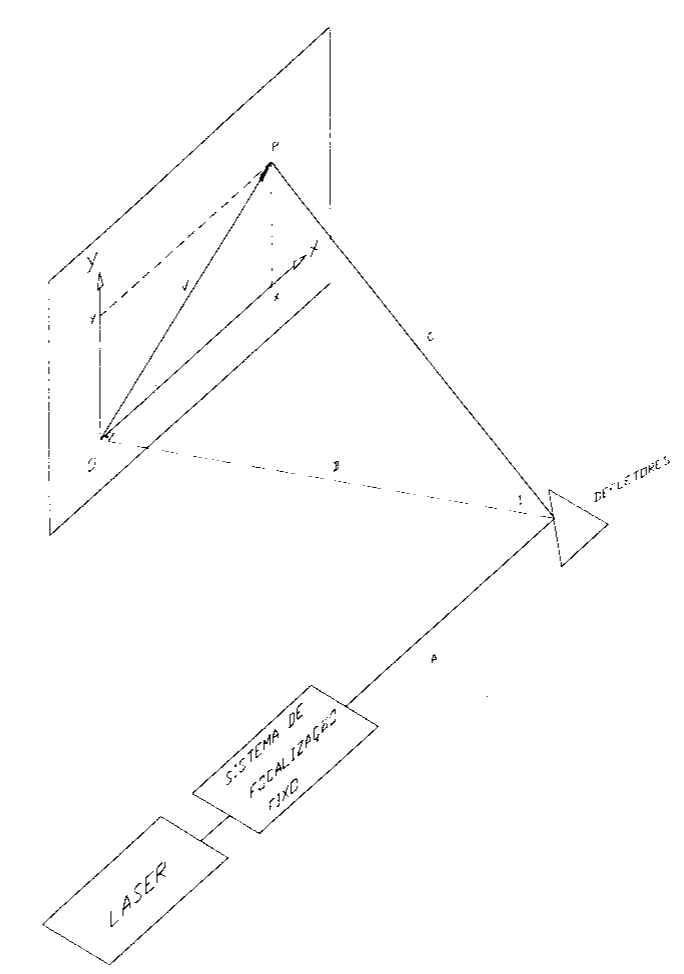

Figura 2.19 : Variação da Distância Focal em Função do Ponto $\mathrm{P}(\mathrm{x}, \mathrm{y})$ no plano.

Na figura acima vemos que o ajuste do foco se dará em relação à distância $\mathrm{C}$ que especificará a nova distância focal $\mathrm{f}$ em função do ponto $\mathrm{P}$, considerando a distância A como constante.

Pela geometria formada temos que: $\quad \mathrm{f}=\mathrm{A}+\mathrm{C}$

Onde

$$
\mathrm{C}=\left(\mathrm{V}^{2}+\mathrm{B}^{2}\right)^{1 / 2} \text { e } \quad \mathrm{V}^{2}=\mathrm{x}^{2}+\mathrm{y}^{2}
$$

Portanto

$$
f=A+\left(x^{2}+y^{2}+B^{2}\right)^{1 / 2}
$$

Assim, para corrigirmos a distância focal em função do ponto $\mathrm{P}$, devemos gerar um potencial elétrico $\mathrm{v}_{\mathrm{f}}$ proporcional a $\mathrm{f}$ que controlará um dispositivo eletro- 
ótico de focalização. Na figura 2.20 vemos esquematizado um sistema de focalização controlável.

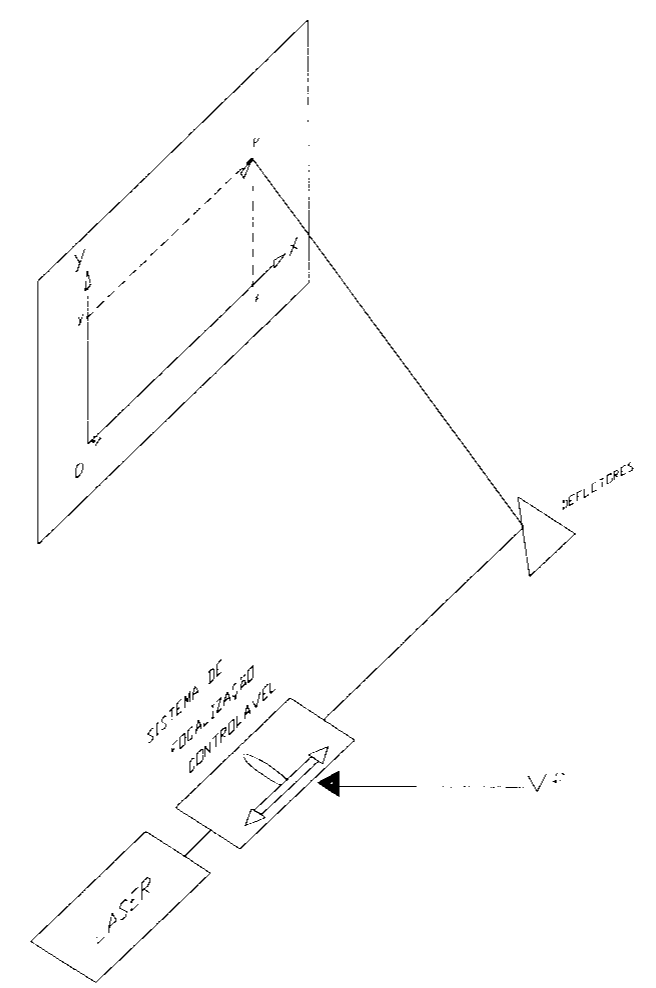

Figura 2.20 : Sistema de focalização controlável.

\subsubsection{Erro de "Almofadamento"}

Outro erro causado em varreduras no plano com defletores dispostos ortogonalmente pode ser visto na figura 2.21 abaixo. Essa distorção é conhecida como distorção de "almofadamento" [7] e também é devida à geometria do sistema. 


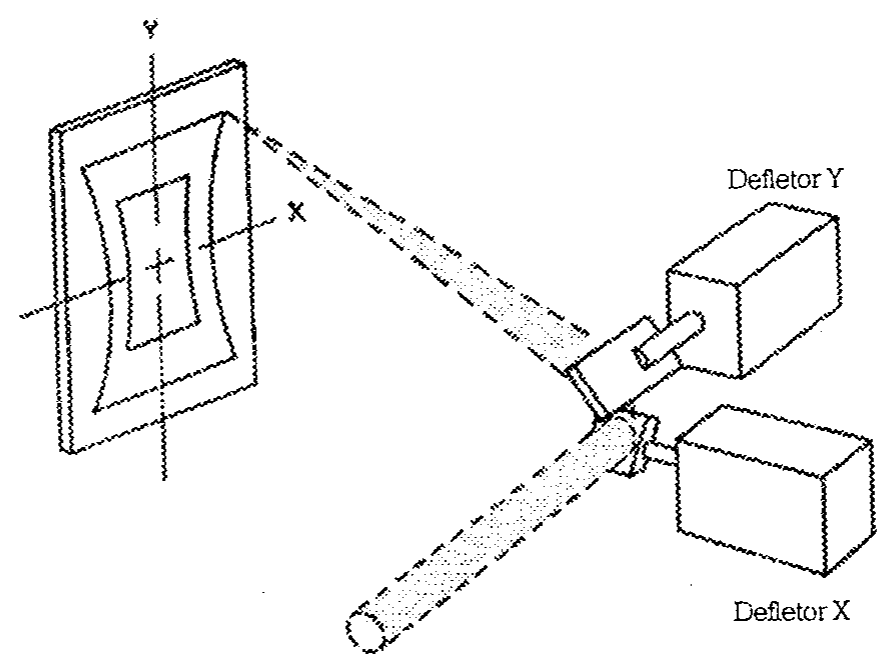

Figura 2.21 : Erro de "Almofadamento".

Essa distorção apresenta não-linearidades tangenciais diferentes em relação a cada eixo devido à sequência dos defletores. Variações apenas no segundo defletor, eixo y no caso, causam também variações no eixo $\mathrm{x}$, primeiro defletor, porém variações no primeiro defletor, $\mathrm{x}$, não causam variações no eixo $\mathrm{y}$, primeiro defletor. $\mathrm{Na}$ figura 2.22 vemos a geometria formada por um ponto $\mathrm{P}(\mathrm{x}, \mathrm{y})$ na tela.

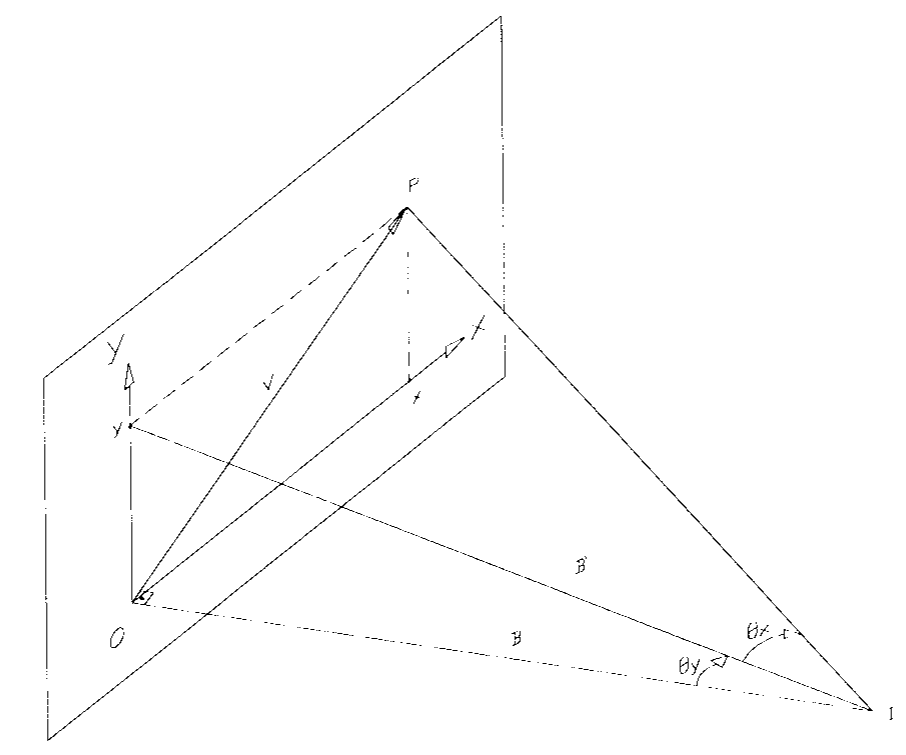

Figura 2.22 : Geometria auxiliar para a correção do erro de "Almofadamento". 
Do triângulo OIy, temos que :

$$
\theta_{\mathrm{y}}=\operatorname{arctg}(\mathrm{y} / \mathrm{B}) \quad \text { e } \quad \mathrm{B}^{\prime}=\left(\mathrm{y}^{2}+\mathrm{B}^{2}\right)^{1 / 2}
$$

Do triângulo PIy, vem que:

Portanto:

$$
\theta_{\mathrm{x}}=\operatorname{arctg}\left(\mathrm{x} / \mathrm{B}^{\prime}\right)
$$

$$
\theta_{\mathrm{x}}=\operatorname{arctg}\left(\mathrm{x} /\left(\mathrm{y}^{2}+\mathrm{B}^{2}\right)^{1 / 2}\right)
$$

Os defletores do tipo eletromagnéticos são controlados por tensão elétrica e apresentam linearidade entre a tensão de controle e o ângulo de deflexão produzido, de maneira que sua função de transferência é do tipo:

$$
\theta=K_{d} \cdot \mathbf{v}
$$

onde $\mathrm{K}_{\mathrm{d}}$ é um valor constante do sistema que significa a taxa de variação do defletor, sendo:

$$
\mathrm{K}_{\mathrm{d}}=\Delta \theta / \Delta \mathrm{v}
$$

Assim, para se atingir um ponto $\mathrm{P}(\mathrm{x}, \mathrm{y})$ no plano teremos que gerar potencias elétricos $v_{x}$ e $v_{y}$ através das expressões:

$$
\begin{gathered}
\mathrm{v}_{\mathrm{x}}=\operatorname{arctg}\left(\mathrm{x} /\left(\mathrm{y}^{2}+\mathrm{B}^{2}\right)^{1 / 2}\right) / \mathrm{K}_{\mathrm{d}} \\
\mathrm{e} \\
\mathrm{v}_{\mathrm{y}}=\operatorname{arctg}(\mathrm{y} / \mathrm{B}) / \mathrm{K}_{\mathrm{d}}
\end{gathered}
$$




\subsubsection{Erro Frequencial}

Outra consideração importante em relação aos defletores é sobre sua frequência de operação. O defletor é um elemento eletromecânico que possui uma inércia relativamente grande frente a resposta em frequência dos computadores, não podendo atingir velocidade de varredura muito alta. A frequência de operação dos defletores é uma característica técnica determinada pelo fabricante para garantia da precisão oferecida. A precisão do trabalho será diretamente afetada à medida em que a velocidade de varredura se aproxima dos limites especificados.

Trabalhando-se numa frequência relativamente alta, as dimensões litografadas no plano serão diminuídas proporcionalmente resultando em erros frequenciais. Mesmo trabalhando-se numa taxa relativamente segura, os cantos de uma figura representam regiões de alta frequência podendo gerar arredondamentos nessas regiões, como podemos ver no "quadrado" da figura 2.23 que foi formado numa velocidade de varredura alta o suficiente a causar uma distorção frequencial.

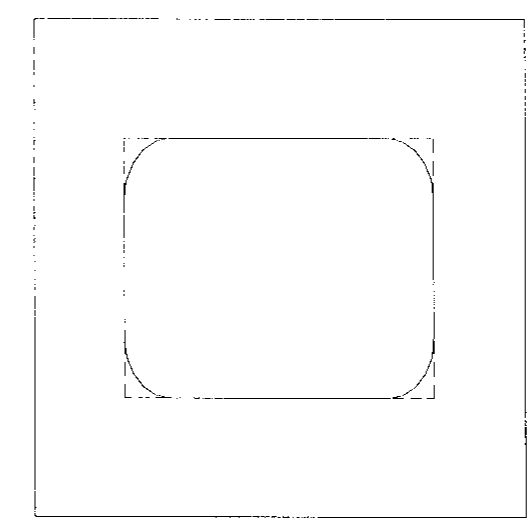

Figura 2.23 : Distorção Frequencial causada por uma velocidade de varredura alta. 


\subsection{Sobre a Interrupção do UV}

A incidência da luz UV sobre a camada de resina deve ocorrer somente durante o período de exposição, sendo interrompido no restante do tempo. A interrupção do feixe é um ponto crítico do sistema pois ela pode se tornar muito demorada em relação ao restante do processo.

Na exposição por projeção, o facho de UV a ser interrompido pode ter uma dimensão que exija um certo tempo para ser interceptado por um elemento físico. Para um número pequeno de camadas esse tempo pode ser pouco significativo, mas para um número elevado de camadas a demora pode se tornar muito inconveniente.

$\mathrm{Na}$ exposição por varredura o diâmetro do feixe é relativamente pequeno, entretanto a velocidade de varredura pode ser relativamente alta e causar exposições indevidas caso não haja um sincronismo eficiente de controle.

O sincronismo deve garantir sempre que a varredura só comece quando o interruptor estiver totalmente aberto, além disso toda vez que se for começar a varredura de uma nova região os defletores devem ser primeiro alinhados no ponto inicial dessa região, depois o interruptor deve ser aberto e só então a varredura pode prosseguir. Se essa sequência não for obedecida, corre-se o risco de se litografar filetes indevidos quando do deslocamento do feixe de um ponto distante qualquer para o ponto inicial da nova região, como podemos observar na figura 2.24 abaixo. 


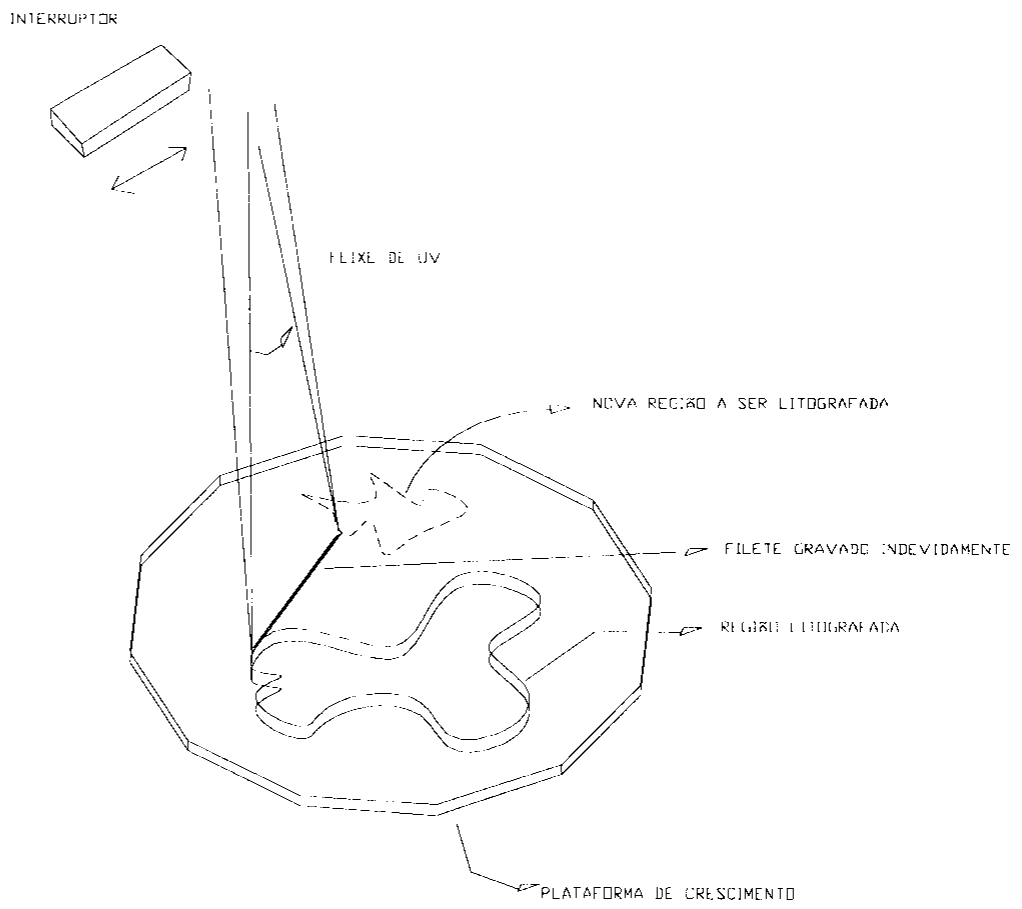

Figura 2.24.: Filetes litografados indevidamente pela falta de sincronismo entre interrupção e varredura. 


\section{AUTOMAÇÃO DO PROCESSO DE ESTEREOLITOGRAFIA}

\subsection{Introdução}

Para a integração e controle do processo de estereolitografia foi utilizado um computador Pentium-MMX de 200MHz com 32 Mbytes de memória RAM. Através dos programas desenvolvidos em Basic, AutoLisp e $\mathrm{C}^{++}$, o computador realiza as tarefas de aquisição do modelo 3D por extração de bordas, de tratamento desses dados, e de controle da instrumentação externa (plataforma de crescimento, direcionamento do laser e controle de interrupção).

Para a comunicação entre o computador e a instrumentação externa foi desenvolvida uma interface que trabalha conectada ao barramento interno ISA do PC. 


\subsection{Interface de Controle}

A interface é responsável pela conversão, dupla, Digital/Analógica (D/A) que controla os defletores (x e y) do laser, e dos controladores (drivers) dos dois motores de passo, um da plataforma de crescimento e outro da interrupção da luz UV no modo de exposição por projeção. A interrupção no modo de exposição por varredura aproveita o mesmo sinal de controle do motor de passo para controlar o relê de interrupção. Na interface foram utilizados Circuitos Integrados TTL comuns da linha 74LS, uma porta paralela (8255) e um conversor duplo D/A de 12 bits (DAC8213) da marca Burr-Brown. Na figura 3.1 abaixo temos o diagrama em blocos da interface, na figura 3.2 vemos sua foto e no apêndice A temos o esquema elétrico completo da mesma.

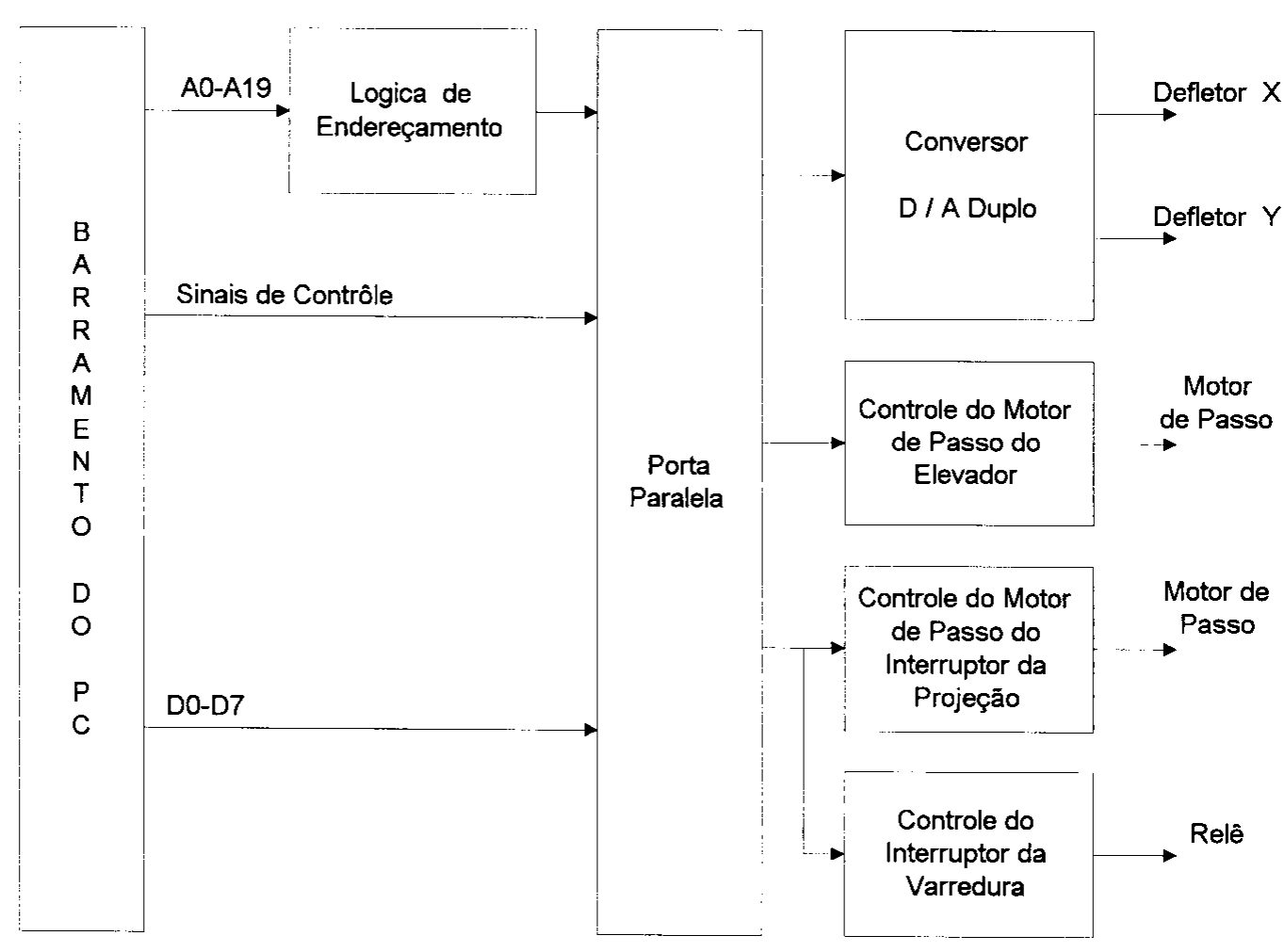

Figura 3.1 : Diagrama de Blocos da Interface. 


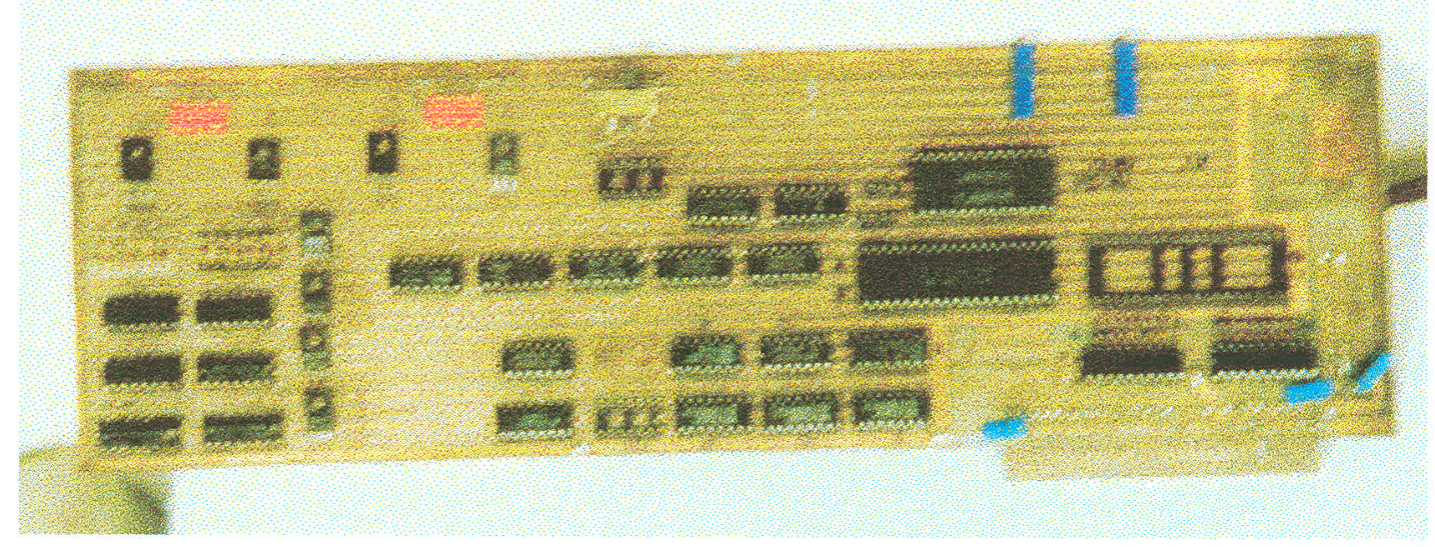

Figura 3.2 : Fotografia da Interface.

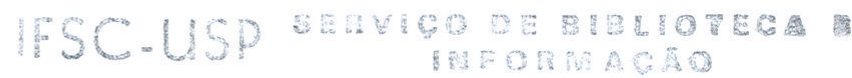




\subsection{Preparação das camadas}

Através de um motor de passo devidamente acoplado à plataforma por um elemento rosca-sem-fim controla-se a espessura da camada que se forma acima da plataforma à medida que esta submerge

O elevador desenvolvido apresenta pouca complexidade mecânica tendo sido construído com os materiais comuns alumínio e latão, sendo a plataforma de crescimento de aço inoxidável. A plataforma de crescimento está fixada num eixo oco com rosca interna em sua extremidade inferior. Por essa rosca interna um elemento rosca-sem-fim, acoplado diretamente em sua extremidade inferior ao motor de passo, promove o deslocamento vertical da plataforma. Duas constantes estão envolvidas no deslocamento da plataforma: $\mathrm{O}$ avanço da rosca-sem-fim, $\mathrm{P}_{\mathrm{r}}$, e o número de passos por revolução do motor de passo, $\mathrm{N}_{\mathrm{m}}$. Associando essas duas constantes podemos determinar a constante de deslocamento vertical da plataforma, $\mathrm{K}_{\mathrm{p}}$, como sendo:

$$
\mathrm{K}_{\mathrm{p}}=\mathrm{P}_{\mathrm{r}} / \mathrm{N}_{\mathrm{m}}
$$

A rosca-sem-fim foi construída com um passo $P_{r}=1 \mathrm{~mm} /$ revolução, e o motor de passo necessita de 100 passos para completar uma volta $\left(\mathrm{N}_{\mathrm{m}}=100\right.$ passos / revolução). Portanto:

$$
\mathrm{K}_{\mathrm{p}}=0,01 \mathrm{~mm} / \text { passo }
$$

A resolução em relação ao eixo $z$, que é a menor espessura da camada possível é então $0,01 \mathrm{~mm}$. Na figura 3.3 abaixo vemos a fotografia do elevador. 


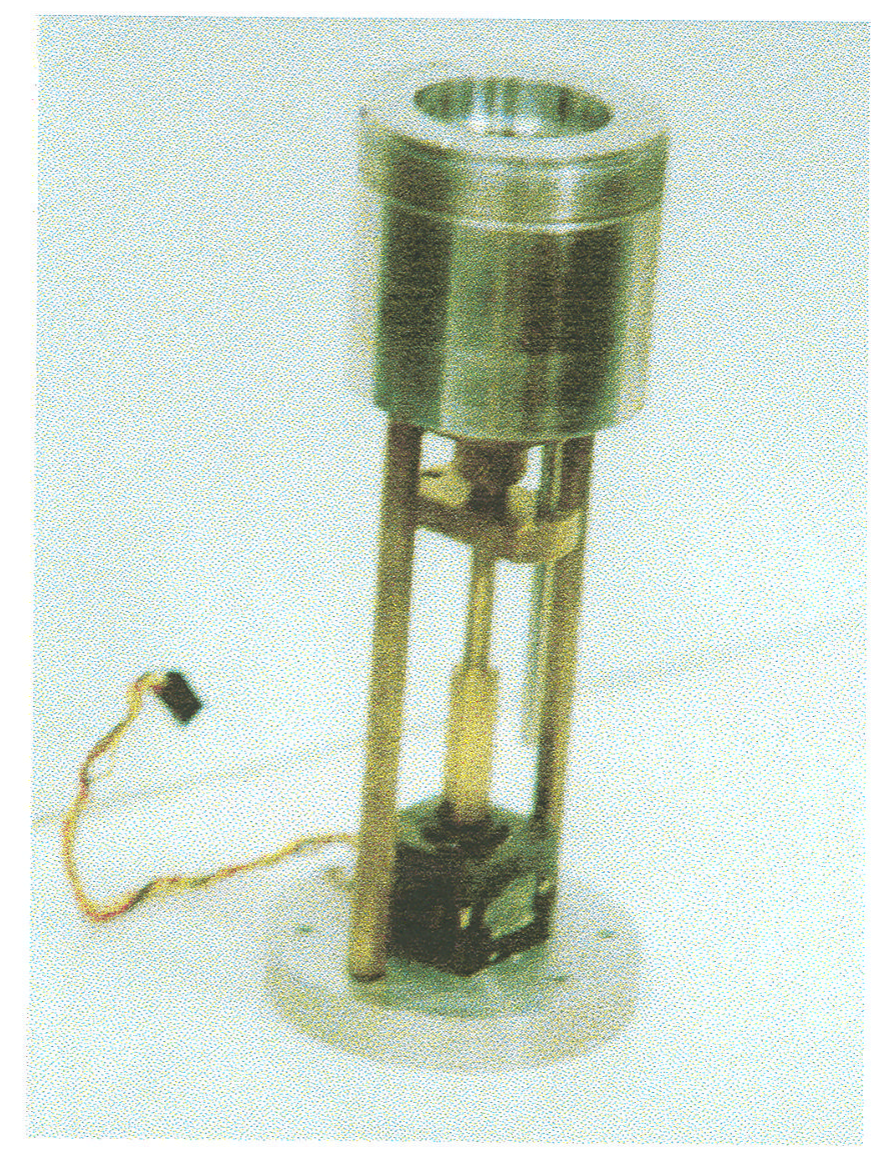

Figura 3.3 : Fotografia do Elevador.

Uma desvantagem do uso da janela no caso de construção por superfície fixada, é que a região da camada curada pelo UV além de aderir à camada inferior (ou à plataforma, caso estejamos na primeira camada), aderirá também à janela, exigindo muito esforço para um motor de passo. O problema da aderência foi minimizado revestindo internamente a janela de quartzo com uma folha fina de celofane, a qual além de oferecer uma aderência bem menor do que o quartzo, possui uma elasticidade apreciável para o desgrude. Na figura 3.4 vemos em andamento o processo de desgrude com o uso da folha de celofane como interface. 


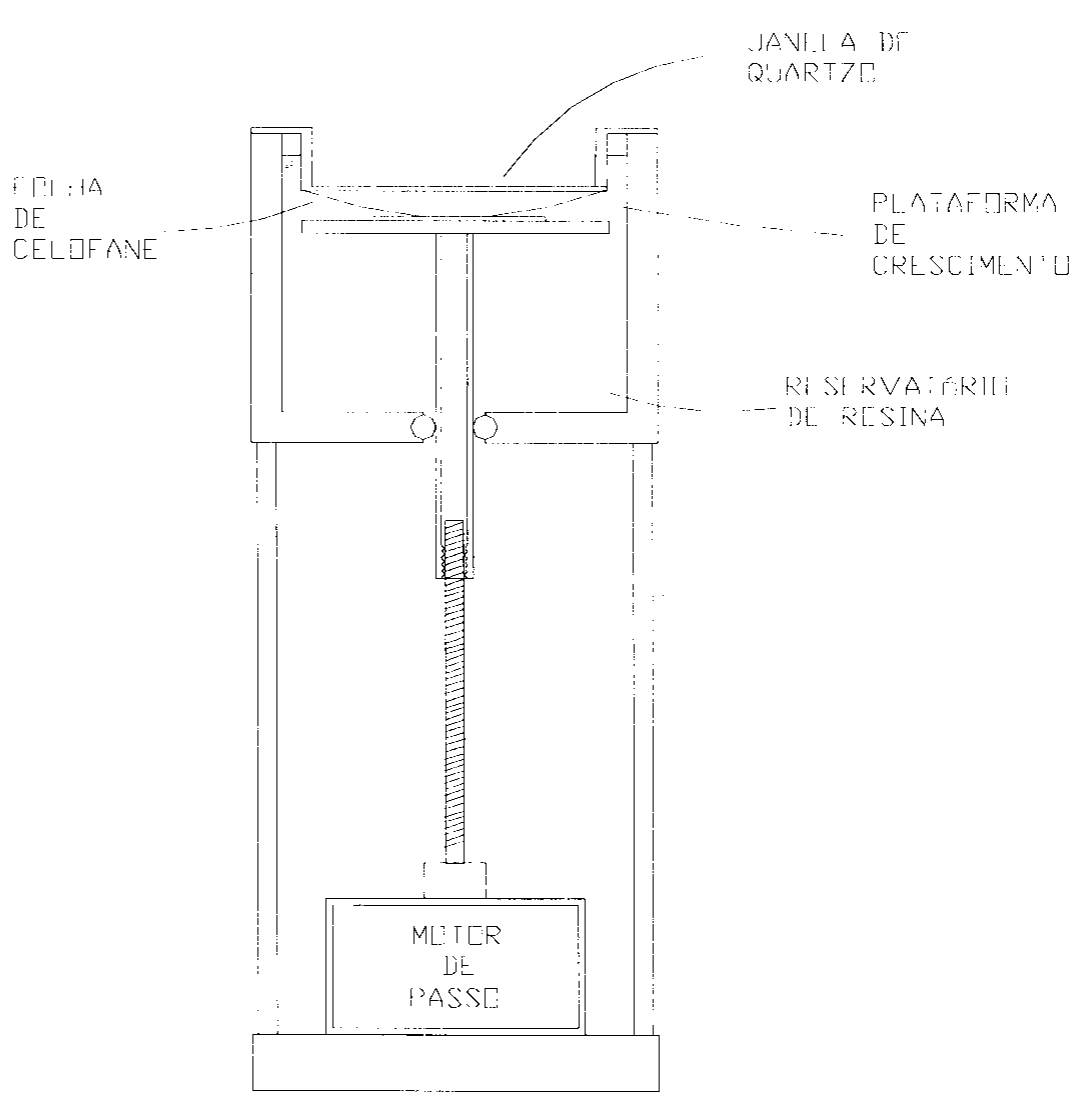

Figura 3.4: Desgrudamento da peça com o uso da folha de celofane.

A absorção de UV pelo celofane não foi significativa em relação ao tempo de cura da resina sendo também compensada pela falta de $\mathrm{O}_{2}$. Apesar das dificuldades de manuseio e fixação da folha de celofane na janela e também pela sua curta durabilidade, a mesma mostrou-se uma solução razoável quanto ao desgrude da peça. A elasticidade da folha de celofane exige que para o desgrudamento completo da peça, a plataforma realize um deslocamento $\mathrm{H}$ adiante da espessura $\mathrm{d}$ retornando em seguida a esta posição. Na figura 3.5 vemos esquematizado a forma do deslocamento realizado pela plataforma para a criação de uma camada. 


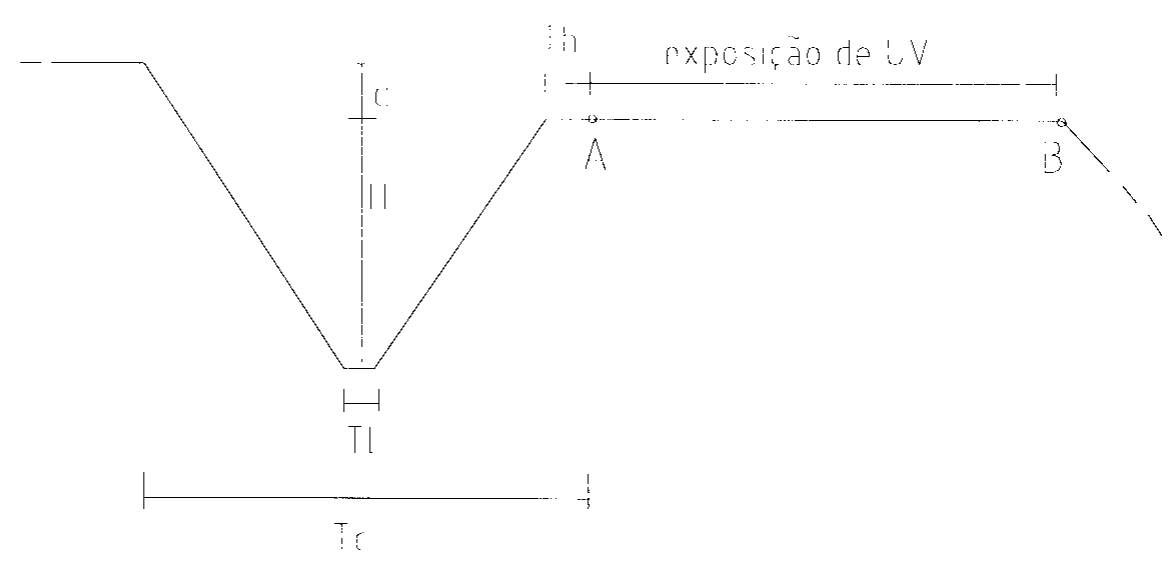

Figura 3.5: Ciclo completo do processo de estereolitografia.

A figura acima mostra um ciclo completo do processo de estereolitografia, compreendendo a preparação da camada (no intervalo de tempo Tc) e a exposição ao $\mathrm{UV}$, onde os pontos A e B correspondem respectivamente aos instantes de abertura e de interrupção da luz. Os intervalos de tempo $\mathrm{Tl}$ e $\mathrm{Th}$ (respectivamente tempo de espera em baixo e tempo de espera em cima) foram incluídos para suavizar o funcionamento do motor de passo e também para dar tempo de acomodações por parte da resina e da folha de celofane. Como a velocidade da plataforma é razoavelmente baixa, tanto $\mathrm{Tl}$ quanto $\mathrm{Th}$ têm valores baixos em relação ao tempo total do ciclo. A espessura d da camada é um dado proveniente do modelo segundo o qual será construído o protótipo. A velocidade da plataforma, o afastamento $\mathrm{H}$ e os intervalos de espera $\mathrm{Tl}$ e $\mathrm{Th}$ são valores empíricos e portanto devem ser determinados experimentalmente. No nosso sistema o valor de $\mathrm{H}$ está entre 1 e $4 \mathrm{~mm}$, $\mathrm{Tl}$ e Th respectivamente estão em torno de $0,1 \mathrm{~s}$ e 0,5 s respectivamente. $\mathrm{O}$ elevador 
desenvolvido apresenta uma taxa de deslocamento vertical da plataforma (eixo $z$ ) $K_{p}$ $=0,01 \mathrm{~mm} /$ passo. Para determinarmos o número de passos, $P_{d}$, da descida $\mathrm{H}+\mathrm{D}$ da plataforma e o número de passos, $\mathbf{P}_{\mathbf{s}}$, de subida da plataforma, usa-se as expressões:

$$
P_{d}=(H+d) / K_{p} \quad \text { e } \quad P_{s}=H / K_{p}
$$

Na figura 3.6 abaixo vemos o diagrama de formação das camadas.

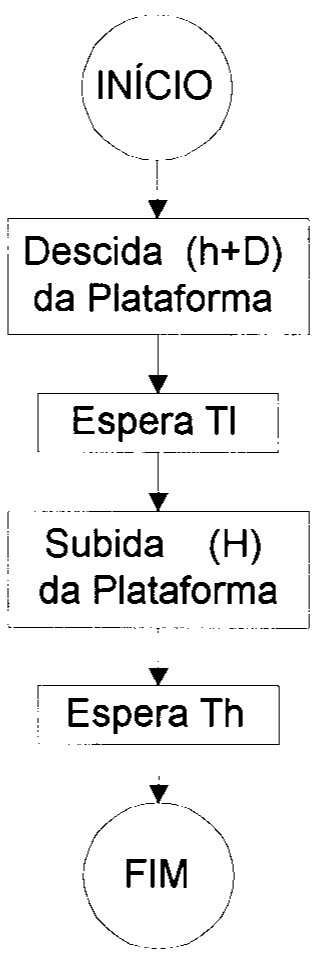

Figura 3.6: Diagrama de formação de camada. 


\subsection{Sistemas de Interrupção}

O sistema de interrupção do UV para o caso de exposição por projeção foi feito com uma hélice de quatro pás acoplada a um motor de passo como mostrado na figura 3.7

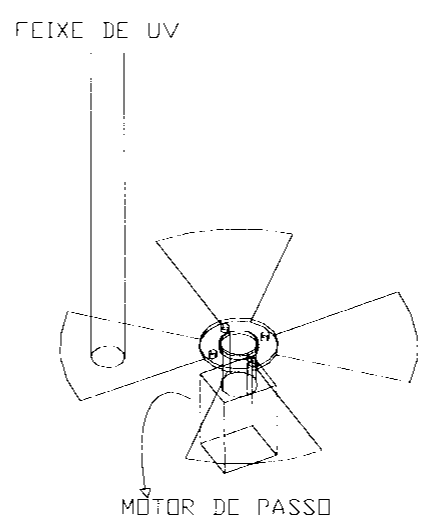

Figura 3.7 : Sistema de Interrupção para a Exposição por Projeção.

Na exposição por varredura, o diâmetro do feixe a ser interrompido é menor que no caso anterior, entretanto a velocidade de operação deve ser maior, sendo um caso em que um simples relê pôde ser usado satisfatoriamente. Na figura 3.8 vemos esquematizado a utilização de um relê como elemento interruptor.

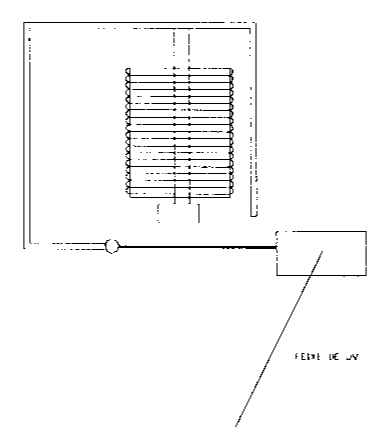

Figura 3.8 : Sistema de Interrupção para a Exposição por Varredura. 


\subsection{Programas de Computador}

Sobre os programas de computador, para a exposição ao UV por projeção foi usada a linguagem VisualBasic (Apêndice B). Na exposição por varredura o modelo da peça deve ser construído, ou acessado, pelo AutoCad-R13 onde, através da linguagem AutoLisp (Apêndice C) é feita a aquisição do modelo pela extração das bordas $3 \mathrm{D}$ e a criação de um arquivo dessas bordas. Após a aquisição do modelo, o tratamento da figura e o controle geral, do elevador, dos defletores e do interruptor é feito em $\mathrm{C}^{++}$(Apêndice D) com o programa Borland-4.5.

O controle do processo do sistema de exposição por projeção, tanto por superficie livre quanto por superficie fixada foi realizado em linguagem VisualBasic O programa é responsável por realizar o ciclo do processo de estereolitografia mostrado na figura 3.5 promovendo a formação das camadas através do controle do elevador e a exposição ao UV através do controle da interrupção.

Na figura 3.9 abaixo vemos a tela de controle do programa desenvolvido. 


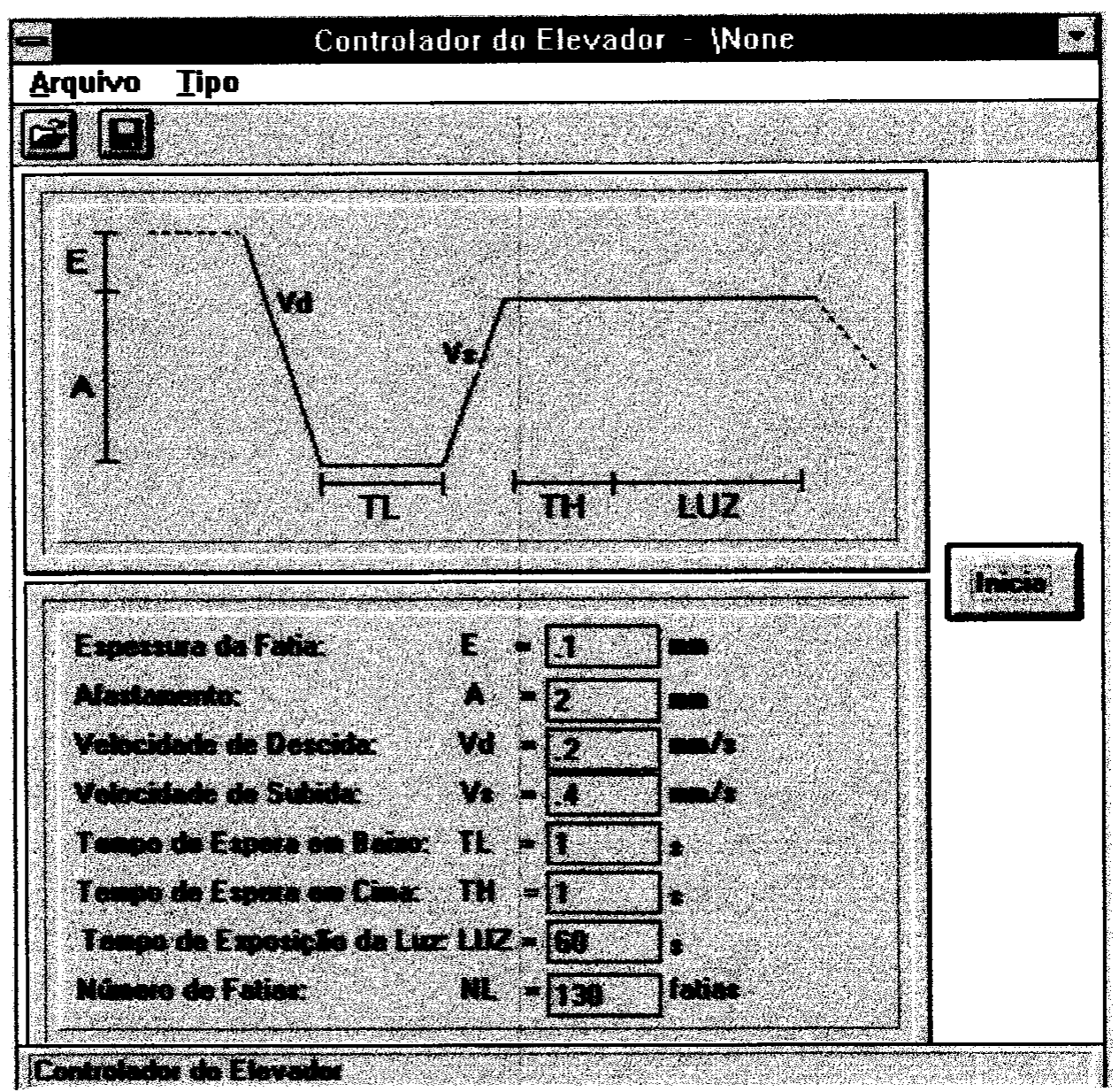

Figura 3.9 : Tela do programa de controle ciclo de estereolitografia por projeção desenvolvido em VisualBasic. 


\subsection{Sistema de Exposição por Projeção}

O sistema ótico utilizado no sistema de exposição por projeção tanto para construção por superficie livre como para superficie é formado por uma lente e um autocolimador, sendo que essas três lentes são de quartzo com $25 \mathrm{~mm}$ de diâmetro e distância focal de $25 \mathrm{~mm}$, sendo que e o orifício do autocolimador possui $0,5 \mathrm{~mm}$ de diâmetro. Na figura 3.10 abaixo vemos a fotografia do autocolimador ótico.

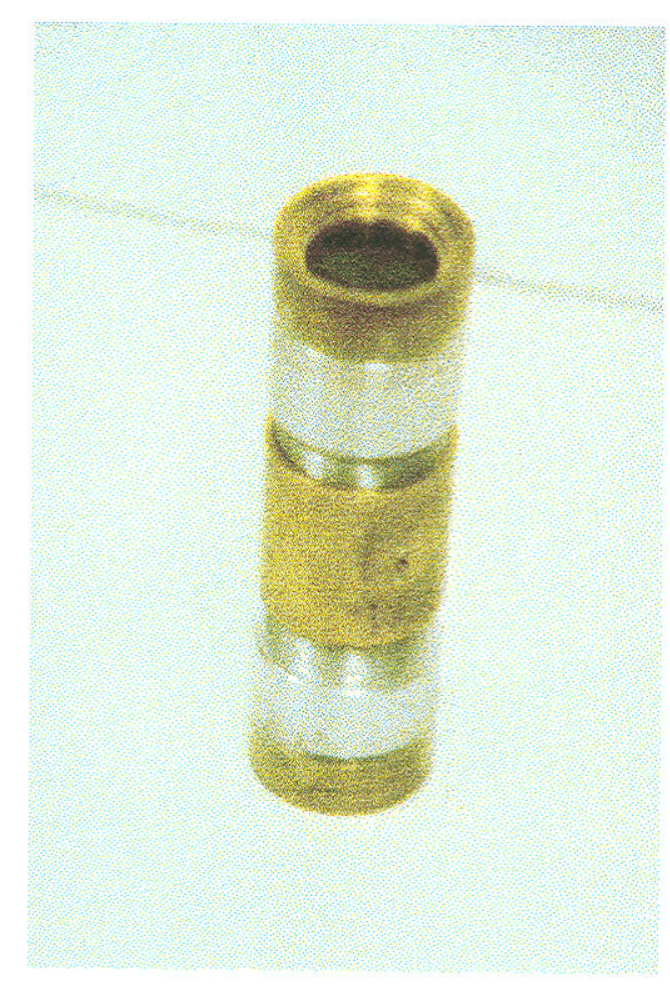

Figura 3.10 : Fotografia do Autocolimador Ótico.

A fonte de luz UV utilizada no processo de exposição por projeção foi uma lâmpada de Xenônio. A fotomáscara foi fixada sobre a janela facilitando a focalização pois sua imagem projetada está a apenas $2 \mathrm{~mm}$ de distância, que é a espessura da 
janela. Na figura 3.11 abaixo podemos ver esquematizado o sistema de exposição por projeção utilizado

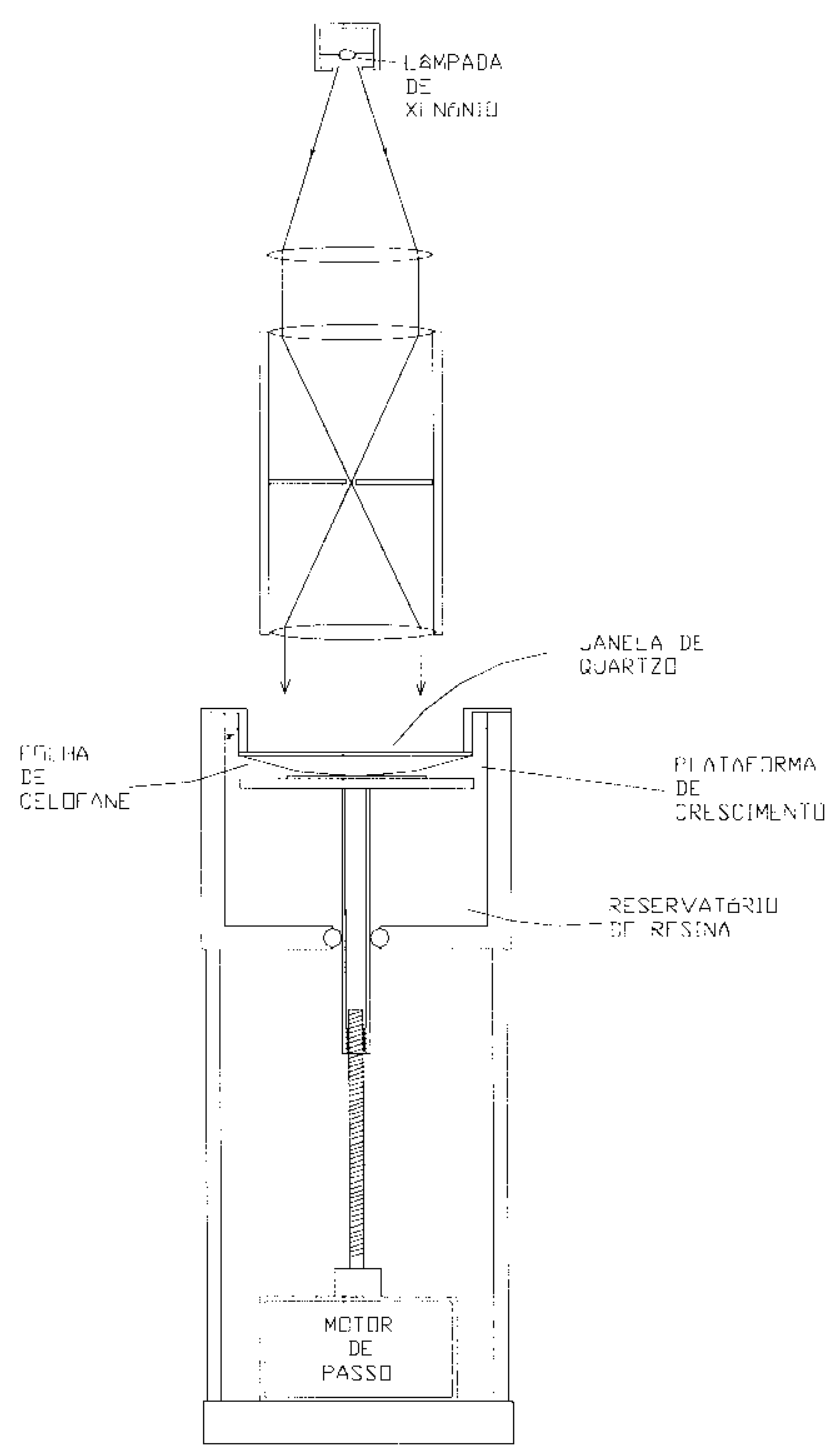

Figura 3.11 : Sistema de Projeção.

$\mathrm{Na}$ figura 3.12 abaixo vemos a fotografia do sistema completo de estereolitografia por exposição por projeção. 


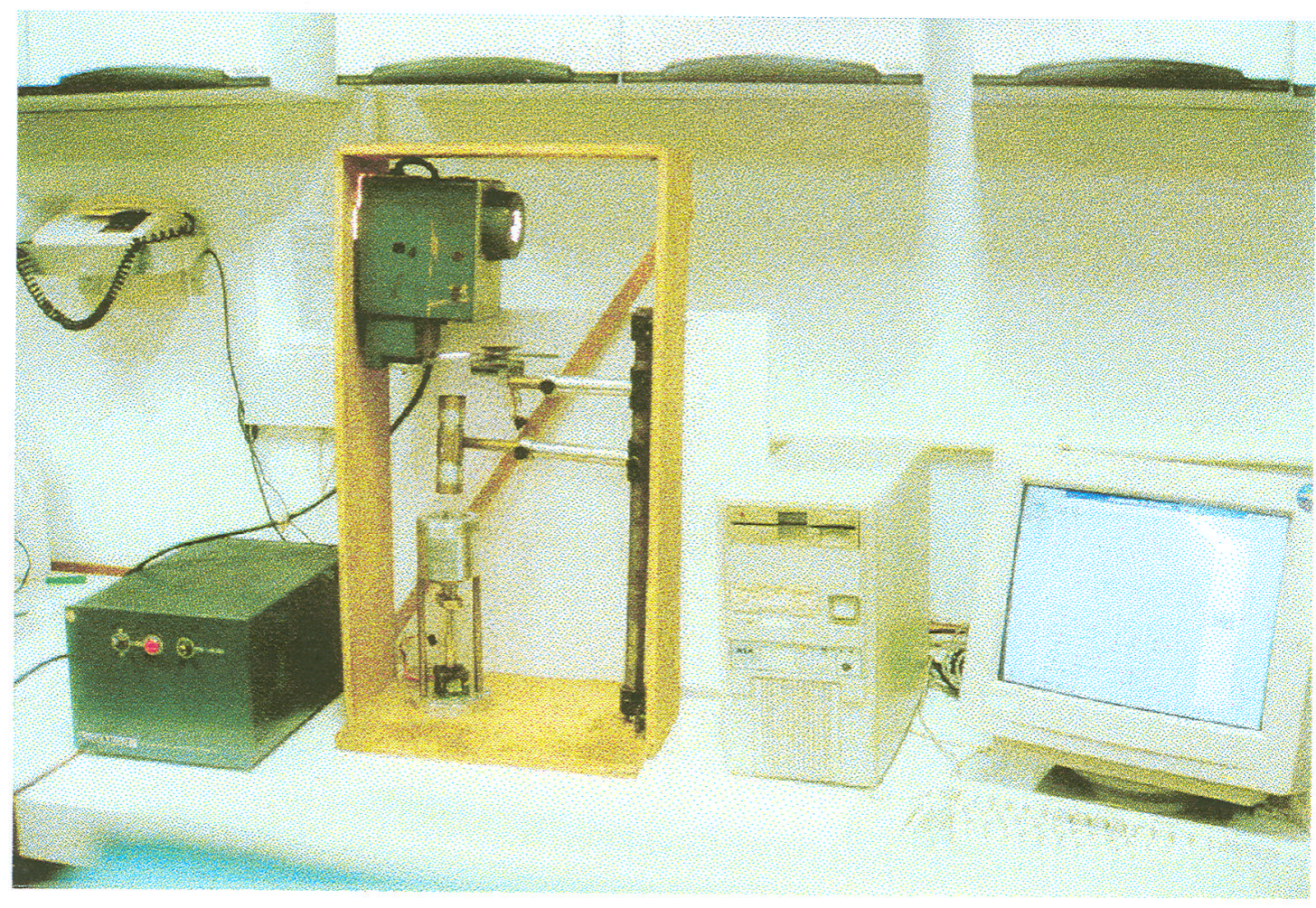

Figura 3.12 : Fotografia do sistema completo de estereolitografia por projeção. 


\subsubsection{Resultados de Construção por Superfície Livre}

Diversos protótipos foram construídos pela projeção da imagem do modelo através de fotomáscaras. Para cada protótipo foi utilizada apenas uma máscara, resultando que cada um deles ficou como que extrudado.

As peças construídas por projeção por superficie livre foram as primeiras as serem confeccionadas. A resina tinha pouco tempo de fabricação e portanto estava em plenas condições de uso. Nas figuras r1, r2 e r3 vemos os resultados obtidos por esse processo

A tabela 3.1 abaixo mostra as condições de exposição em relação à espessura das camadas e do tempo de exposição das peças dessas três figuras.

Tabela 3.1 : Condições de exposição por superfície livre.

\begin{tabular}{|c|c|c|}
\hline & Espessura d das Camadas & Tempo de Exposição \\
\hline Figuras r1 e r2 & entre 0,15 e $0,25 \mathrm{~mm}$ & entre 40 e $60 \mathrm{~s}$ \\
\hline Figura r3 & entre 0,05 e $0,15 \mathrm{~mm}$ & entre 15 e $30 \mathrm{~s}$ \\
\hline
\end{tabular}

Nas peças das figuras $\mathrm{r} 1$ e $\mathrm{r} 2$ vemos claramente arredondamentos no topo dessas peças

$\mathrm{Na}$ figura $\mathrm{r} 3$ as peças são de diâmetro bem menor que as anteriores e os arredondamentos são igualmente menores 


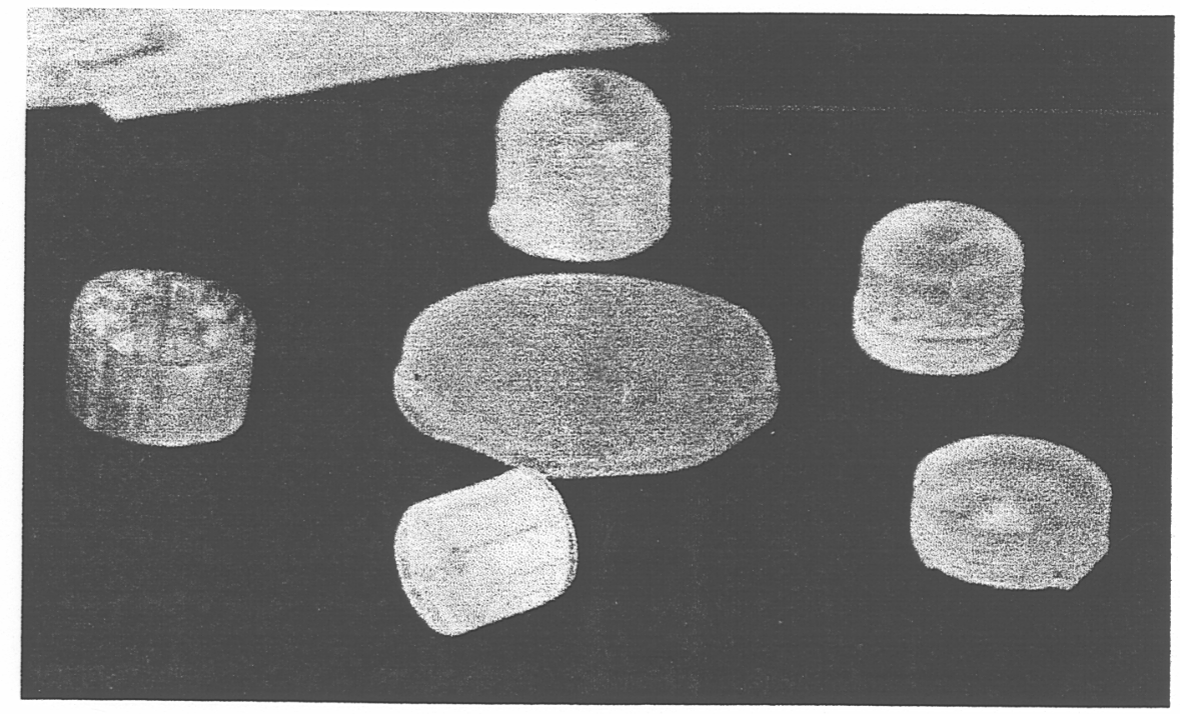

Figura r1

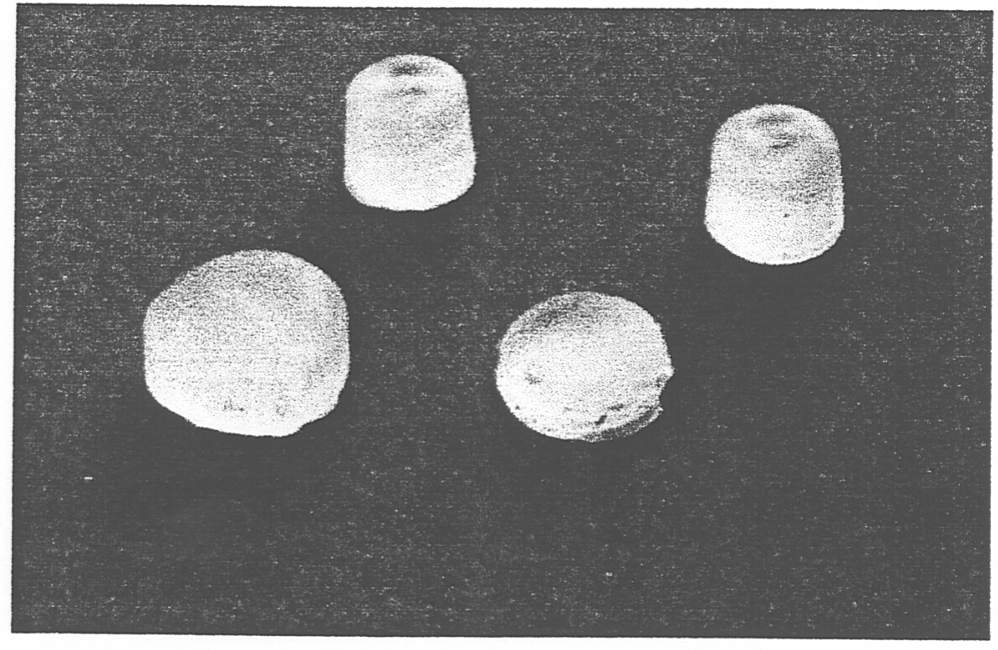

Figura r2

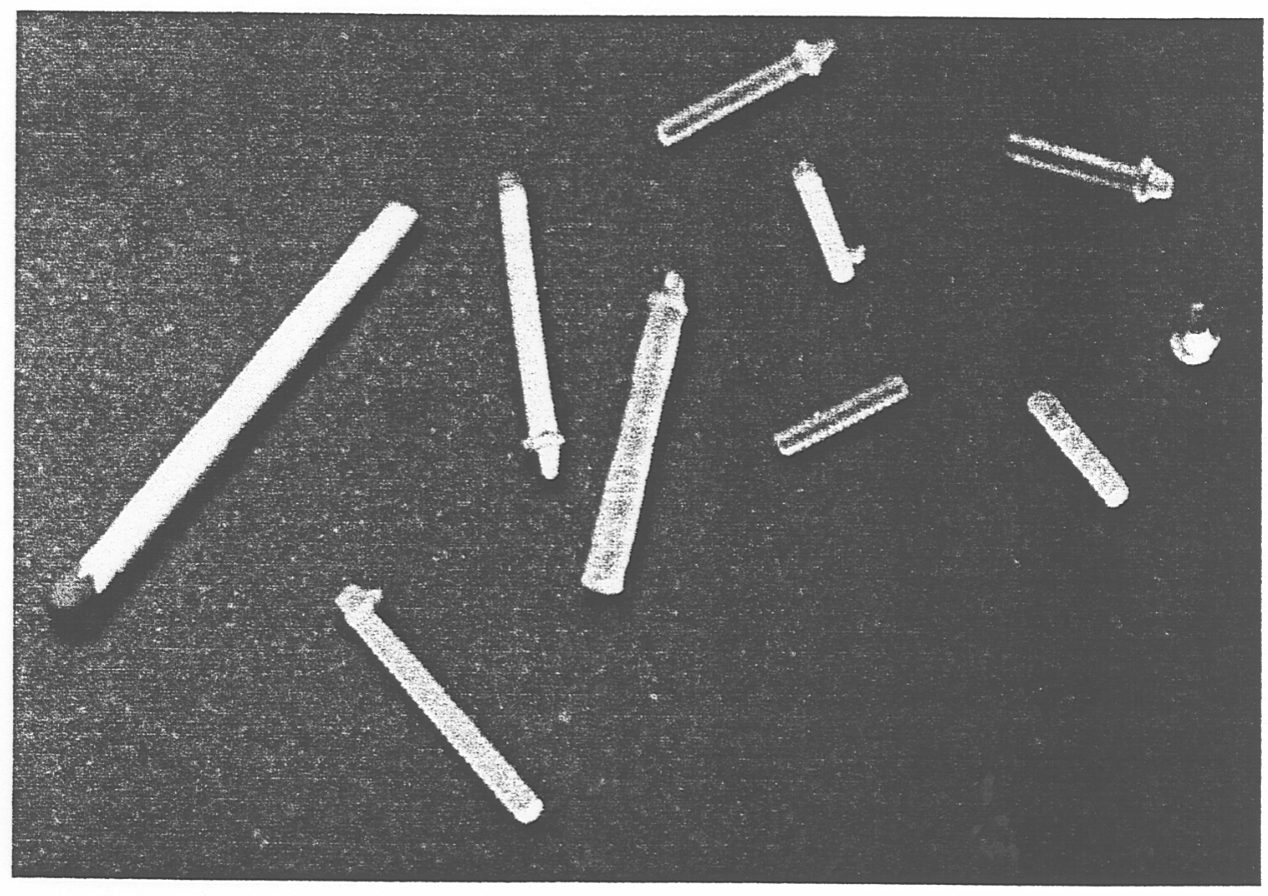

Figurar3 


\subsubsection{Resultados de Construção por Superfície Fixada}

Os resultados obtidos por exposição por superficie fixada são mostrados nas figuras $r 4$ a r9.

As figuras $\mathrm{r} 4$ e r5 mostram uma visão geral de conjunto de peças. Nas figuras r6 a r9 vemos peças em destaque. E nas figuras $\mathrm{r} 10$ a r12 vemos peças construídas com espessura muito finas.

$\mathrm{Na}$ tabela 3.2 abaixo temos as condições de exposição para esse método.

Tabela 3.2: Condiçб̃es de Exposição por Superfície Fixada.

\begin{tabular}{|c|c|c|}
\hline & Espessura d das camadas & Tempo de Exposição \\
\hline Figura r4 a r9 & $0,1 \mathrm{~mm}$ & entre 20 e 30 s \\
\hline Figura r10 e r11 & $0,05 \mathrm{~mm}$ & $12 \mathrm{~s}$ \\
\hline Figura r12 & $0,01 \mathrm{~mm}$ & $8 \mathrm{~s}$ \\
\hline
\end{tabular}

Quando da construção das peças por esse método, a resina já estava com prazo de validade vencido (6 meses), entretanto seu comportamento em relação ao tempo de cura não apresentou variações perceptíveis. 


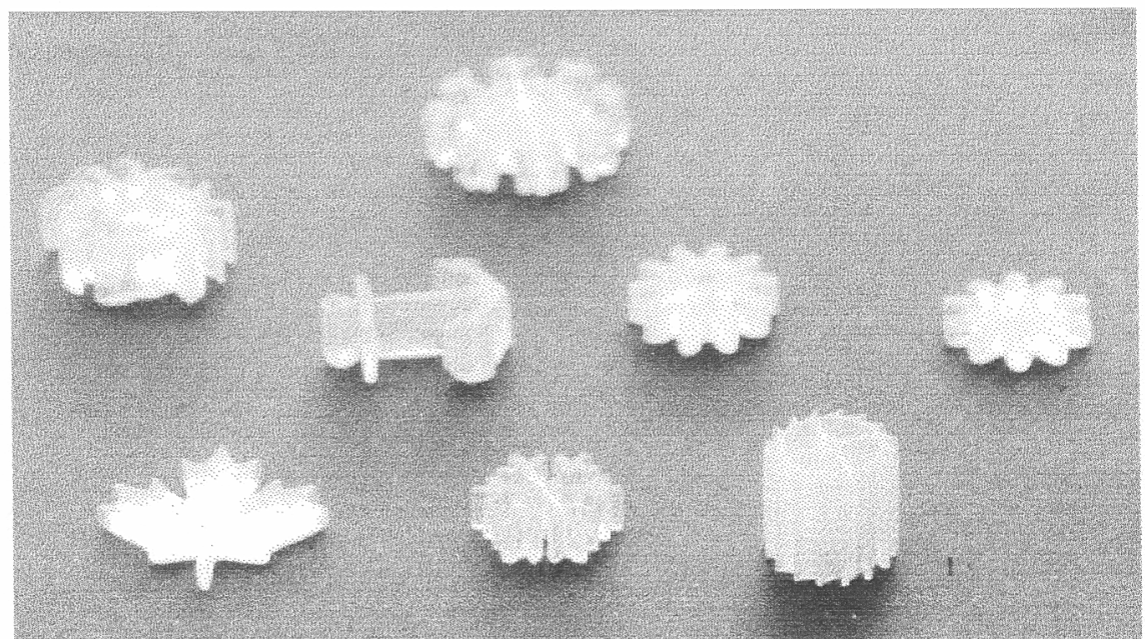

Figura r4

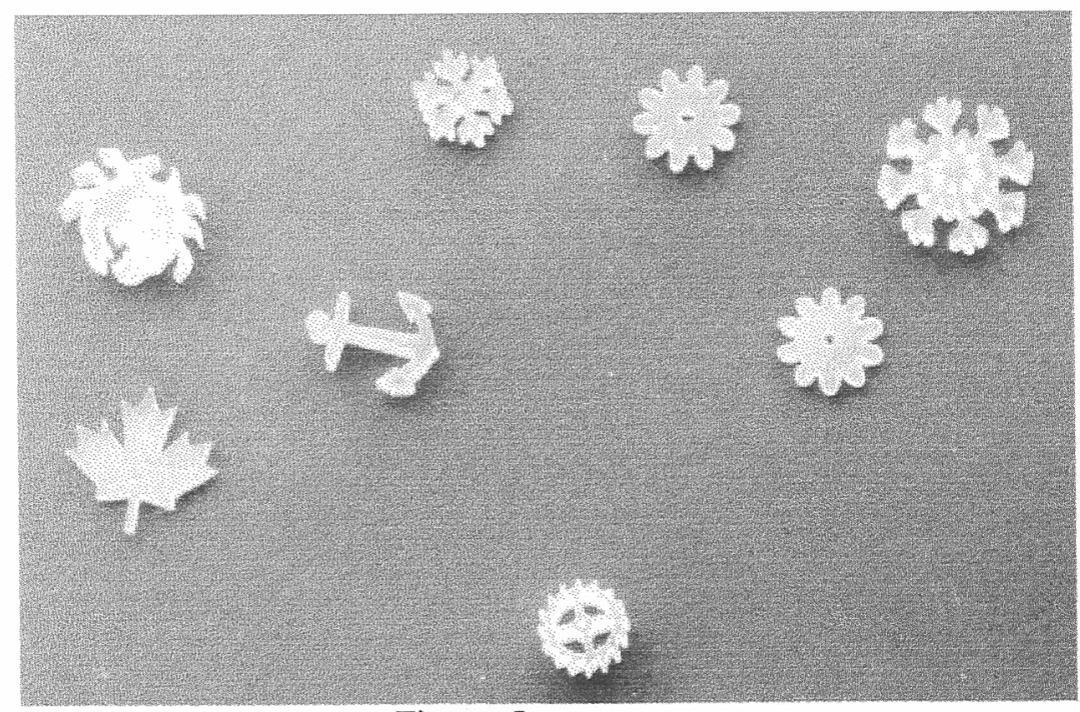

Figura r5

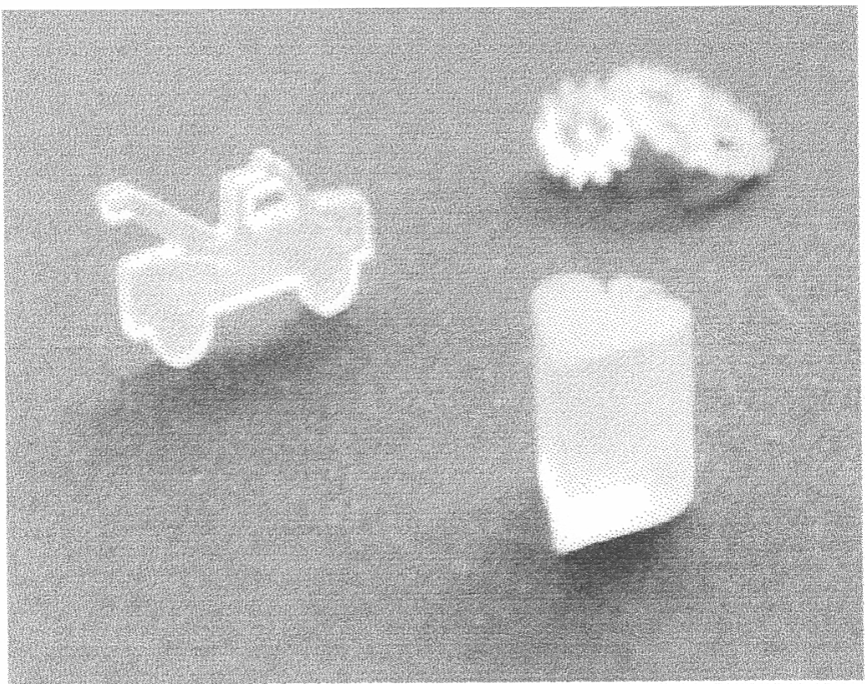

Figura r6 


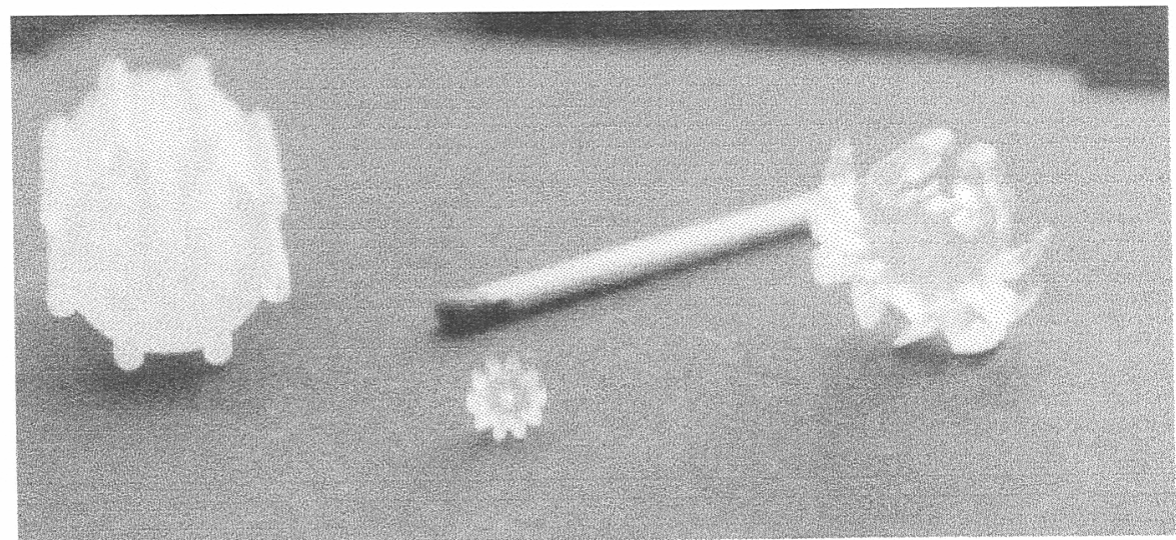

Figura $\mathrm{r} 7$

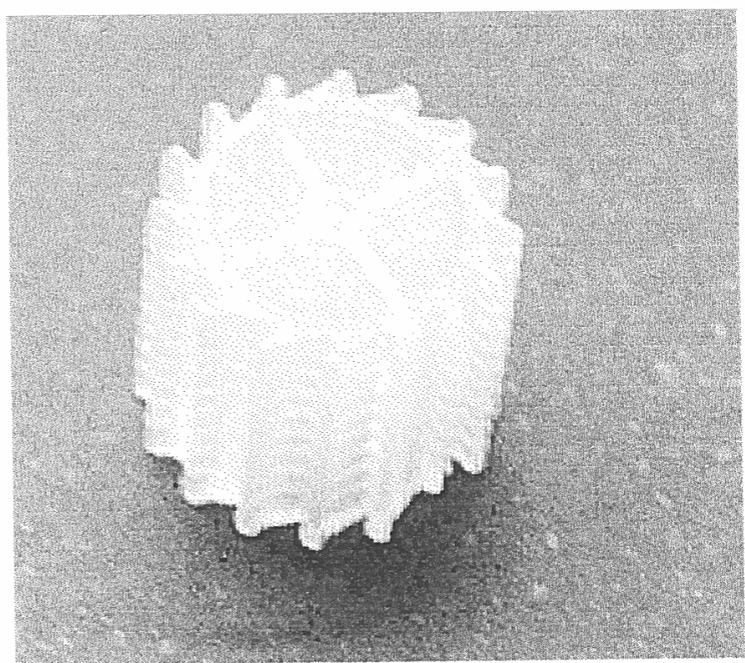

Figura r8

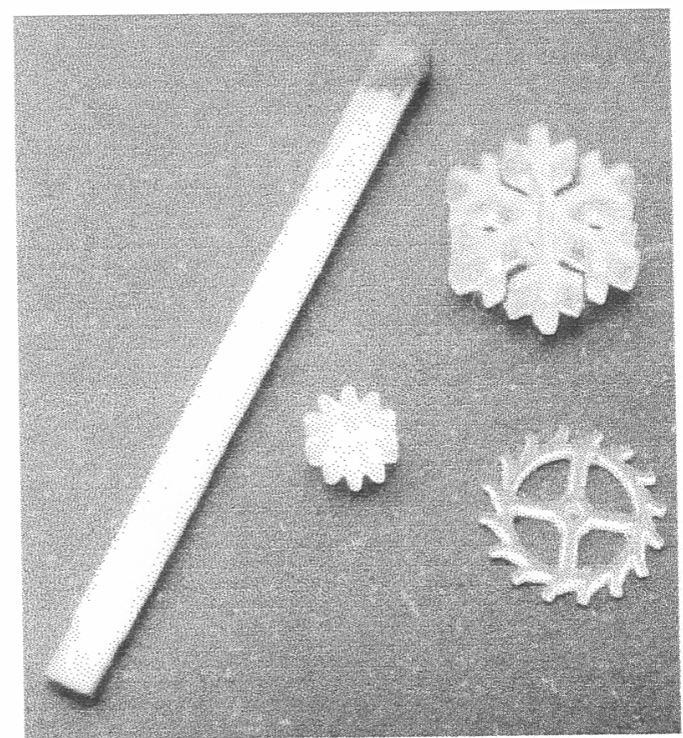

Figura r9 

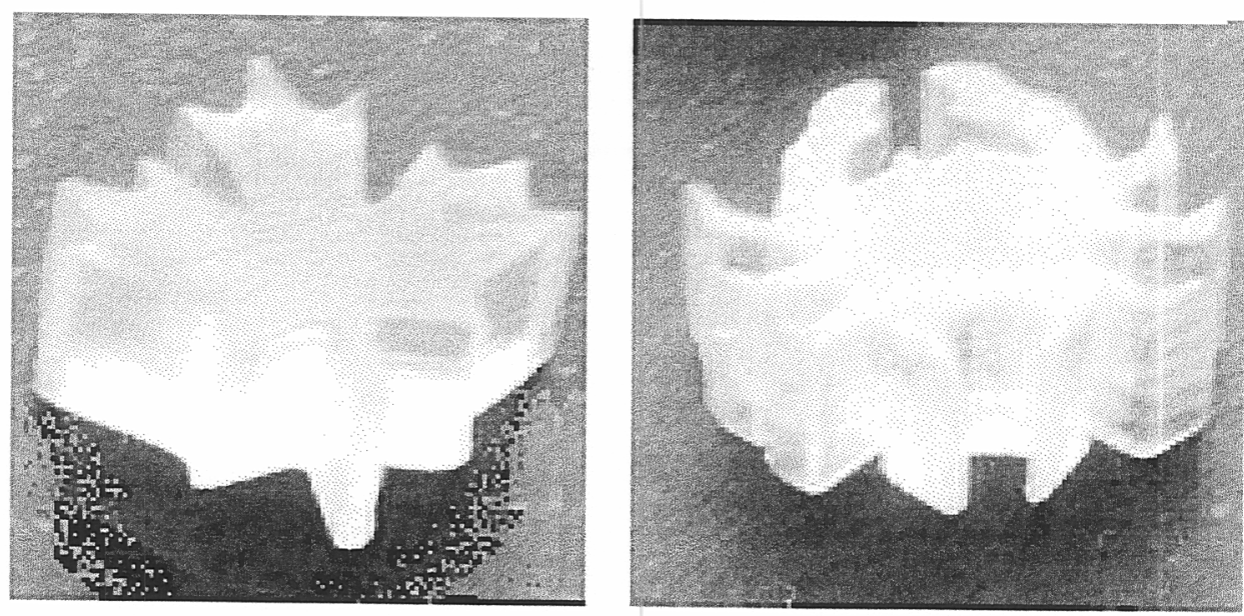

Figura r10

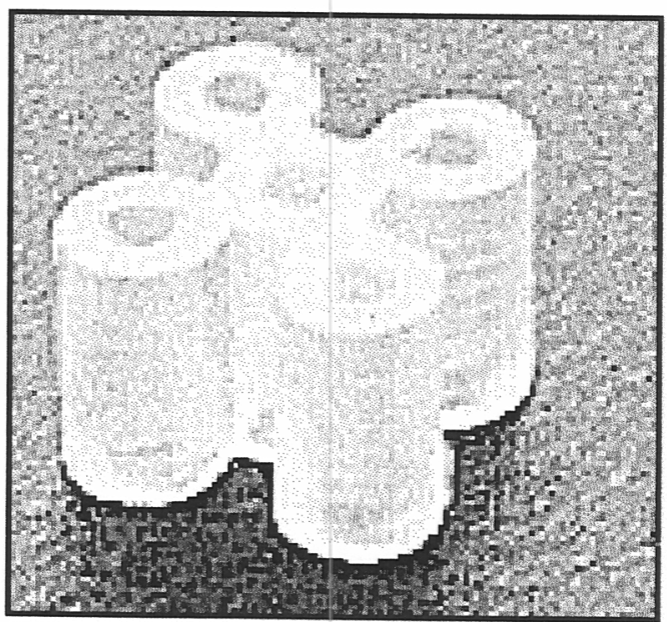

Figura r11

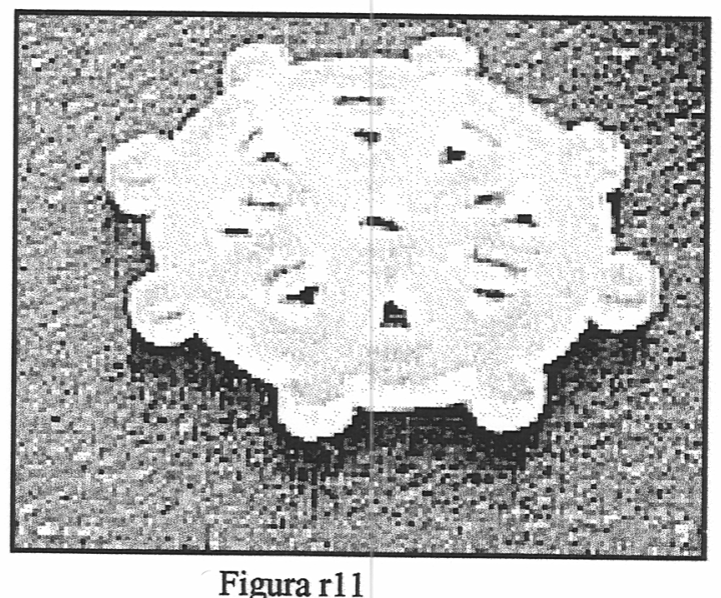

Figura r11 
As máscaras usadas para a projeção das imagens dessas peças estão na figura r15 abaixo.
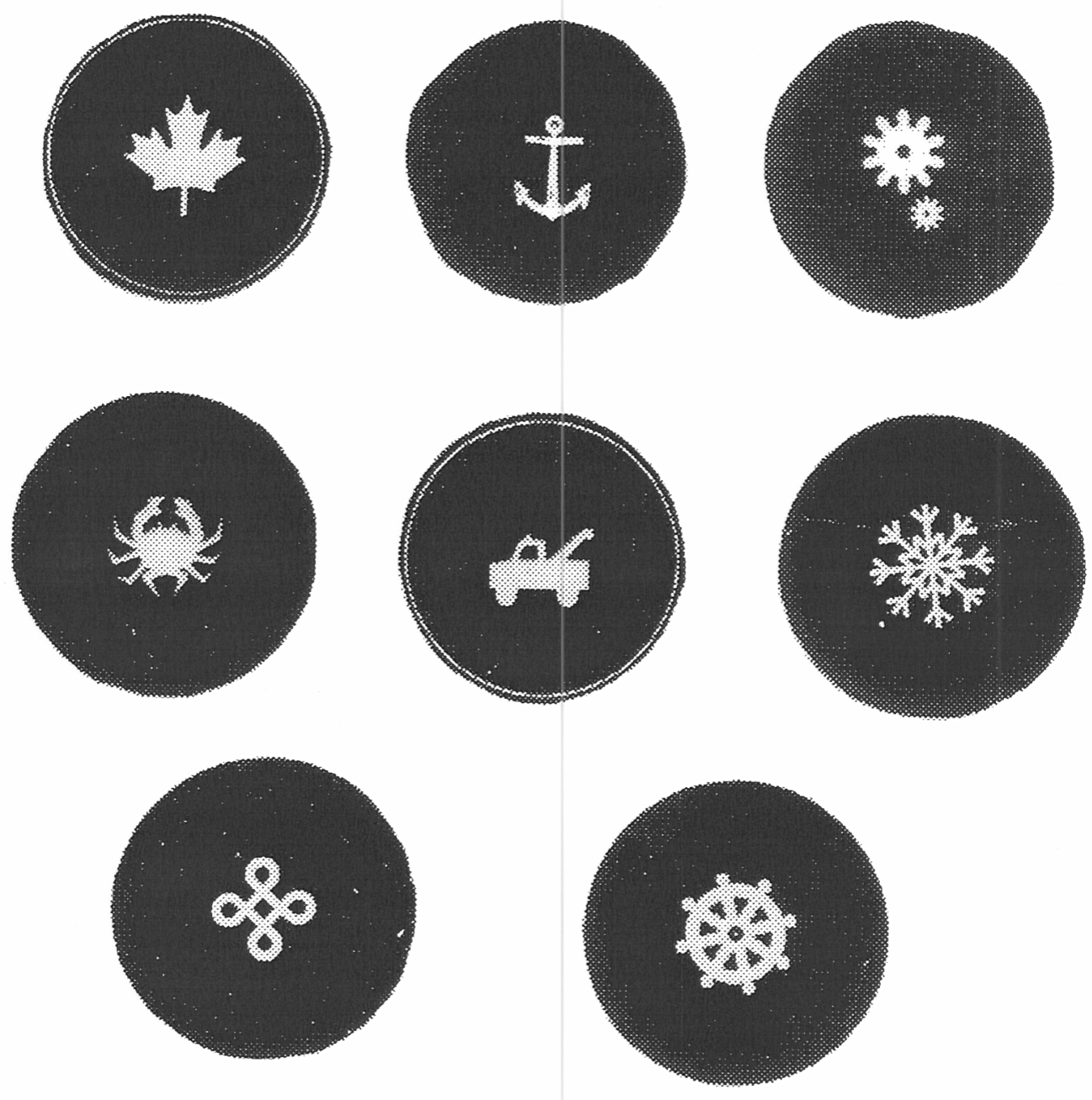

Figura r15 : Fotomáscaras usadas na projeção das peças. 


\subsection{Sistema de Exposição por Varredura}

Neste trabalho foi desenvolvida toda a metodologia para o processo de exposição por varredura. Entretanto pela não disponibilidade do laser de UV o processo não pôde ser implementado.

No sistema de exposição por varredura, o direcionamento do laser foi feito com dois defletores (x e y) da marca General Scanning modelo AEX200. Esses defletores operam controlados por tensão analógica, $\mathrm{v}$, na faixa de $0 \mathrm{~V}$ a $5 \mathrm{~V}$, resultando deslocamentos angulares, $\theta$, na faixa de $0^{\circ}$ a $7,5^{\circ}$. Como a resolução dos D/A's, e consequente controle dos defletores, é de 12 bits (1 em 4096), temos que a resolução dos defletores é de $0,0018^{\circ}$. Na figura 3.13 abaixo vemos a fotografia dos defletores.

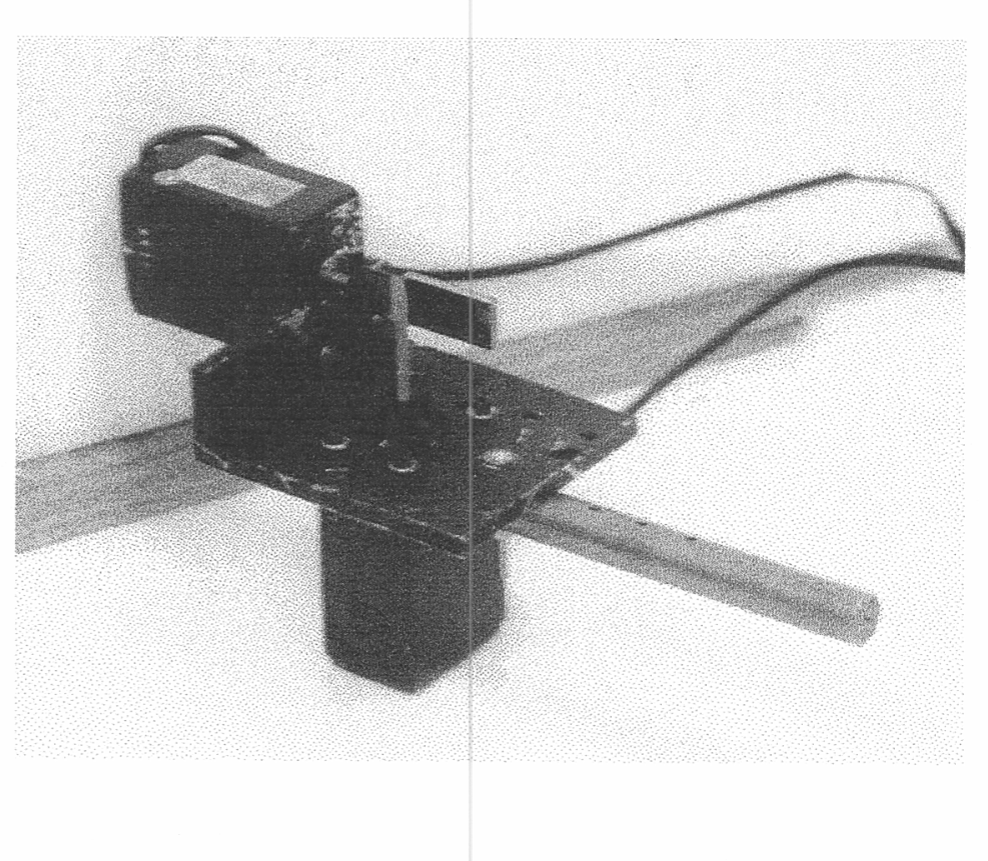

Figura 3.13 : Fotografia dos Defletores. 
No plano XY, a dimensão máxima das peças é de $40 \mathrm{~mm}$, portanto, para 12 bits, a resolução no plano é de $0,0098 \mathrm{~mm}$. Essa resolução é referente ao deslocamento do feixe de laser, entretanto o diâmetro do feixe não atingirá um diâmetro tão pequeno, resultando numa disposição Justaposta das células.

No sistema de exposição por varredura as tarefas de aquisição do modelo e de controle do feixe de UV são mais complexas. Como a aquisição do modelo é feita em linguagem AutoLisp sobre desenhos no AutoCad-R13 e o controle do feixe de UV e demais controles são feitos em $\mathrm{C}^{++}$, há uma necessidade de interrupção do processo entre a aquisição do modelo e a construção da peça.

Para realizar a aquisição do modelo e controlar o feixe de UV foram desenvolvidas três técnicas:

\section{1 - Extração de Bordas 3D}

2 - Preenchimento de uma Figura 2D

3 - Varredura de Saída

A extração das bordas 3D corresponde à aquisição do modelo propriamente dita. $\mathrm{O}$ preenchimento da figura 2D é uma etapa intermediária de preparação da figura (secção) a ser litografada, e a varredura de saída realiza o direcionamento propriamente dito do feixe de UV percorrendo os pontos da secção de acordo com critérios pré estabelecidos. 


\subsubsection{Aquisição do Modelo}

A técnica utilizada requer que o modelo possa ser acessado pelo AutoCadR13 onde será feita a extração dos pontos através de um programa específico desenvolvido em AutoLisp. Esse programa deverá fornecer como saída um arquivo contendo o número de camadas que irão compor o protótipo, as dimensões máximas do modelo, a espessura das camadas e os pontos pertencentes às bordas de cada secção. Esse arquivo é o resultado da aquisição do modelo, cujo formato podemos ver na tabela 3.3 .

Tabela 3.3 : Formato do Arquivo resultado da Aquisição do Modelo.

$(\mathrm{N}=\ldots \ldots \ldots)$
$(\mathrm{I}=\ldots \ldots \ldots)$
$(\mathrm{J}=\ldots \ldots \ldots)$
$(\mathrm{d}=\ldots \ldots \ldots)$
$(\mathrm{C} 1)$
$(\ldots \ldots, \ldots)$
.
.
$(\mathrm{C} 2)$
$(\ldots \ldots, \ldots)$
$(\ldots, \ldots)$
.

$\left(\mathrm{C}_{N C}\right)$


$\mathrm{O}$ conjunto dos pontos $\mathrm{P}(\mathrm{x}, \mathrm{y})$ pertencentes às bordas serão usados para representar posições de elementos numa matriz $\mathrm{M}(\mathrm{I}, \mathrm{J})$ numa correspondência direta $\mathrm{p}_{\mathrm{x}, \mathrm{y}} \rightarrow \mathrm{m}_{\mathrm{i}, \mathrm{j}}$ onde serão processados em linguagem $\mathrm{C}^{++}$para preenchimento e para a varredura de saída. Como posições de elementos numa matriz são representados por números inteiros, ísso implica que as coordenadas $(\mathrm{x}, \mathrm{y})$ dos pontos deverão ser arredondados. E, como a posição do primeiro elemento da matriz é $(0,0)$, então a figura 3D deverá estar posicionada no plano xy de maneira que seus valores $\mathrm{x}_{\min } \mathrm{e}$ $\mathrm{y}_{\min }$ fiquem respectivamente sobre os eixos $\mathrm{x}$ e $\mathrm{y}$. $\mathrm{Na}$ figura 3.14 vemos o posicionamento adequado da figura 3D para o tratamento.

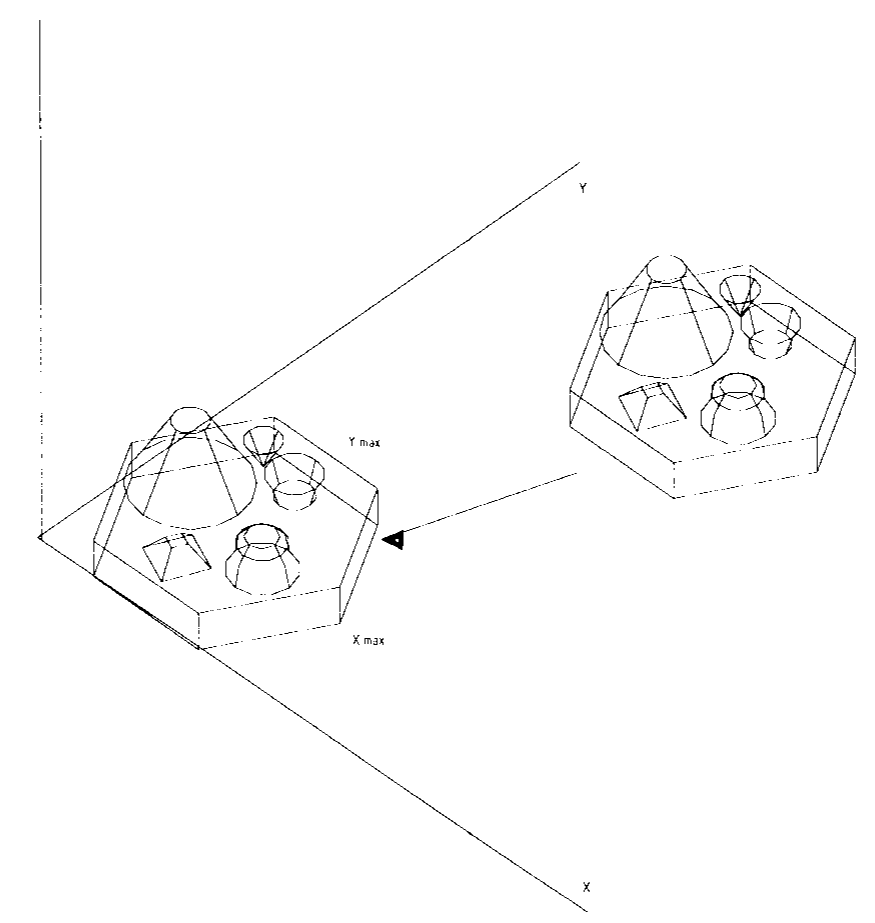

Figura 3.14 : Posicionamento correto da figura 3D para a extração dos pontos.

Com a figura nessa posição, seus valores de $x_{\max }$ e $y_{\max }$ corresponderão respectivamente a I e J, e a extração dos pontos pode então ser realizada.

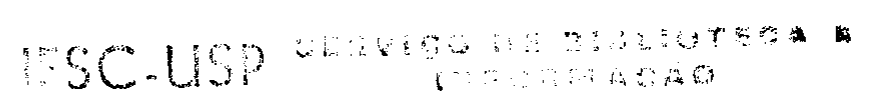




\subsubsection{Extração de Bordas de uma Figura 3D}

Em AutoCad um desenho é formado por partes chamadas entidades. As entidades de uma figura 2D podem ser linhas, círculos, arcos de círculo, elipses e arcos de elípse como as principais, sendo que os desenhos podem ser reduzidos a um conjunto dessas entidades. Cada entidade é representada por um conjunto de valores que a determine, sendo uma linha representada pelos ponto inicial e final, um círculo pela posição do centro e pelo raio, um arco é representado pela posição do centro e pelos ângulos inicial e final, uma elipse pela posição dos dois centros e dos dois semieixos e um arco de elípse pela posição do centro e pelos pontos inicial e final. $\mathrm{Na}$ figura 3.15 vemos a representação dessas entidades.
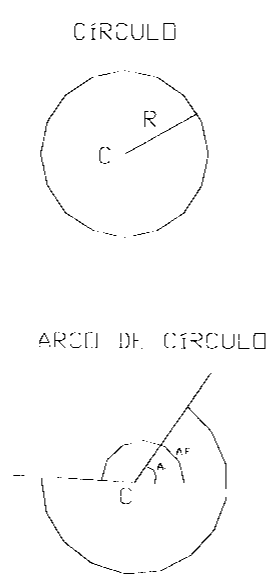

Figura 3.15 : Representação das principais entidades do AutoCad.

Como o protótipo é construído desde a base até o topo, as secções correspondentes serão determinadas ao longo do eixo $z$, desde $z=0$ até $z=z_{\max }$ em intervalos $\Delta z$. 
O seccionamento em AutoLisp é feito pelo comando Section, que gera como resultado uma secção que é definida no AutoCad como região, sendo que para converter a região em suas entidades constituintes deve-se aplicar o comando Explode. Assim, pelo processo de seccionamento seguido da "explosão", a figura 3D fica completamente representada por entidades.

A representação das entidades, como mostrado anteriormente, fornecem apenas valores-chave com os quais pode-se, pela expressão matemática correspondente, calcular-se os pontos pertencentes à curva em questão; sendo esses os pontos de borda. Entretanto não são necessários esses cálculos pois a linguagem AutoLisp possui um comando chamado Measure que faz a divisão de uma entidade em partes iguais especificada pelo operando e inclui pontos nessa divisão.

Uma vez terminado o processo de seccionamento/explosão/divisão, o modelo 3D fica completamente representado por pontos de borda. Na figura 3.16 vemos representada a sequência de extração de pontos pertencentes à borda de uma figura 3D

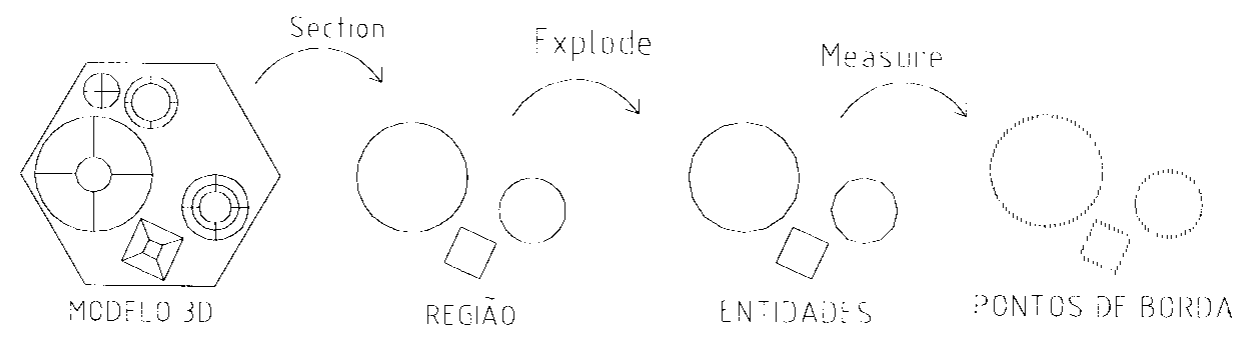

Figura 3.16 : Sequência de Comandos para Extração de Bordas de uma Figura 3D 


\subsubsection{Preenchimento de uma figura 2D}

O preenchimento de uma figura 2D a partir das bordas da mesma resume-se na determinação dos Pontos Internos, ou seja, pontos interiores às bordas externas e exteriores às bordas internas de possíveis furos que a figura $3 \mathrm{D}$ possa ter naquela secção. Após a extração das bordas os pontos $p_{x, y}$ irão modificar para "1" os elementos correspondentes $\mathrm{m}_{\mathrm{i}, \mathrm{j}}$ da matriz $\mathrm{M}$. Como resultado teremos uma matriz em que todos os elementos pertencentes às bordas terão valor igual a "1"e os demais serão iguais a " 0 ". Pelo motivo que se esclarecerá adiante, é necessário a inclusão de duas linhas e duas colunas de " 0 " às margens da figura. Na figura 3.17 vemos os pontos de borda presentes na matriz $\mathrm{M}$.

\begin{tabular}{|l|l|l|l|l|l|l|l|l|l|l|l|l|l|l|l|l|l|l|l|}
\hline 0 & 0 & 0 & 0 & 0 & 0 & 0 & 0 & 0 & 0 & 0 & 0 & 0 & 0 & 0 & 0 & 0 & 0 & 0 & 0 \\
\hline 0 & 0 & 0 & 0 & 0 & 0 & 0 & 0 & 0 & 0 & 0 & 0 & 0 & 0 & 0 & 0 & 0 & 0 & 0 & 0 \\
\hline 0 & 0 & 0 & 0 & $\mathbf{1}$ & $\mathbf{1}$ & $\mathbf{1}$ & $\mathbf{1}$ & $\mathbf{1}$ & 0 & 0 & 0 & $\mathbf{1}$ & 0 & 0 & 0 & 0 & 0 & 0 & 0 \\
\hline 0 & 0 & 0 & $\mathbf{1}$ & 0 & 0 & 0 & 0 & 0 & $\mathbf{1}$ & 0 & $\mathbf{1}$ & 0 & $\mathbf{1}$ & 0 & 0 & 0 & 0 & 0 & 0 \\
\hline 0 & 0 & 0 & $\mathbf{1}$ & 0 & 0 & 0 & 0 & 0 & 0 & $\mathbf{1}$ & 0 & 0 & 0 & $\mathbf{1}$ & 0 & 0 & 0 & 0 & 0 \\
\hline 0 & 0 & 0 & 0 & $\mathbf{1}$ & 0 & 0 & 0 & 0 & 0 & 0 & 0 & 0 & 0 & 0 & $\mathbf{1}$ & 0 & 0 & 0 & 0 \\
\hline 0 & 0 & 0 & 0 & 0 & $\mathbf{1}$ & 0 & 0 & 0 & 0 & 0 & 0 & 0 & 0 & 0 & 0 & $\mathbf{1}$ & 0 & 0 & 0 \\
\hline 0 & 0 & 0 & 0 & 0 & 0 & $\mathbf{1}$ & 0 & 0 & 0 & 0 & 0 & 0 & 0 & 0 & 0 & 0 & $\mathbf{1}$ & 0 & 0 \\
\hline 0 & 0 & 0 & 0 & 0 & $\mathbf{1}$ & 0 & 0 & 0 & $\mathbf{1}$ & $\mathbf{1}$ & $\mathbf{1}$ & $\mathbf{1}$ & $\mathbf{1}$ & 0 & 0 & 0 & $\mathbf{1}$ & 0 & 0 \\
\hline 0 & 0 & 0 & 0 & $\mathbf{1}$ & 0 & 0 & 0 & $\mathbf{1}$ & 0 & 0 & 0 & 0 & $\mathbf{1}$ & 0 & 0 & 0 & $\mathbf{1}$ & 0 & 0 \\
\hline 0 & 0 & 0 & $\mathbf{1}$ & 0 & 0 & 0 & $\mathbf{1}$ & 0 & 0 & 0 & 0 & 0 & $\mathbf{1}$ & 0 & 0 & $\mathbf{1}$ & 0 & 0 & 0 \\
\hline 0 & 0 & $\mathbf{1}$ & 0 & 0 & 0 & 0 & $\mathbf{1}$ & 0 & 0 & 0 & 0 & 0 & $\mathbf{1}$ & 0 & $\mathbf{1}$ & 0 & 0 & 0 & 0 \\
\hline 0 & 0 & $\mathbf{1}$ & 0 & 0 & 0 & 0 & 0 & $\mathbf{1}$ & $\mathbf{1}$ & $\mathbf{1}$ & $\mathbf{1}$ & $\mathbf{1}$ & $\mathbf{1}$ & 0 & $\mathbf{1}$ & 0 & 0 & 0 & 0 \\
\hline 0 & 0 & $\mathbf{1}$ & 0 & 0 & 0 & 0 & 0 & 0 & 0 & 0 & 0 & 0 & 0 & 0 & $\mathbf{1}$ & 0 & 0 & 0 & 0 \\
\hline 0 & 0 & $\mathbf{1}$ & 0 & 0 & 0 & 0 & 0 & 0 & 0 & 0 & 0 & 0 & 0 & 0 & $\mathbf{1}$ & 0 & 0 & 0 & 0 \\
\hline 0 & 0 & $\mathbf{1}$ & 0 & 0 & 0 & 0 & $\mathbf{1}$ & $\mathbf{1}$ & $\mathbf{1}$ & $\mathbf{1}$ & 0 & 0 & 0 & 0 & 0 & $\mathbf{1}$ & 0 & 0 & 0 \\
\hline 0 & 0 & 0 & $\mathbf{1}$ & $\mathbf{1}$ & $\mathbf{1}$ & $\mathbf{1}$ & 0 & 0 & 0 & 0 & $\mathbf{1}$ & 0 & 0 & 0 & 0 & $\mathbf{1}$ & 0 & 0 & 0 \\
\hline 0 & 0 & 0 & 0 & 0 & 0 & 0 & 0 & 0 & 0 & 0 & 0 & $\mathbf{1}$ & $\mathbf{1}$ & $\mathbf{1}$ & $\mathbf{1}$ & $\mathbf{1}$ & 0 & 0 & 0 \\
\hline 0 & 0 & 0 & 0 & 0 & 0 & 0 & 0 & 0 & 0 & 0 & 0 & 0 & 0 & 0 & 0 & 0 & 0 & 0 & 0 \\
\hline 0 & 0 & 0 & 0 & 0 & 0 & 0 & 0 & 0 & 0 & 0 & 0 & 0 & 0 & 0 & 0 & 0 & 0 & 0 & 0 \\
\hline
\end{tabular}

Figura 3.17 : Exemplo de uma matriz M com os elementos das bordas de uma figura. 
A determinação dos Pontos Internos é feita varrendo-se linearmente a matriz pelas linhas e colunas e determinando a situação de cada elemento encontrado. Existem três situações possíveis para um elemento:

Situaçãol - Ponto Fora (F)

Situação 2 - Ponto de Borda (B).

Situação 3 - Ponto Interno (PI).

Os Pontos de Borda e os Pontos Internos constituem o conjunto dos pontos de interesse. Como a matriz que nos chega apresenta tanto os pontos $\mathrm{F}$ quanto os pontos PI iguais a "0", faz-se necessário o preenchimento da figura modificando para " 2 " os Pontos Internos para que todos os pontos de interesse possam ser percorridos mais facilmente pela varredura de saída.

A varredura de preenchimento começa em $\mathrm{m}_{0,0}$ e termina em $\mathrm{m}_{\mathrm{I}, \mathrm{I}}$; e com certeza $\mathrm{m}_{0,0}=0$, ou seja, sua situação é $\mathrm{F}$. Assim, estando do lado de fora, enquanto elementos percorridos tiverem valor igual a " 0 ", tais elementos também serão $F$. Quando um valor "1" for encontrado sua situação certamente é B. Quando estivermos na borda e o próximo valor for "0" não podemos saber a priori sua situação, fazendose necessários alguns testes com elementos vizinhos para tal preenchimento. Esses testes são realizados nos elementos PA, PB e PC mostrados na figura 3.18.

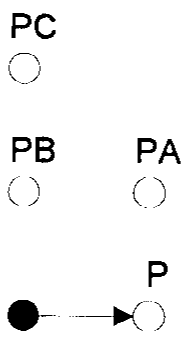

Figura 3.18 : Elementos utilizados para testes de borda. 
Onde :

$$
\begin{aligned}
& P=m_{i, j}, \\
& P A=m_{i-1, j}, \\
& P B=m_{i-1, j-1}, \\
& P C=m_{i-2, j-1} .
\end{aligned}
$$

Se $P A=0(F)$, então $P$ também é $F$.

Se $\mathrm{PA}=2(\mathrm{PI})$, então $\mathrm{P}$ também é PI.

Se $P A=1(B)$ e $P B \neq 1$, então $P$ será de situação "inversa" de $P B$, ou seja:

se PB é F, então P é PI, e

se PB é PI, então P é F.

Se $\mathrm{PA}=1(\mathrm{~B})$ e $\mathrm{PB}=1(\mathrm{~B})$, então $\mathrm{P}$ será de situação "inversa" de $\mathrm{PC}$, ou seja:

se PC é F, então P é PI, e

se PC é PI, então P é F.

Os testes descritos acima determinam as transições de borda que podem ocorrer, e a figura 3.19 mostra tais possibilidades.
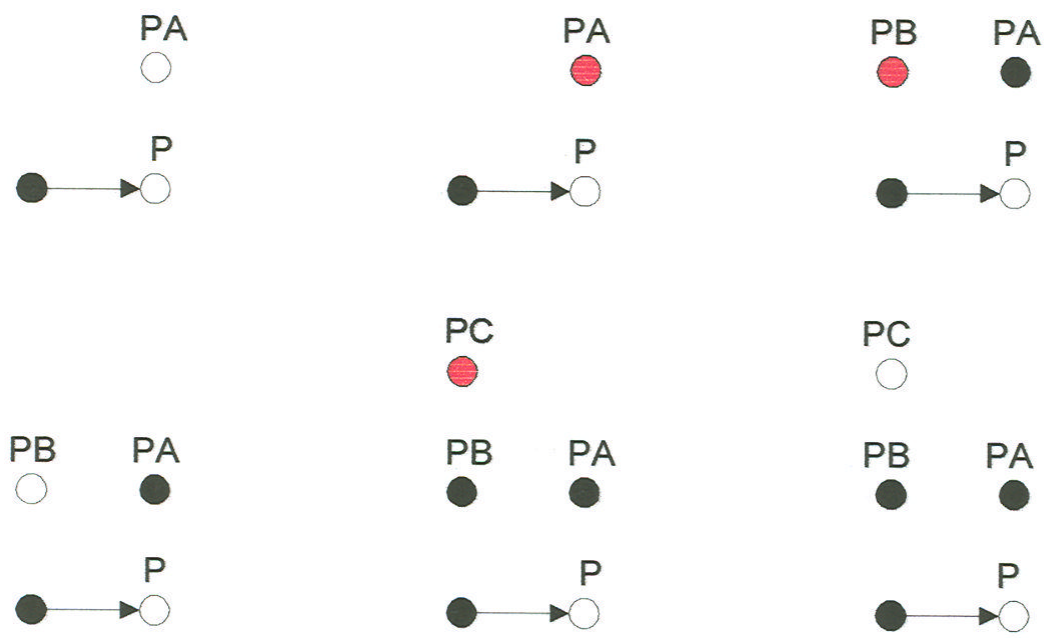

PC
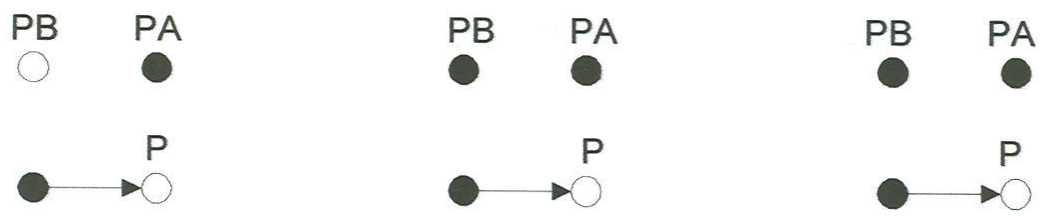

- PB

PI

Figura 3.19: Possíveis bordas que podem ocorrer. 
$\mathrm{Na}$ figura 3.20 vemos o resultado do preenchimento da matriz $\mathrm{M}$ e na figura 3.21 temos o diagrama de preenchimento de uma figura $2 \mathrm{D}$.

\begin{tabular}{|l|l|l|l|l|l|l|l|l|l|l|l|l|l|l|l|l|l|l|l|}
\hline 0 & 0 & 0 & 0 & 0 & 0 & 0 & 0 & 0 & 0 & 0 & 0 & 0 & 0 & 0 & 0 & 0 & 0 & 0 & 0 \\
\hline 0 & 0 & 0 & 0 & 0 & 0 & 0 & 0 & 0 & 0 & 0 & 0 & 0 & 0 & 0 & 0 & 0 & 0 & 0 & 0 \\
\hline 0 & 0 & 0 & 0 & $\mathbf{1}$ & $\mathbf{1}$ & $\mathbf{1}$ & $\mathbf{1}$ & $\mathbf{1}$ & 0 & 0 & 0 & $\mathbf{1}$ & 0 & 0 & 0 & 0 & 0 & 0 & 0 \\
\hline 0 & 0 & 0 & $\mathbf{1}$ & $\mathbf{2}$ & $\mathbf{2}$ & $\mathbf{2}$ & $\mathbf{2}$ & $\mathbf{2}$ & $\mathbf{1}$ & 0 & $\mathbf{1}$ & $\mathbf{2}$ & $\mathbf{1}$ & 0 & 0 & 0 & 0 & 0 & 0 \\
\hline 0 & 0 & 0 & $\mathbf{1}$ & $\mathbf{2}$ & $\mathbf{2}$ & $\mathbf{2}$ & $\mathbf{2}$ & $\mathbf{2}$ & $\mathbf{2}$ & $\mathbf{1}$ & $\mathbf{2}$ & $\mathbf{2}$ & $\mathbf{2}$ & $\mathbf{1}$ & 0 & 0 & 0 & 0 & 0 \\
\hline 0 & 0 & 0 & 0 & $\mathbf{1}$ & $\mathbf{2}$ & $\mathbf{2}$ & $\mathbf{2}$ & $\mathbf{2}$ & $\mathbf{2}$ & $\mathbf{2}$ & $\mathbf{2}$ & $\mathbf{2}$ & $\mathbf{2}$ & $\mathbf{2}$ & $\mathbf{1}$ & 0 & 0 & 0 & 0 \\
\hline 0 & 0 & 0 & 0 & 0 & $\mathbf{1}$ & $\mathbf{2}$ & $\mathbf{2}$ & $\mathbf{2}$ & $\mathbf{2}$ & $\mathbf{2}$ & $\mathbf{2}$ & $\mathbf{2}$ & $\mathbf{2}$ & $\mathbf{2}$ & $\mathbf{2}$ & $\mathbf{1}$ & 0 & 0 & 0 \\
\hline 0 & 0 & 0 & 0 & 0 & 0 & $\mathbf{1}$ & $\mathbf{2}$ & $\mathbf{2}$ & $\mathbf{2}$ & $\mathbf{2}$ & $\mathbf{2}$ & $\mathbf{2}$ & $\mathbf{2}$ & $\mathbf{2}$ & $\mathbf{2}$ & $\mathbf{2}$ & $\mathbf{1}$ & 0 & 0 \\
\hline 0 & 0 & 0 & 0 & 0 & $\mathbf{1}$ & $\mathbf{2}$ & $\mathbf{2}$ & $\mathbf{2}$ & $\mathbf{1}$ & $\mathbf{1}$ & $\mathbf{1}$ & $\mathbf{1}$ & $\mathbf{1}$ & $\mathbf{2}$ & $\mathbf{2}$ & $\mathbf{2}$ & $\mathbf{1}$ & 0 & 0 \\
\hline 0 & 0 & 0 & 0 & $\mathbf{1}$ & $\mathbf{2}$ & $\mathbf{2}$ & $\mathbf{2}$ & $\mathbf{1}$ & 0 & 0 & 0 & 0 & $\mathbf{1}$ & $\mathbf{2}$ & $\mathbf{2}$ & $\mathbf{2}$ & $\mathbf{1}$ & 0 & 0 \\
\hline 0 & 0 & 0 & $\mathbf{1}$ & $\mathbf{2}$ & $\mathbf{2}$ & $\mathbf{2}$ & $\mathbf{1}$ & 0 & 0 & 0 & 0 & 0 & $\mathbf{1}$ & $\mathbf{2}$ & $\mathbf{2}$ & $\mathbf{1}$ & 0 & 0 & 0 \\
\hline 0 & 0 & $\mathbf{1}$ & $\mathbf{2}$ & $\mathbf{2}$ & $\mathbf{2}$ & $\mathbf{2}$ & $\mathbf{1}$ & 0 & 0 & 0 & 0 & 0 & $\mathbf{1}$ & $\mathbf{2}$ & $\mathbf{1}$ & 0 & 0 & 0 & 0 \\
\hline 0 & 0 & $\mathbf{1}$ & $\mathbf{2}$ & $\mathbf{2}$ & $\mathbf{2}$ & $\mathbf{2}$ & $\mathbf{2}$ & $\mathbf{1}$ & $\mathbf{1}$ & $\mathbf{1}$ & $\mathbf{1}$ & $\mathbf{1}$ & $\mathbf{1}$ & $\mathbf{2}$ & $\mathbf{1}$ & 0 & 0 & 0 & 0 \\
\hline 0 & 0 & $\mathbf{1}$ & $\mathbf{2}$ & $\mathbf{2}$ & $\mathbf{2}$ & $\mathbf{2}$ & $\mathbf{2}$ & $\mathbf{2}$ & $\mathbf{2}$ & $\mathbf{2}$ & $\mathbf{2}$ & $\mathbf{2}$ & $\mathbf{2}$ & $\mathbf{2}$ & $\mathbf{1}$ & 0 & 0 & 0 & 0 \\
\hline 0 & 0 & $\mathbf{1}$ & $\mathbf{2}$ & $\mathbf{2}$ & $\mathbf{2}$ & $\mathbf{2}$ & $\mathbf{2}$ & $\mathbf{2}$ & $\mathbf{2}$ & $\mathbf{2}$ & $\mathbf{2}$ & $\mathbf{2}$ & $\mathbf{2}$ & $\mathbf{2}$ & $\mathbf{1}$ & 0 & 0 & 0 & 0 \\
\hline 0 & 0 & $\mathbf{1}$ & $\mathbf{2}$ & $\mathbf{2}$ & $\mathbf{2}$ & $\mathbf{2}$ & $\mathbf{1}$ & $\mathbf{1}$ & $\mathbf{1}$ & $\mathbf{1}$ & $\mathbf{2}$ & $\mathbf{2}$ & $\mathbf{2}$ & $\mathbf{2}$ & $\mathbf{2}$ & $\mathbf{1}$ & 0 & 0 & 0 \\
\hline 0 & 0 & 0 & $\mathbf{1}$ & $\mathbf{1}$ & $\mathbf{1}$ & $\mathbf{1}$ & 0 & 0 & 0 & 0 & $\mathbf{1}$ & $\mathbf{2}$ & $\mathbf{2}$ & $\mathbf{2}$ & $\mathbf{2}$ & $\mathbf{1}$ & 0 & 0 & 0 \\
\hline 0 & 0 & 0 & 0 & 0 & 0 & 0 & 0 & 0 & 0 & 0 & 0 & $\mathbf{1}$ & $\mathbf{1}$ & $\mathbf{1}$ & $\mathbf{1}$ & $\mathbf{1}$ & 0 & 0 & 0 \\
\hline 0 & 0 & 0 & 0 & 0 & 0 & 0 & 0 & 0 & 0 & 0 & 0 & 0 & 0 & 0 & 0 & 0 & 0 & 0 & 0 \\
\hline 0 & 0 & 0 & 0 & 0 & 0 & 0 & 0 & 0 & 0 & 0 & 0 & 0 & 0 & 0 & 0 & 0 & 0 & 0 & 0 \\
\hline
\end{tabular}

Figura 3.20 : Matriz M após preenchimento. 


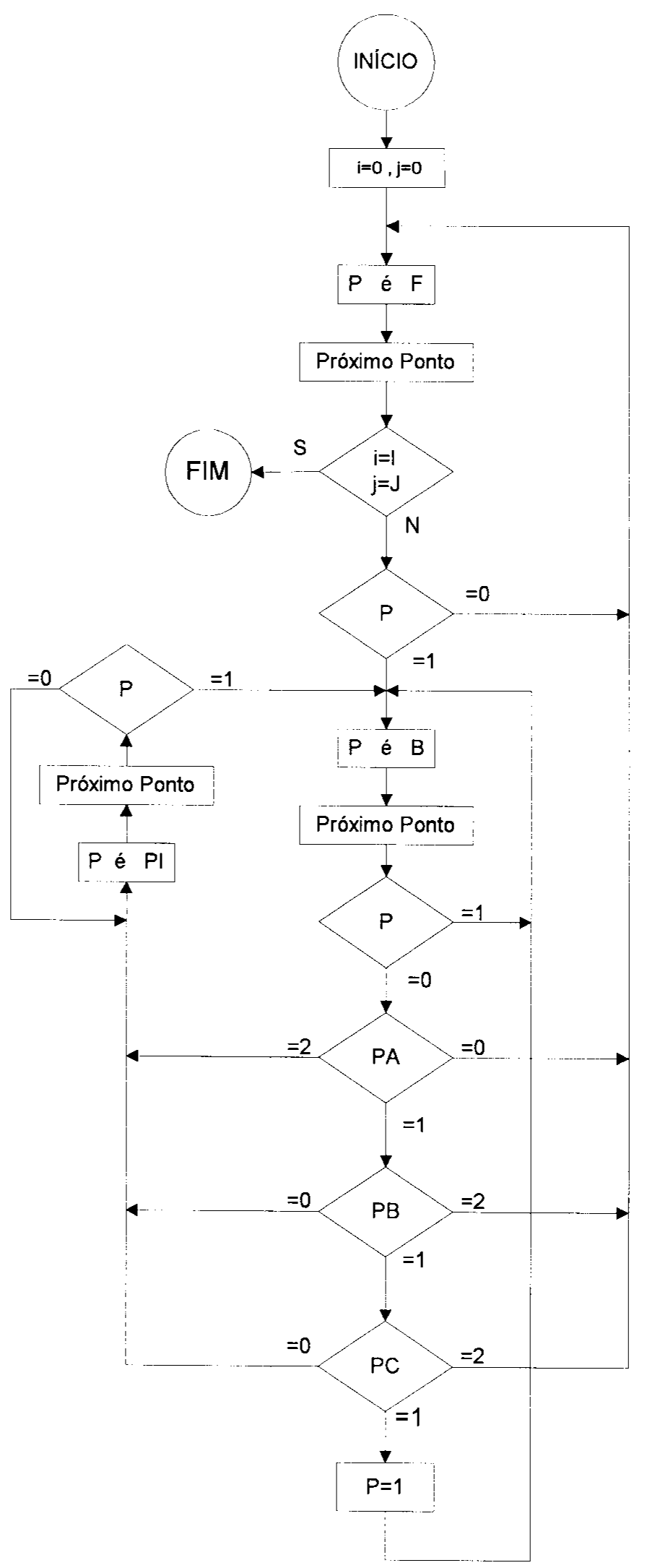

Figura 3.21 : Diagrama de preenchimento de uma figura 2D. 


\subsubsection{Varredura de Saída}

Agora que a matriz correspondente a uma determinada secção está pronta podemos exportar as coordenadas dos pontos de interesse numa correspondência entre as posições desses elementos com os potenciais elétricos que controlarão os defletores $\mathrm{X}$ e $\mathrm{Y}$ direcionando assim o feixe de luz UV sobre a camada de resina já preparada.

$\mathrm{Na}$ construção efetiva de uma peça mecânica não podemos pensar em seus pontos como sendo apenas posições de pixels, por isso optou-se por uma varredura "contínua" do feixe de luz UV com o intuito de suavizar os contornos das peças. O sentido de continuidade no caso, é que o feixe de luz deve ser dirigido sempre a um ponto vizinho do atual, em qualquer direção que seja. Se optássemos por uma varredura por linhas ou por colunas por exemplo, não conseguiríamos a mesma qualidade nos contornos e, cada vez que o feixe de luz tivesse que retroceder ao início da próxima linha (ou coluna) haveria a necessidade de sua interrupção, o que retardaria o processo pois a interrupção é um ponto crítico do sistema.

A varredura é feita da periferia para o centro no sentido horário como mostrado na figura 3.22 .

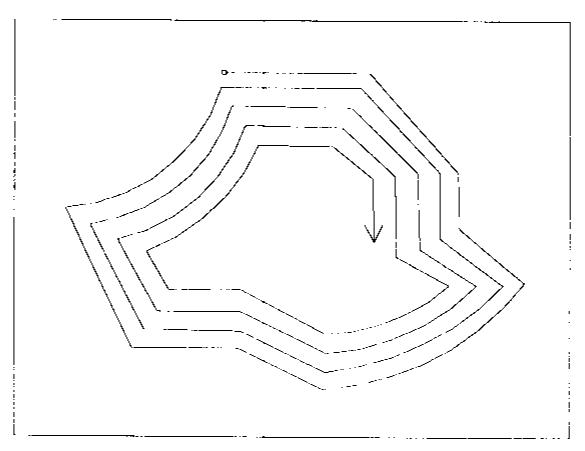

Figura 3.22 : Sentido de varredura do feixe de luz UV. 
Em termos da matriz $M$, a varredura inicia em $m_{0,0}$ e prossegue linearmente pelas linhas e colunas até encontrar um elemento da figura (ponto de interesse) quando então passa a percorrê-la no sentido horário por elementos periféricos e, à medida que esses elementos são percorridos seus valores são mudados para " 0 " para que não sejam repassados. Quando não mais houverem elementos com valor diferente de " 0 " a varredura volta onde tinha parado e continua linearmente em busca de outro ponto de interesse, até $m_{I, J}$.

Para percorrer os pontos de interesse, existem oito possibilidades de deslocamento que são os oito sentidos possíveis entre elementos vizinhos como podemos ver esquematizado na tabela da tabela 3.4 .

Tabela 3.4: Os oito sentidos possiveis de deslocamento entre elementos vizinhos.

\begin{tabular}{|c|c|c|c|}
\hline Sentido N & Sentido NE & Sentido L & Sentido SE \\
\hline Sentido S & Sentido SO & Sentido O & Sentido NO \\
\hline 0 & & & \\
\hline & & & \\
\hline
\end{tabular}

Para que o deslocamento ocorra no sentido horário, devem ser escolhidos pontos de interesse que façam vizinhança à esquerda com elementos de valor iguais a "0". Para tanto foram escolhidos alguns pontos estratégicos da vizinhança do ponto atual $\mathrm{P}$ para constituírem uma máscara a ser utilizada na decisão do trajeto a ser tomado. Como existem oito sentidos possíveis, a máscara deve ter suas coordenadas 
ajustadas para cada um deles. Na tabela 3.5 vemos a máscara ajustada para os oito sentidos possíveis.

Tabela 3.5 Posicionamento da máscara para os oito sentidos possiveis.

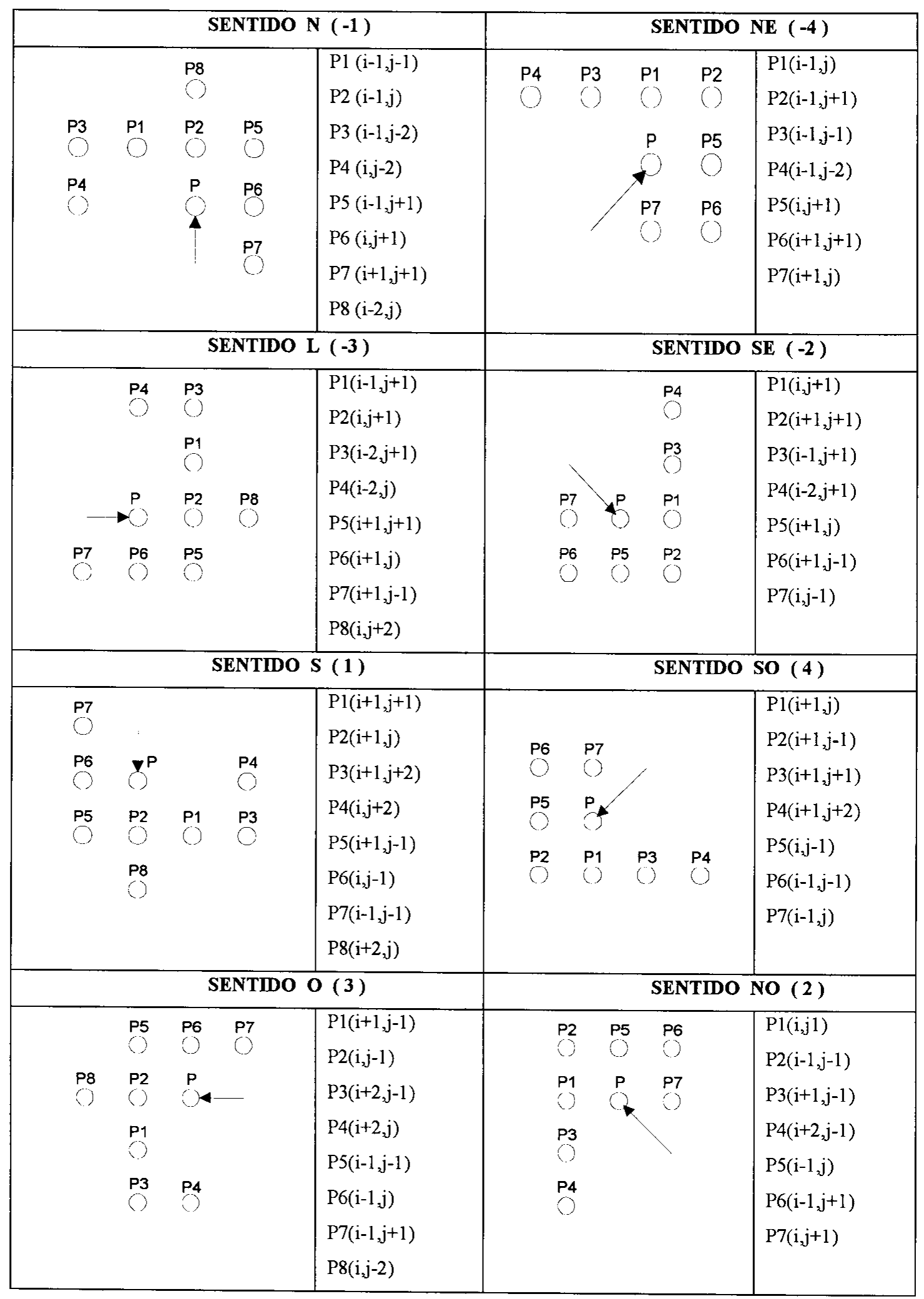


Como podemos observar na figura acima, a máscara atinge até dois elementos de distância em relação ao ponto atual $\mathrm{P}$, sendo esse o motivo da adição das duas linhas e duas colunas à matriz.

A cada deslocamento ocorrido a máscara deve ser ajustada para o novo (ou não) sentido. Para se saber qual foi o sentido do deslocamento analisamos a posição atual do ponto $P$ em relação ao ponto anterior através da expressão $\Delta=\left(\mathrm{i}-\mathrm{i}_{\mathrm{a}}\right)$ $3^{*}\left(\mathrm{j}-\mathrm{j}_{\mathrm{a}}\right)$, onde $\mathrm{i}$ e $\mathrm{j}$ são as coordenadas do ponto $P$ e $\mathrm{i}_{\mathrm{a}}$ e $\mathrm{j}_{\mathrm{a}}$ são as coordenadas do ponto anterior. Como os elementos são vizinhos, $\left(i-i_{a}\right)$ e $\left(j-j_{a}\right)$ só podem ter como valor $-1,0$ ou 1 , o que resulta para $\Delta$ apenas as oito possibilidades que constam entre parênteses na tabela 3.5 .

Uma vez ajustada a máscara para o sentido do deslocamento devemos testar seus elementos para decidirmos qual o trajeto a ser tomado. Como o sentido de varredura é horário, deve ser dada preferência ao trajeto mais à esquerda possível em relação ao sentido de deslocamento. Os trajetos são sequências de um ou mais pontos que ao serem percorridos descrevem formatos próprios que caracterizam as curvaturas do deslocamento

Foram implementadas sete curvaturas que determinam os sete ângulos possíveis que podem ocorrer entre dois deslocamentos consecutivos. O ângulo foi medido no sentido horário em relação ao último deslocamento, resultando que as curvaturas podem ser:

- Curvatura de $45^{\circ}$

- Curvatura de $90^{\circ}$

- Curvatura de $135^{\circ}$

- Curvatura de $180^{\circ}$ 
- Curvatura de $225^{\circ}$

- Curvatura de $270^{\circ}$

- Curvatura de $315^{\circ}$

Com exceção das curvaturas de 45 e $90^{\circ}$, todas as outras têm o trajeto que independe do sentido de deslocamento em que a máscara esteja ajustada, ou seja, a sequência de pontos que deverão ser percorridos para descrever uma determinada curvatura é a mesma em quaisquer dos oito sentidos. Para as curvaturas de 45 e $90^{\circ}$ existem dois trajetos possíveis para cada uma delas, sendo que cada trajeto depende da inclinação do sentido de deslocamento. Foram determinadas duas classes de inclinações:

- Inclinação Reta, que compreende os sentidos N, S, L e O .

- Inclinação Obliqua, que compreende os sentidos NE, SE, SO e NO.

Nas tabelas 3.6 e 3.7 vemos as curvaturas e respectivos trajetos para os sentidos L e NE como exemplo nas duas inclinações. Para qualquer outro sentido basta girar adequadamente a curvatura correspondente na respectiva inclinação.

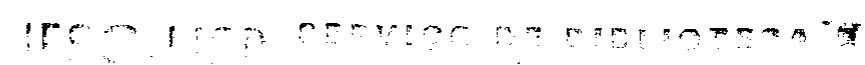


Tabela 3. 6: Curvaturas implementadas para o sentido $\mathrm{L}$.

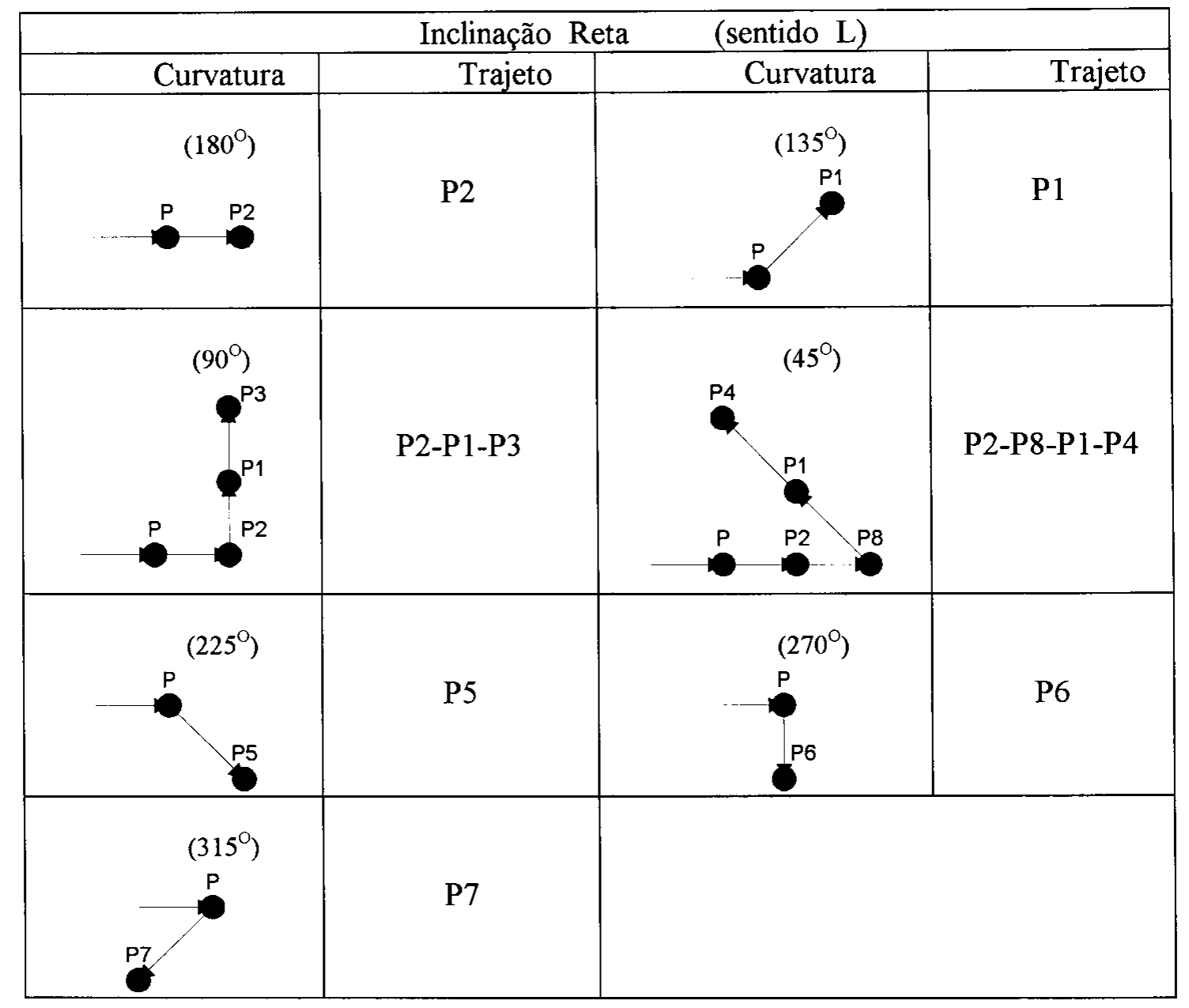


Tabela 3.7 Curvaturas implementadas para o sentido NE.

\begin{tabular}{|c|c|c|c|}
\hline \multicolumn{2}{|c|}{ Inclinação Obliqua } & \multicolumn{2}{|l|}{ (sentido NE) } \\
\hline Curvatura & Trajeto & Curvatura & $\begin{array}{c}\text { Trajet } \\
0\end{array}$ \\
\hline$\left(180^{\circ}\right)$ & P2 & $\begin{array}{r}\left(135^{\circ}\right) \\
P 1 \\
P\end{array}$ & $\mathrm{P} 1$ \\
\hline${ }^{\left(90^{\circ}\right)}$ & P3 & $\begin{array}{l}\left(45^{\circ}\right) \\
\mathrm{P} 1\end{array}$ & P2-P1-P3-P4 \\
\hline$\stackrel{\left(225^{\circ}\right)}{\mathrm{P}} \stackrel{\mathrm{PS}}{\mathrm{D}}^{\mathrm{P}}$ & P5 & $\left(270^{\circ}\right)$ & P6 \\
\hline & P7 & & \\
\hline
\end{tabular}


Na figura 3.23 temos o fluxograma da varredura de saída.

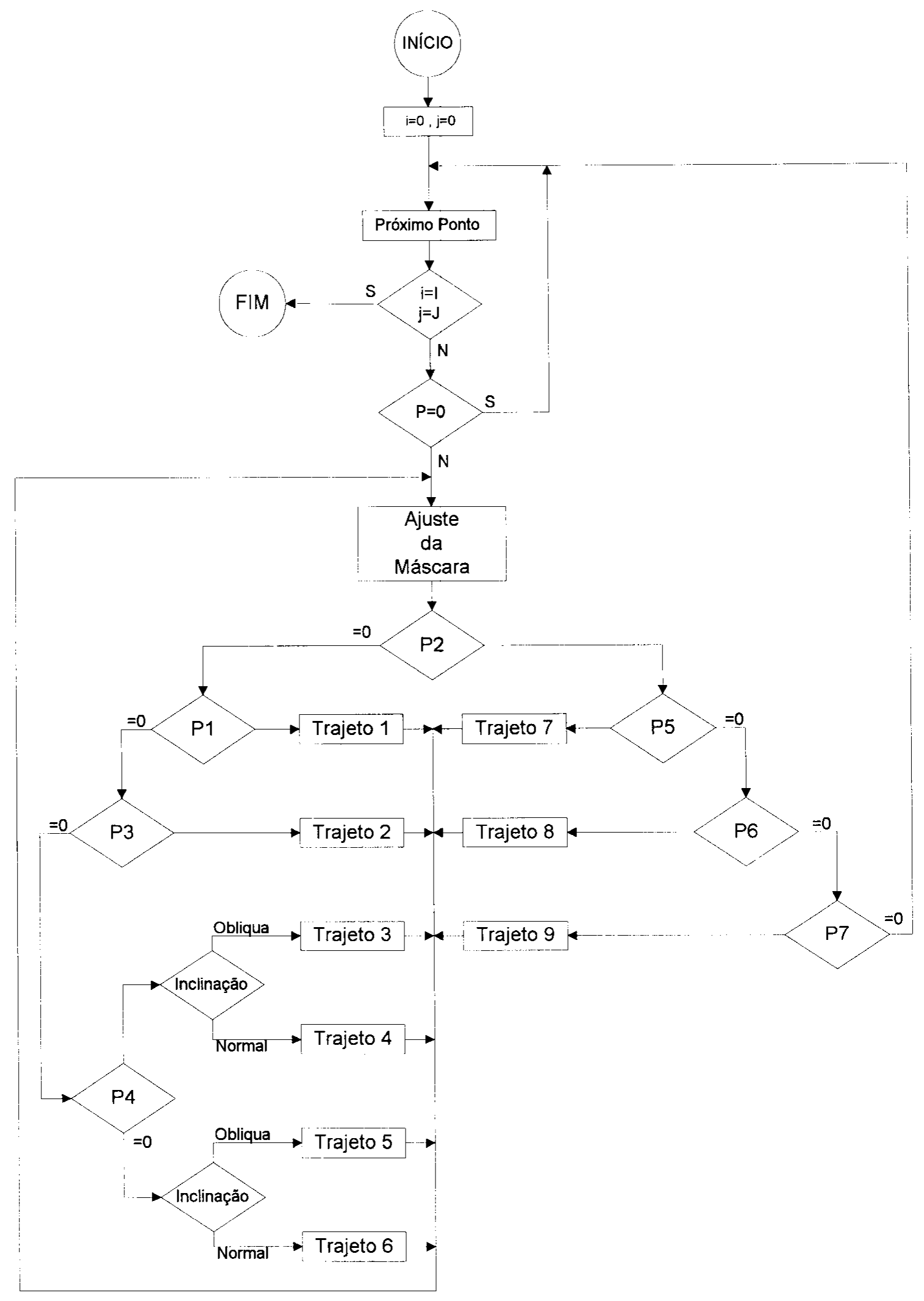

Figura 3.23 : Fluxograma da Varredura de Saída. 


\section{ANÁLISE DOS RESULTADOS}

As peças construídas por exposição por superfície livre apresentam arredondamentos causados pela tensão superficial e pela viscosidade da resina. Nas peças das figuras r1 e r2 a área das seç̧ões tem um valor suficientemente alto de maneira a tornar esse problema um limitante muito grande em relação à espessura mínima que se pode conseguir. Nas peças da figura r3, pelo fato dos diâmetros serem razoavelmente pequenos, o efeito do arredondamento não é tão proeminente quanto o das peças anteriores, embora fisicamente esse problema não pode deixar de existir simplesmente pela área da região litografada.

Com relação ao tempo de cura da resina o processo por superficie livre mostrou-se mais lento que por superficie fixada, sendo essa variação devida à presença de $\mathrm{O}_{2}$ do ar em contato com a superficie da resina no local da incidência do UV [1]. No caso do processo por superfície fixada, a janela de quartzo faz a interface com a resina de maneira a eliminar a presença do Oxigênio e por isso proporciona um aumento da velocidade de cura. Uma desvantagem do uso de uma janela desse tipo é que a peça gruda-se nela e exige medidas a esse respeito. Foi usada uma folha fina de celofane entre a resina e a janela minimizando muito esse problema, embora tal folha se danifique relativamente fácil exigindo sua troca. 
Pôde ser observado uma relação entre espessura da camada e tempo necessário de exposição ao UV para a cura da resina, sendo que esse tempo aumenta com o aumento da espessura.

Quanto à definição das camadas litografadas, analisando apenas as peças construídas por superficie fixada, vemos que essa definição é muito boa e acompanha a definição das fotomáscaras. Em relação ao eixo $z$, a melhor resolução conseguida foi de $0,01 \mathrm{~mm}$. Nessa mesma direção pode-se ver ondulações que são devidas a desalinhamentos mecânicos do elevador. 


\section{CONCLUSÕES E SUGESTÕES PARA CONTINUIDADE}

O desenvolvimento do presente trabalho resultados mais qualitativos que quantitativos. Para se conseguir resultados quantitativos seria necessário, além de melhores condições de infra-estrutura, uma quantidade grande de experimentos para um melhor domínio do comportamento da resina e da técnica em geral em função das muitas variáveis e dos muitos detalhes que o sistema abrange.

Um dos pontos principais do processo de estereolitografia é a cura da resina, de maneira que todos os fatores envolvidos devem ser considerados e dominados, por ísso são necessários experimentos específicos de natureza ótico-química.

Além dos fatores abordados no capítulo 2, um detalhe importante que deve ser considerado em trabalhos futuros é o decaimento do poder de cura da resina em função do tempo, sendo especificado em seis meses o prazo de validade determinado pelo fabricante. Essa variação deve ser considerada pois o decaimento pôde ser percebido sem instrumentos após períodos além do prazo de validade. Mesmo após esse período pode-se controlar a cura da resina pelas condições de exposição, ou seja, pelas outras variáveis como o tempo de exposição e a intensidade da luz UV. A correção desse problema pode ser feita através de uma curva da capacidade de absorção da resina ao UV em função do tempo, se mantida a mesma qualidade por 
parte do fabricante, caso contrário devem ser feitos testes periódicos para a determinação das condições de exposição.

Os dois métodos de exposição apresentados, por projeção e por varredura, apresentam vantagens e desvantagens. Pode-se dizer com certeza que a definição no plano XY para o método de exposição por projeção é superior ao da exposição por varredura, de acordo com [1]. Embora não tenham sido construídas peças por este último processo, a digitalização que ocorre no plano $\mathrm{XY}$ não suplantaria a definição de um fotolito, ou seja, o diâmetro do feixe de UV e consequentemente o diâmetro da "Célula Solidificada" não chega a valores tão pequenos quanto as dimensões que o fotolito pode oferecer.

Apesar da boa definição que se pode conseguir com as fotomáscaras, o método de projeção é muito limitado em termos de viabilidades técnicas e econômicas. Para peças muito complicadas que necessitam de um grande número de fotomáscaras o processo se torna oneroso por causa do preço dos fotolitos e, tecnicamente as dificuldades de posicionamento destes é muito grande. Essa é uma grande desvantagem desse método de exposição que não ocorre na exposição por varredura. Por varredura a definição é menor, entretanto a flexibilidade quanto a possibilidades de construção de um maior número de peças faz desse método de exposição mais adequado de modo geral.

Uma limitação à técnica de sobreposição de camadas, para ambos os métodos, diz respeito à sustentação. A necessidade de sustentação, e aderência, de cada camada, que pode ser traduzida em termos matemáticos como sentido de monotonicidade, é um limitante de construção de peças muito delicadas e pequenas 
para serem subdivididas em partes monotônicas, podendo por conseguinte inviabilizar a montagem de tais peças.

Como dito anteriormente, o desempenho do sistema está diretamente relacionado com a profundidade e aplicabilidade das pesquisas dos aspectos relevantes à integração do sistema. Portanto, devemos aperfeiçoar os diversos itens referentes ao assunto, usar novos desenvolvimentos tecnológicos, de instrumentação e de programas, e pesquisar novas possibilidades que uma técnica com várias configurações possíveis como esta pode oferecer

Uma novidade surgida no último ano é a possibilidade de interação direta entre a linguagem Visual-Basic e o programa AutoCad-R14. Esse advento torna desnecessário o uso da lingugem AutoLisp que até então era a única linguagem a acessar os desenhos do AutoCad. Pela facilidade e flexibilidade oferecidas pela linguagem Visual-Basic, todo o controle do equipamento passará a ser feito por uma única linguagem sem que haja a necessidade de interrupção entre as etapas de aquisição do modelo e construção efetiva da peça

Ainda com relação à programações, é interessante e conveniente a inclusão de um algoritmo para determinação dos sentidos de monotonicidade da peça e, caso não haja o programa deverá sugerir bipartições da peça em partes monotônicas.

Outra possibilidade seria a implementação de um programa dedicado a fazer interpolações de imagens resultantes de Tomografia por Ressonância Magnética. Na medicina, especialmente quando se necessita de implantes de próteses, em geral de ossos, seria necessária uma quantidade muito grande dessas imagens para se conseguir a definição necessária ao caso, daí a validade das interpolações. 
Outro ponto que pode oferecer melhorias no desempenho seria uma varredura inteligente das camadas pelo feixe de UV. Como foi desenvolvido neste trabalho, o deslocamento é feito sempre entre elementos vizinhos (de distância unitária) de maneira que para áreas muito grandes são necessárias uma quantidade muito grande de deslocamentos devido grande número de elementos da matriz da imagem da figura. Assim, para se acelerar o processo de construção da peça, é necessário aumentar-se a velocidade de, o que favorece a uma diminuição da precisão além de exigir defletores mais rápidos e portanto mais caros. Uma sugestão seria controlar-se o diâmetro do feixe de UV, através do sistema controlável de focalização de maneira a se cobrir uma superficie maior por deslocamento; o que necessitaria de um número menor de elementos na matriz da figura que agora teria uma "malha" (grid) maior. Quando se abre o diâmetro do feixe simplesmente alterando sua distância focal a densidade de energia incidente na resina diminui, entretanto o tempo para se cobrir a mesma área deve permanecer inalterado ou muito próximo

Outra possibilidade de diminuição do tempo de cura da resina nas construções por superfície livre é com o uso de $\mathrm{He}$ na superfície da resina , uma vez que o $\mathrm{O}_{2}$ é, no caso, um elemento inibidor da reação.[1]

Uma possibilidade de direcionamento de um feixe é com o uso de posicionadores mecânicos $\mathrm{XY}$ (mesa $\mathrm{XY}$ ) que direcionaria o feixe de um laser através de uma fibra ótica e de um autocolimador próprio para esse caso. As vantagens que podem ser alcançadas são em relação ao preço uma vez que se tornam desnecessários os defletores.

Associando-se um controle do diâmetro do feixe a uma varredura inteligente, uma mesa XY e a fibra ótica com o autocolimador podemos esperar um tempo total 
de varredura próximo ou maior que o atual, porém como a velocidade do deslocamento é mais baixa podemos conseguir uma precisão pelo menos equivalente, e de menor custo.

Também em relação à mecânica do equipamento, o interruptor eletromagnético podem ser construídos, ou encontrado no mercado, modelos cujo tempo de operação pode ser menor que $10 \mathrm{~ms}$. 


\section{BIBLIOGRAFIA}

[1] Wohlers T T; "Rapid Prototyping System" Nat. Comp. Graphics Assoc, pp 588-605, 1992.

[2] Clair J J; “ A biphotonic process in stereolitography” Pure Appl. Opt, pp.169-172, 1993

[3] Mark-Bikales-Overberger-Menges, "Encyclopedia of Polimer Science and Engeneering", vol. 11, pp 186-212 - John Willey \& Sons.

[4] Takagi T e Nakajima N; "Photoforming Aplied to Fine Machine" Proc. IEEE Micro Electro Mechanical Systems pp. 173-178, New York, NY, USA 1993.

[5] Suzumor K, Koga A e Riyoko H; "Microfabrication of Integrated FMAs using Stereolitography" Proc. IEEE Micro Electro Mechanical Systems, pp. 136-141., Oiso, Japan, 1994.

[6] Evseev A V e Markov, M. A; "Layer by Layer Manufacture of Parts from liquid Photopolimerisable compositions by XeCL laser radiation," Kvantovaya Elektronik, vol. 21, ( $\mathrm{n}^{\circ}$ 5), pp 495-498, Moskva, maio de 1994; Transaction Quantun Eletronics, vol. 24, (n $\mathrm{n}^{\circ}$ ), pp 458-461, maio de 1994.

[7] General Scanning/EYE Technology - Suplemento do Manual do Equipamento Modelo AEX200.

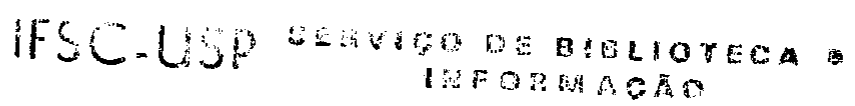




\section{BIBLIOGRAFIA COMPLEMENTAR}

[8] Cheshire D G, Harrison D K e Wormand P W ; "Novel Techniques for Tableware Development", Proc. $3^{\text {rd }}$ Europe Conference on Rapid Prototyping and Manufacturing, pp 181-190, Nottingham, Inglaterra, julho, 1994.

[9] Dolenc A e Makela I; "Slicing procedures for layered manufacturing tecniques", Computer Aided Design, vol. 26, (nº 2), pp 119-126, fevereiro de 1994.

[10] Nagae $\mathrm{T}$, Agui $\mathrm{T}$ e Nagahashi $\mathrm{H}$; "Interpolation of $\mathrm{CT}$ slices for laser stereolithography", IEICE Transactions on Information and Systems, vol. E76-D, $\left(\mathrm{n}^{\circ} 8\right)$, pp 905-911, agosto de 1993.

[11] Nagae T , Agui $\mathrm{T}$ e Nagahashi $\mathrm{H}$; "Orientable closed surface construction from volume data", IEICE Transactions on Information and Systems, vol. E76-D, $\left(n^{\circ} 2\right), p p$ 269-273, fevereiro de 1993.

[12] Sheng X e Hirsh B E; "Triangulation of trimmed surfaces in parametric space", Computer Aided Design, vol. 24, (nº 8), pp 437-444, agosto de 1992.

[13] Cerrada C, Ikeuchi K, Weiss L e Reddy R, "A 3D-object reconstruction system integrating range-image processing and rapid prototyping", Engineering System with Intelligence, pp 333 -340, 1991. 
[14] Weiss L E , Gursoz E L, Prinz F B , Fussell P S e outros, "A rapid tool manufacturing system based on stereolithography and thermal spraying", Manufacturing Review, vol. 3, (n 1 ), pp 40-48, março de 1990.

[15] Bose P e Toussaint G, "Geometric and computational aspects of manufacturing processes", Computer \& Graphycs, vol. 18, (n $\left.{ }^{\circ} 4\right)$, pp 487-497, julho/agosto de 1994.

[16] Sprow E E, "Rapid prototyping: beyond the wet look", vol. 109, ( $\left.\mathrm{n}^{\mathrm{o}} 5\right)$, pp 58-64, novembro de 1992

[17] Wohlers T T; "Make fiction fact fast (rapid prototyping systems)", Manufacturing Engineering, vol. 106, pp 44-49, março de 1991.

[18] Rosenberg D e Vasilopoulos A ,"Smart prototypes (medical devices)", Computer Graphics World, vol. $13\left(\mathrm{n}^{\circ}\right.$ 6), pp 99-100, junho de 1990. 


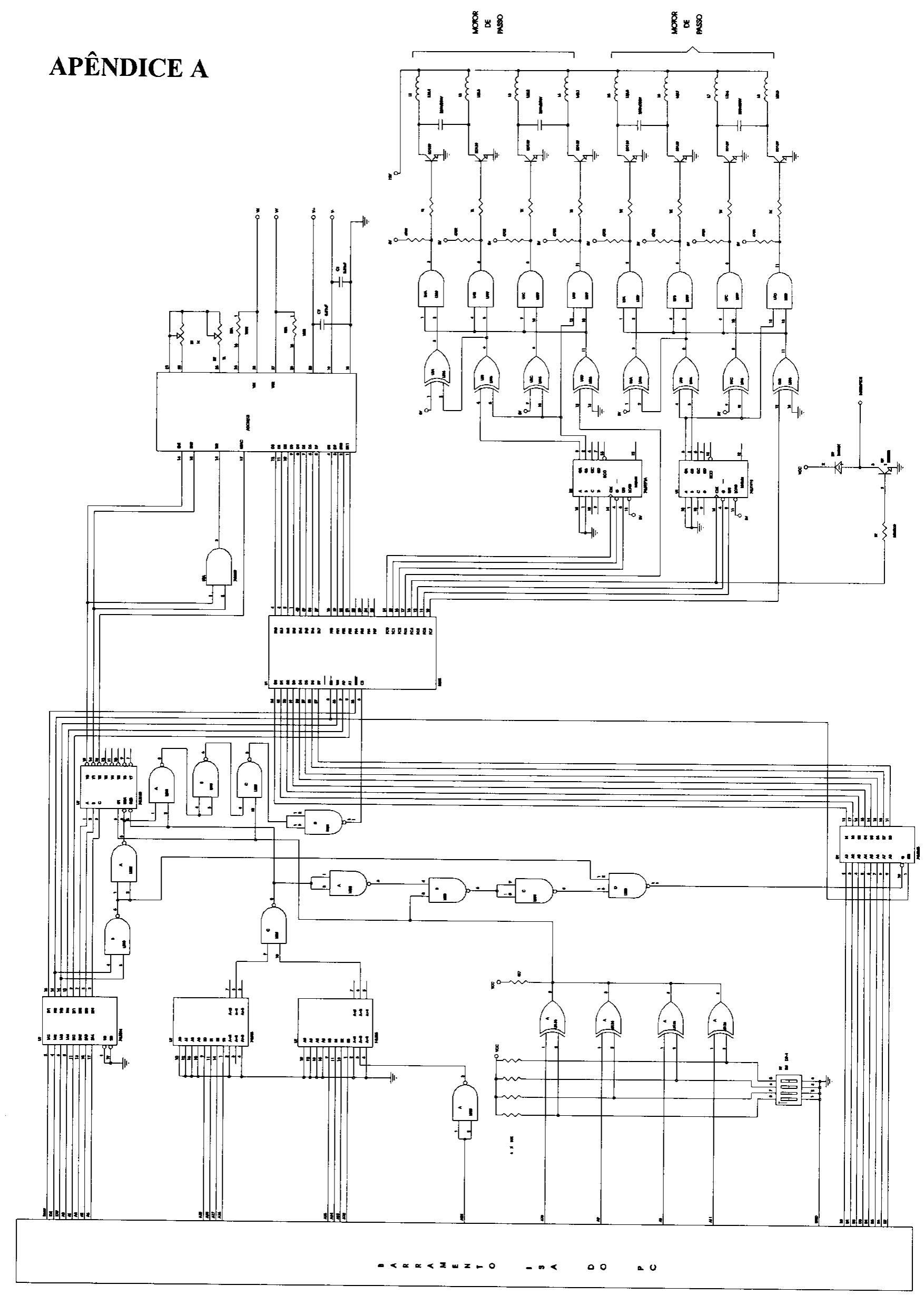




\section{APÊNDICE B}

' Função para movimentar o motor de passo Declare Sub pout Lib

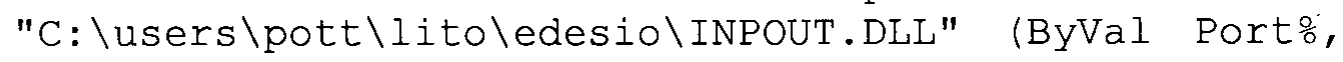
ByVal Valor\%)

Global Caminho As string 'Contém os Paths. Está definida em Load do formulário Principal

Global Salvou As Integer

Global PathNome As String

Global Arquivo As String

Global Modificado As Integer

Global Saida As Integer

Global Tempo As Integer

Global Duracao As Double

Global E As Double 'Espessura

Global A As Double 'Afastamento

Global Vd As Double 'Velocidade de descida

Global Vs As Double 'Velocidade de subida

Global TL As Double 'Tempo de espera em baixo

Global TH As Double 'Tempo de espera em cima

Global LUZ As Double 'Tempo de esposição da luz

Global NL As Integer 'Número de fatias

Sub Controlador ()

Dim AtrasoDesc As Integer

Dim Atrasosub As Integer

Dim Desce As Long

Dim Sobe As Long

Call Inicializa Motor

'Falta implementar a duracao da construcao

Duracao $=\mathrm{NL} *(\mathrm{TL}+\mathrm{TH}+\mathrm{LUZ}+(\mathrm{E}+\mathrm{A}) / \mathrm{Vd}+\mathrm{A} /$ Vs) 'Em segundos

AtrasoDesc $=-476 *$ Val (Principal.VdValue.Text) +318

AtrasoSub $=-476 * \operatorname{Val}($ Principal.VsValue.Text) +318 


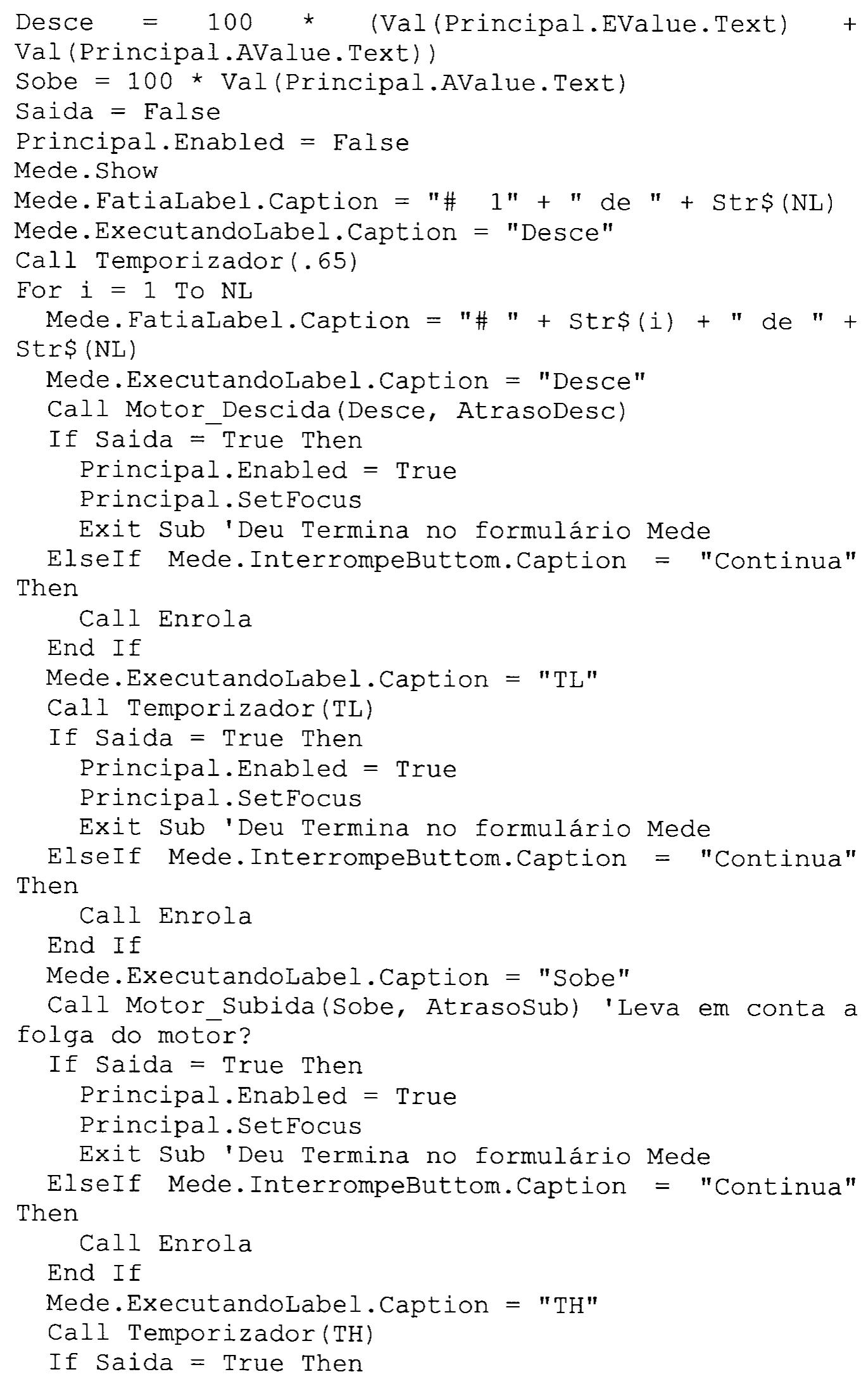




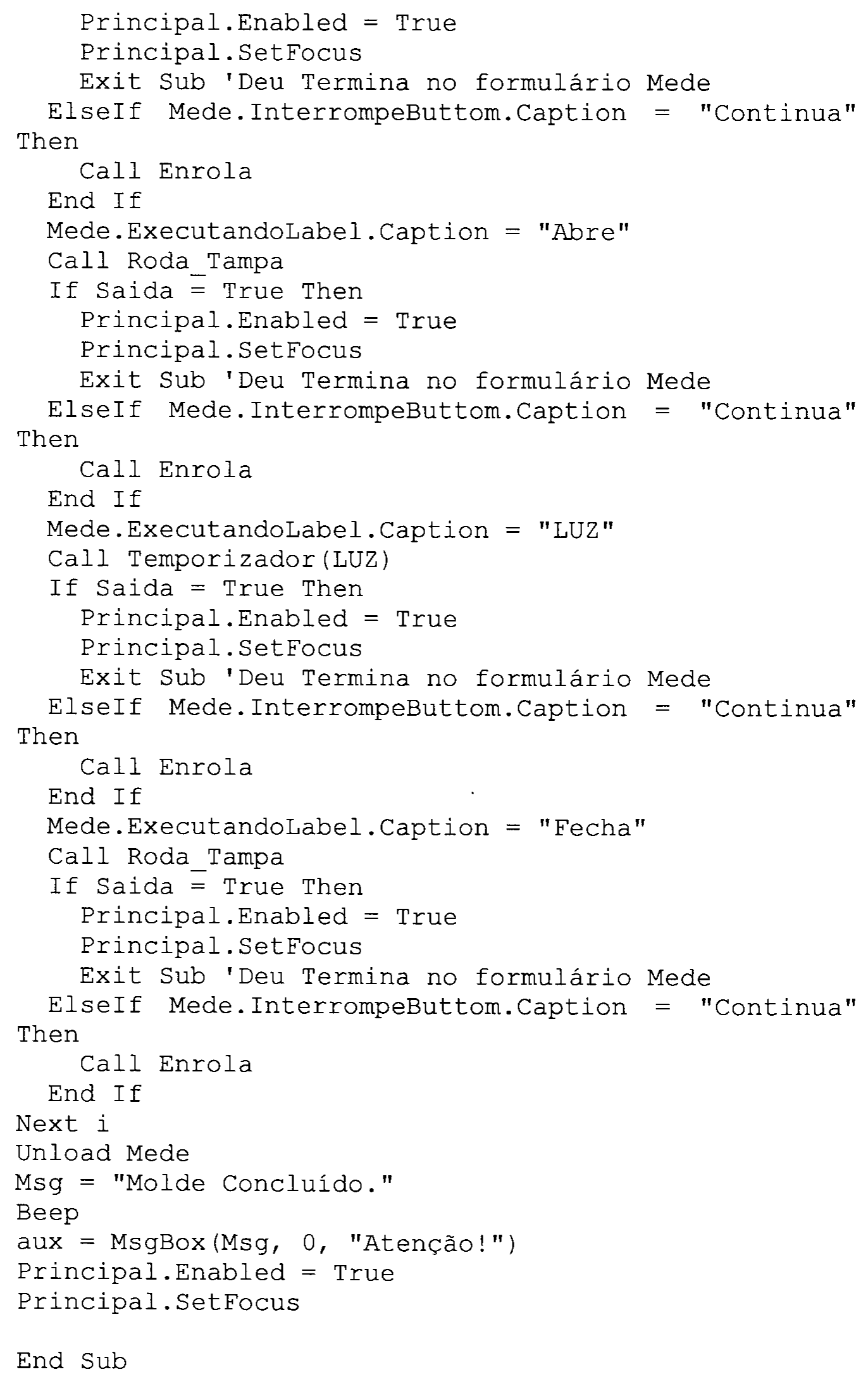

End Sub 
Sub Delay (Numero As Integer)

For $i=1$ To Numero

$j=i$

$i=j$

Next i

End Sub

Sub Enrola ()

While Mede.InterrompeButtom.Caption = "Continua" DoEvents

If Saida $=$ True Then Exit Sub

Wend

End Sub

Sub Inicializa_Motor ()

Call pout $(2051,128)$

End Sub

Sub Le_Arquivo ()

Principal. Caption = "Controlador do Elevador - \"+ Arquivo

Open PathNome For Input As \#2 ' Open to read file. Input \#2, $\mathrm{E}$

Principal. EValue. Text $=\mathrm{E}$

Input \#2, A

Principal. AValue. Text $=A$

Input \#2, Vd

Principal.VdValue. Text $=\mathrm{Vd}$

Input \#2, Vs

Principal.VsValue. Text $=\mathrm{Vs}$

Input \#2, TL

Principal. TLValue. Text $=\mathrm{TL}$

Input \#2, $\mathrm{TH}$

Principal. THValue. Text $=\mathrm{TH}$

Input \#2, LUZ

Principal. LUZValue. Text $=$ LUZ

Input \#2, NL

Principal. NLValue. Text $=\mathrm{NL}$ 


\section{Close \#2}

End Sub

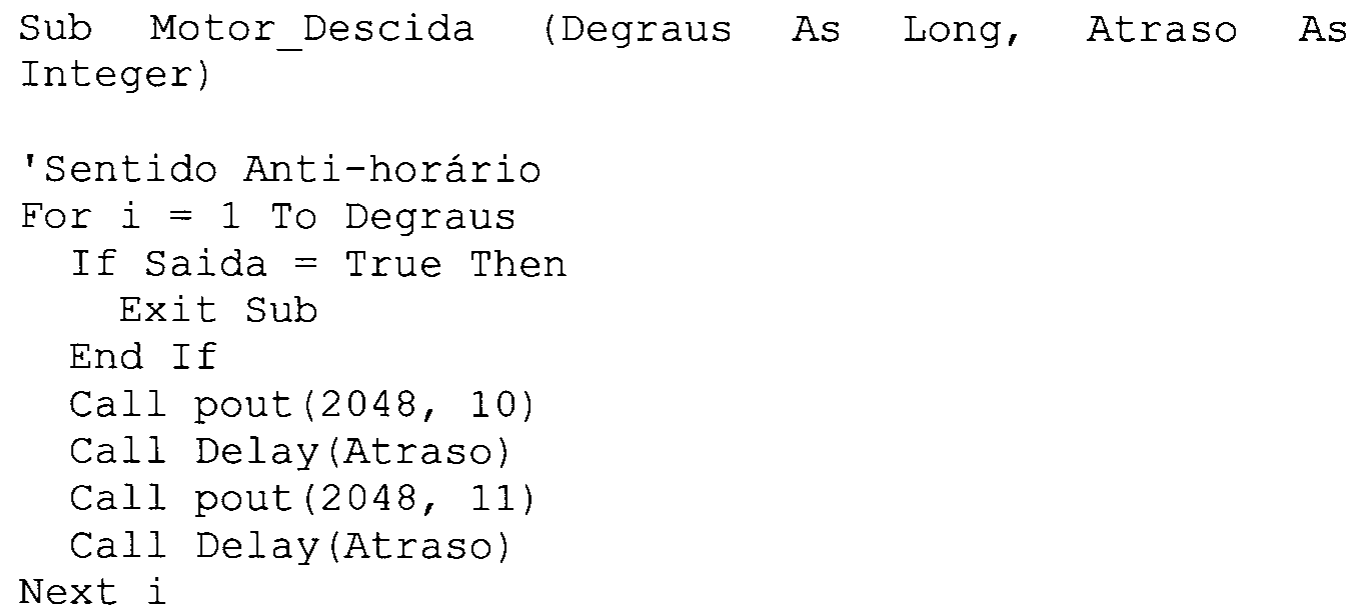

End Sub

Sub Motor_Subida (Degraus As Long, Atraso As Integer)

' Sentido Horário

For $i=1$ To Degraus

If Saida $=$ True Then Exit Sub

End If

Call pout $(2048,8)$

Call Delay (Atraso)

Call pout (2048, 9)

Call Delay(Atraso)

Next i

End Sub

Sub Roda_Tampa ()

For $i=1$ To 25

Call pout $(2048,128)$

Call Delay(200)

Call pout $(2048,144)$

Call Delay(200)

Next i

End Sub 


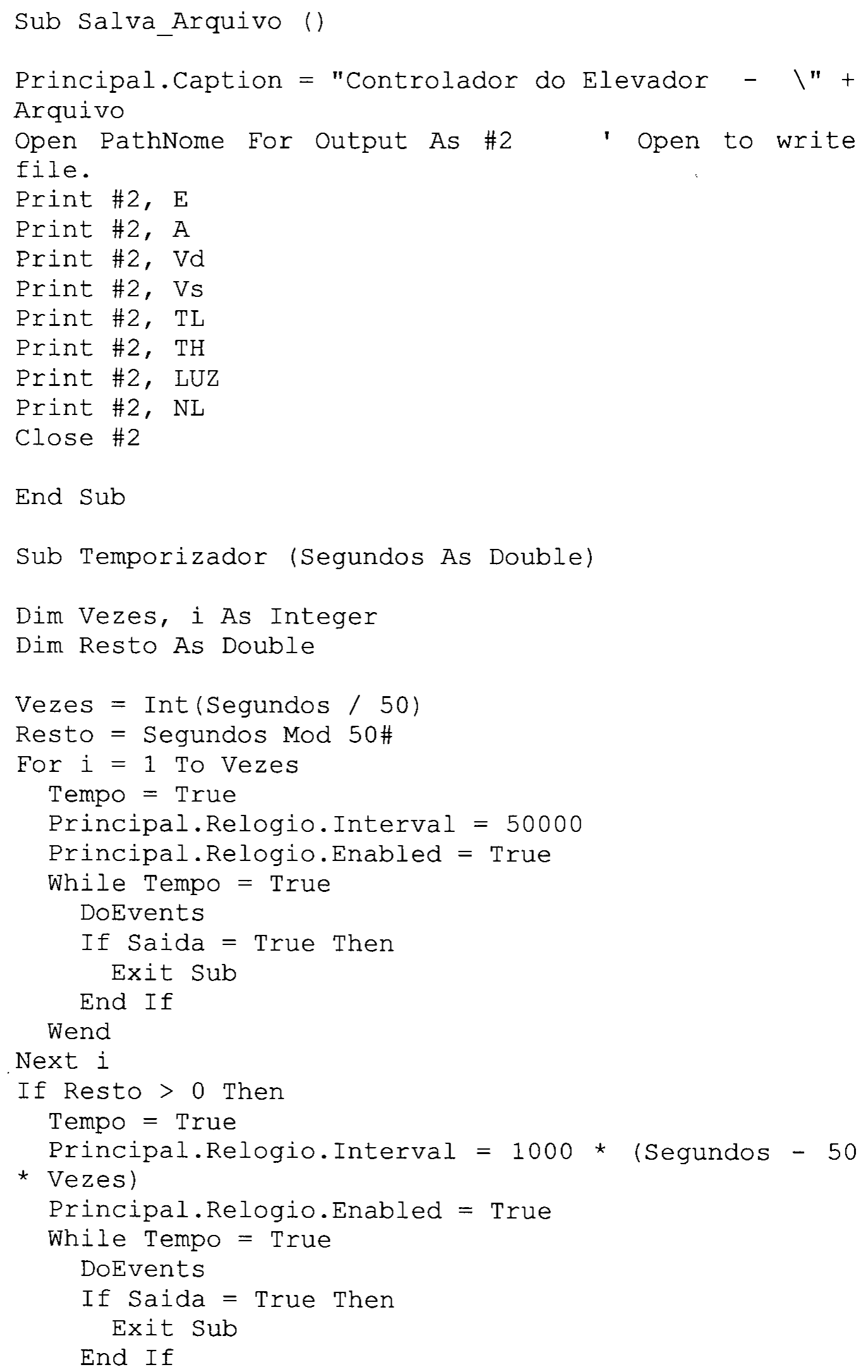


Wend

End If

End Sub

Sub Testa_Entrada ()

'Falta implementar os testes da entrada dos dados End Sub 


\section{APÊNDICE C}

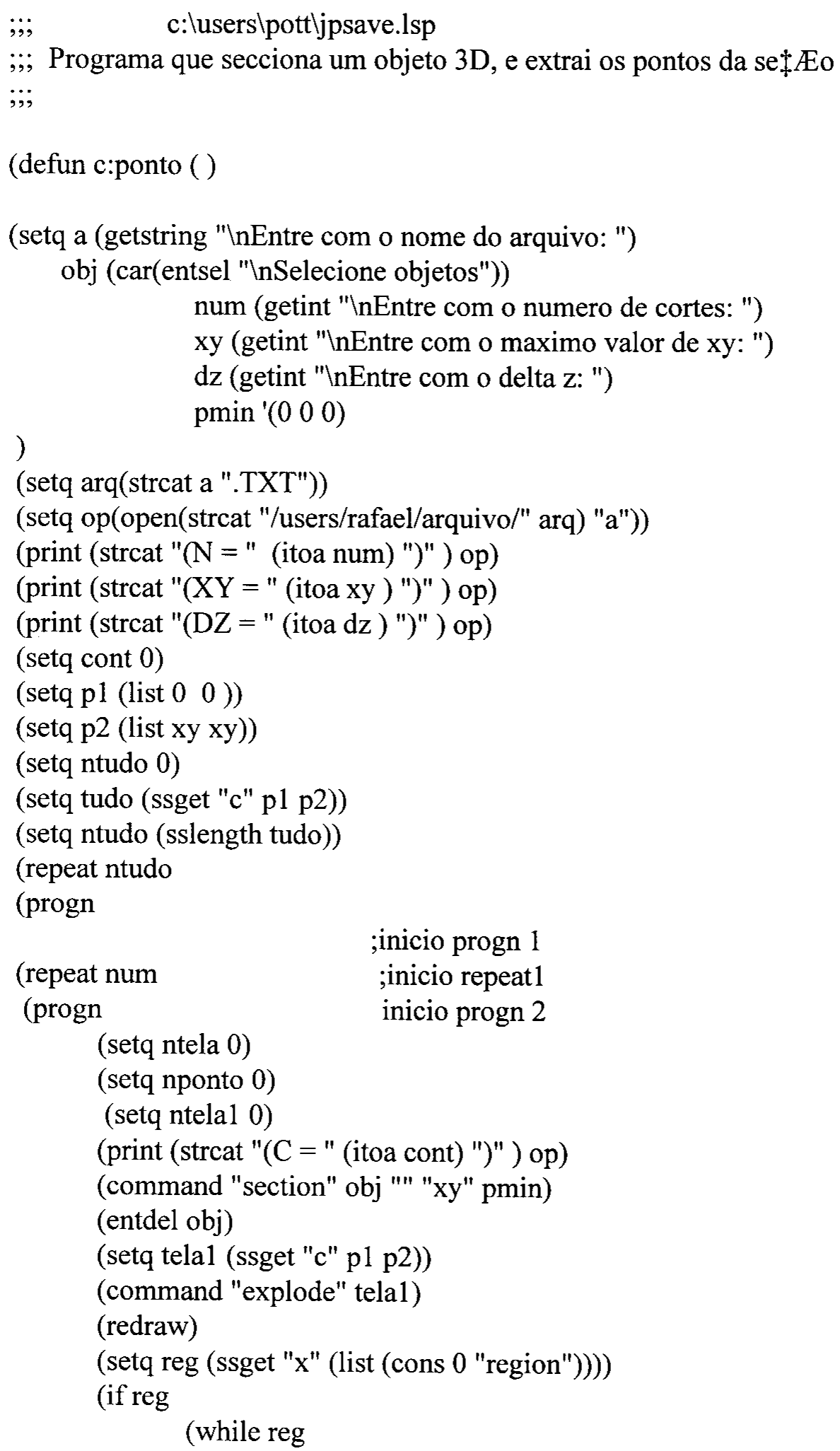




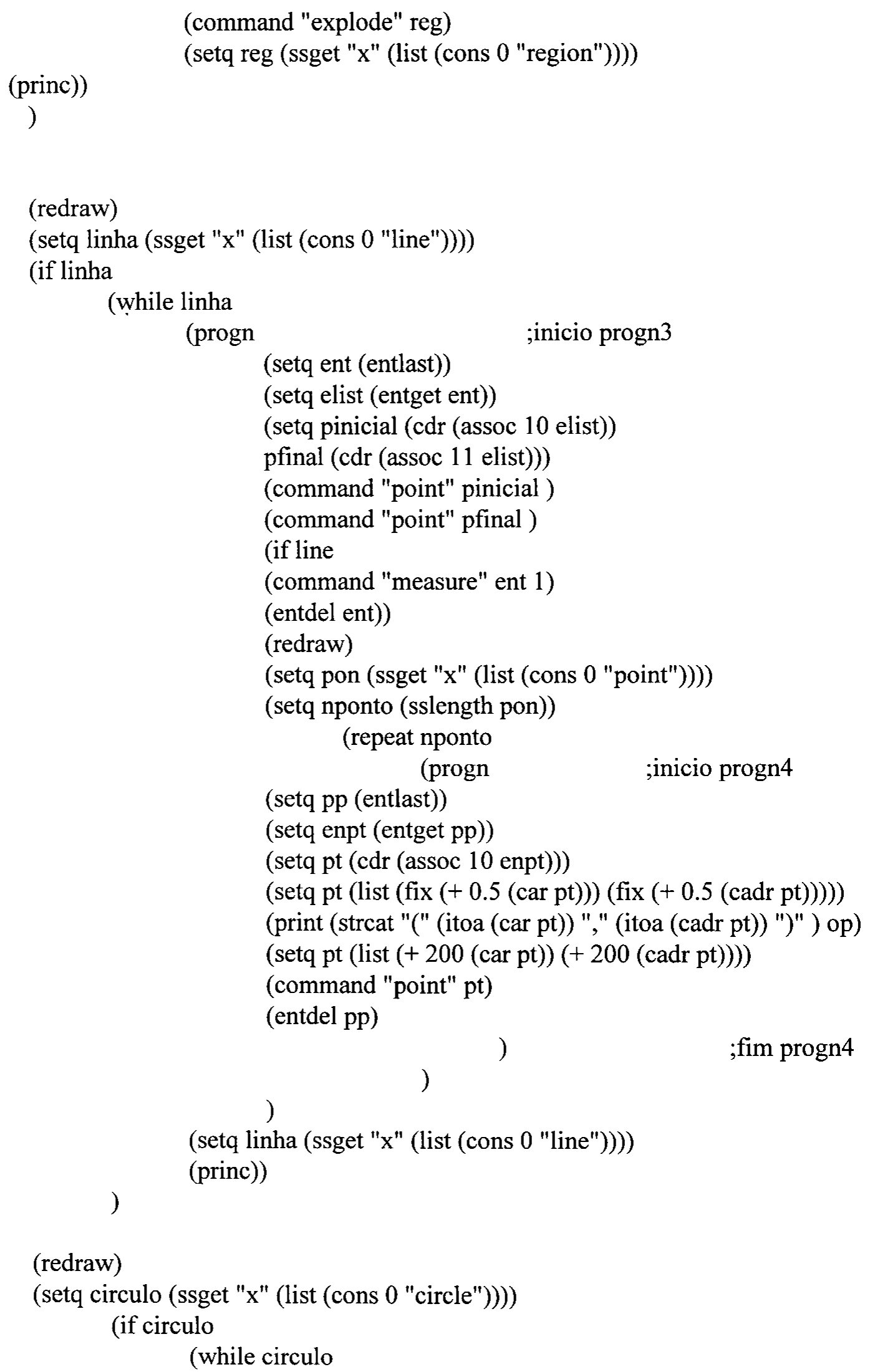



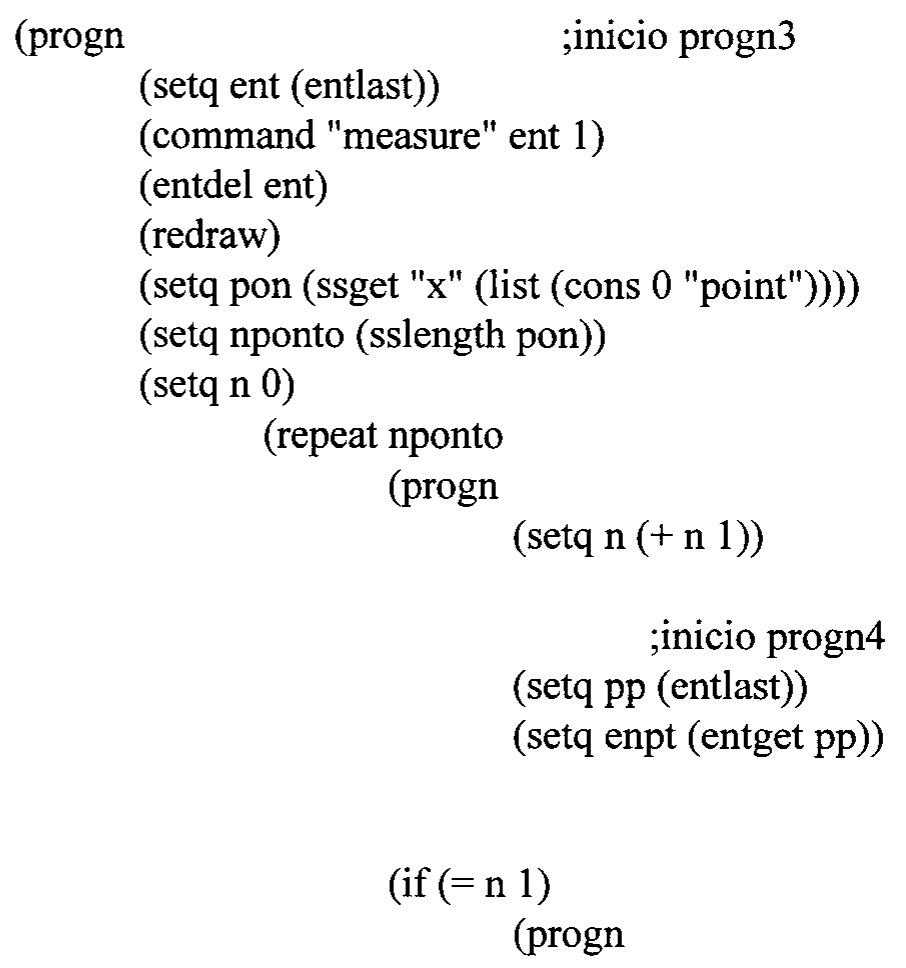

(setq pini (cdr (assoc 10 enpt)))

(setq pxi (car pini))

(setq pyi (cadr pini))

)

(if (= $\mathrm{n}$ nponto)

(progn

(setq pf (cdr (assoc 10 enpt)))

(setq pxf(car pf))

(setq pyf (cadr pf))

(setq px (/ (+ pxi pxf 2$))$

(setq py (/ (+ pyi pyf) 2))

(setq pf (list px py))

(setq pf (list (fix (+ 0.5 (car pf))) (fix (+ 0.5 (cadr pf)))))

(print (strcat "(" (itoa (car pf)) "," (itoa (cadr pf)) ")" ) op) )

\footnotetext{
(setq pt (cdr (assoc 10 enpt)))

(setq pt (list (fix $(+0.5($ car pt))) $($ fix $(+0.5($ cadr pt $)))))$ (print (strcat "(" (itoa (car pt)) "," (itoa (cadr pt)) ")" ) op) (entdel pp) 


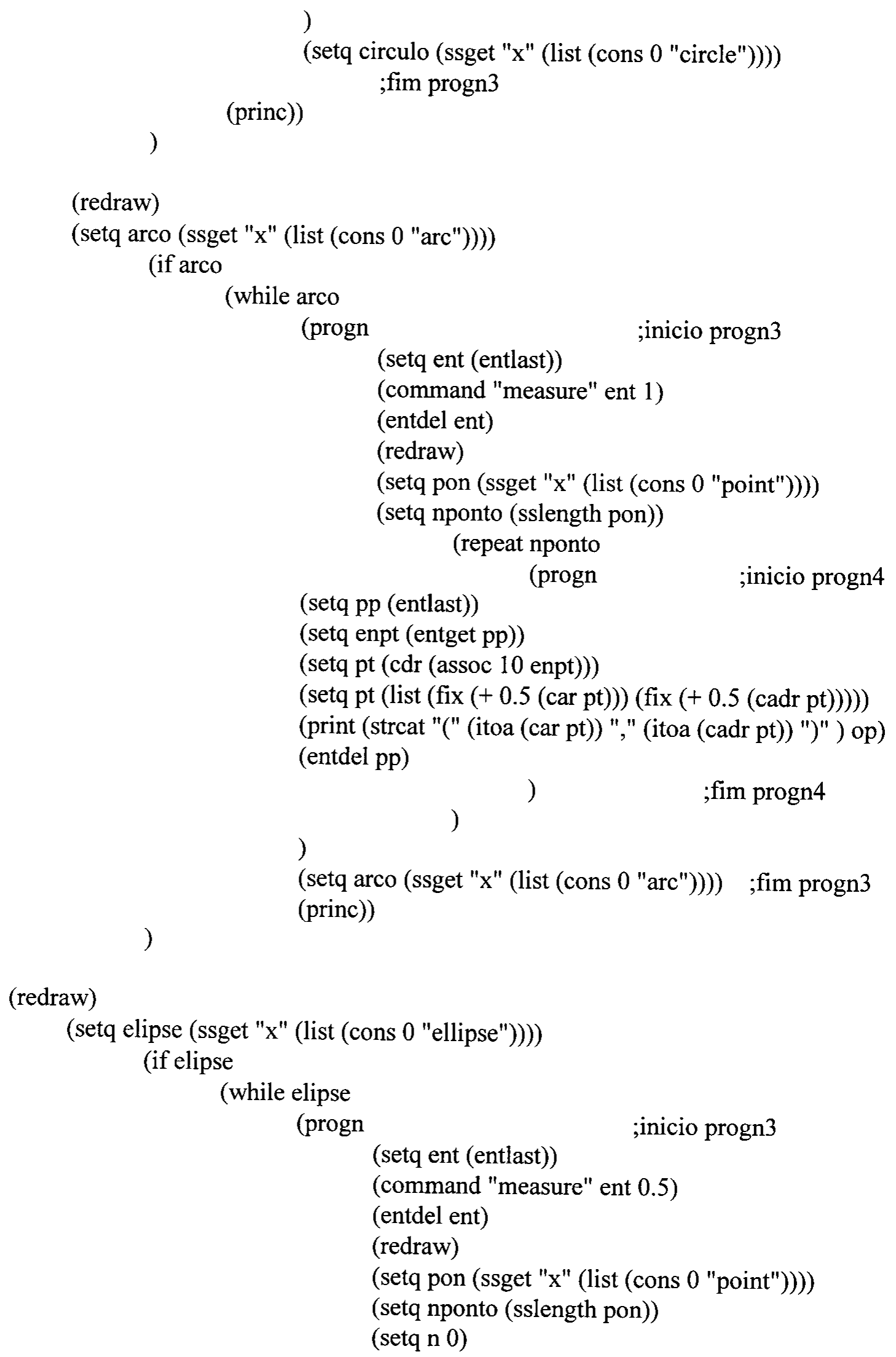


(repeat nponto
(progn

$(\operatorname{setq} n(+n 1))$

;inicio progn 4

(setq pp (entlast))

(setq enpt (entget pp))

(if $(=\mathrm{n} 1)$

(progn

(setq pini (cdr (assoc 10 enpt)))

(setq pxi (car pini))

(setq pyi (cadr pini))

)

(setq pf (cdr (assoc 10 enpt)))

)

(if (= n nponto)

(progn

(setq pxf (car pf))

(setq pyf (cadr pf))

(setq px (/ (+ pxi pxf) 2))

(setq py (/ (+ pyi pyf) 2))

(setq pf (list px py))

(command "point" pf)

$($ setq pf (list (fix $(+0.5($ car pf $)))($ fix $(+0.5($ cadr pf $)))))$

(print (strcat "(" (itoa (car pf)) "," (itoa (cadr pf)) ")" ) op) )

(setq pt (cdr (assoc 10 enpt)))

(setq pt (list (fix (+ 0.5 (car pt))) (fix $(+0.5$ (cadr pt)))))

(print (strcat "(" (itoa (car pt)) "," (itoa (cadr pt)) ")" ) op) (entdel pp)

;fim progn4

)

(setq elipse (ssget "x" (list (cons 0 "elipse")))) ;fim progn3

(princ))

)

(entdel obj)

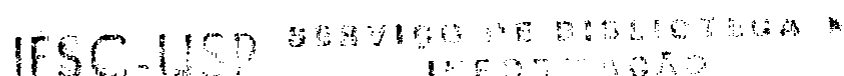


(setq pmin (list (car pmin) (cadr pmin) $(+\mathrm{dz}$ (caddr pmin)))) (setq cont $(+1$ cont))

) ;fim progn2

)

(entdel (entlast))

)

)

;fim progn 1

(redraw)

(close op)

(princ)

) 


\section{APÊNDICE D}

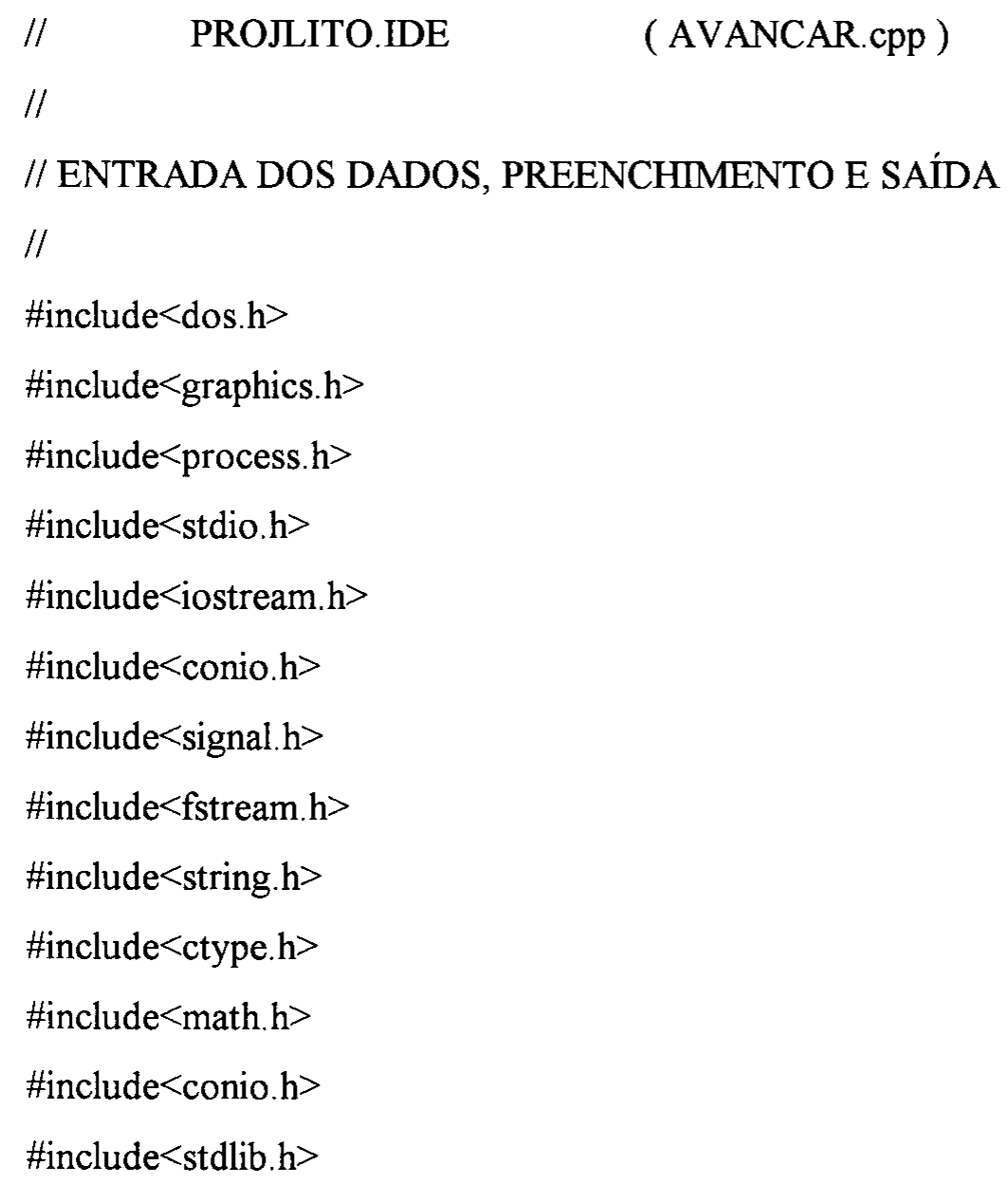


char ch;

char XY,DZ,C;

int $\mathrm{CASO}=0$;

int $\mathrm{NC}=0$;

int NCf;

int $\mathrm{vl}=0$;

int vlf;

int $\mathrm{VALOR}=0$;

int camada;

int espessura;

int valor [10];

int i1,i2,i3,i4,i5, i6,i7,i8;

int $\mathrm{j} 1, \mathrm{j} 2, \mathrm{j} 3, \mathrm{j} 4, \mathrm{j} 5, \mathrm{j} 6, \mathrm{j} 7, \mathrm{j} 8$;

int A,P;

int ia,ja;

int DELTA;

int FIM=0;

int Iespera $=0$;

int Jespera $=0$;

int proximo,ninguem;

int nc,ij;

int NPC [1000]; //numero de pontos por camada

int $* * \mathrm{M}$;

int ${ }^{* *} \mathrm{CBi}$;

int $* * \mathrm{CBj}$;

int $\mathrm{dT}, \mathrm{dTT}$;

int $\mathrm{DTL}=10$;

int DTP $=1$;

int DT=200;

int Vxl,Vxh,Vyl,Vyh,ajuste;

int motor;

void defletores $(\mathrm{i}, \mathrm{j})$ 


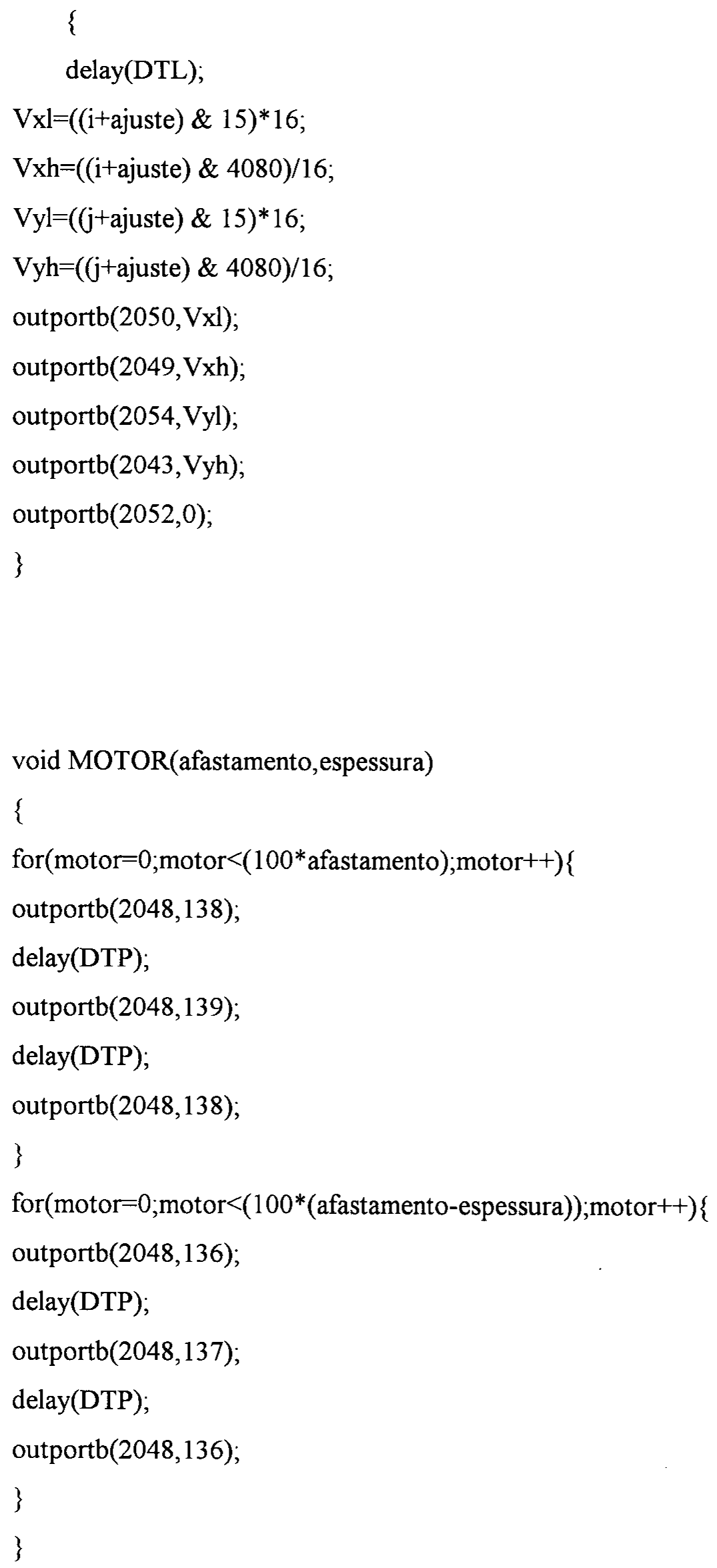




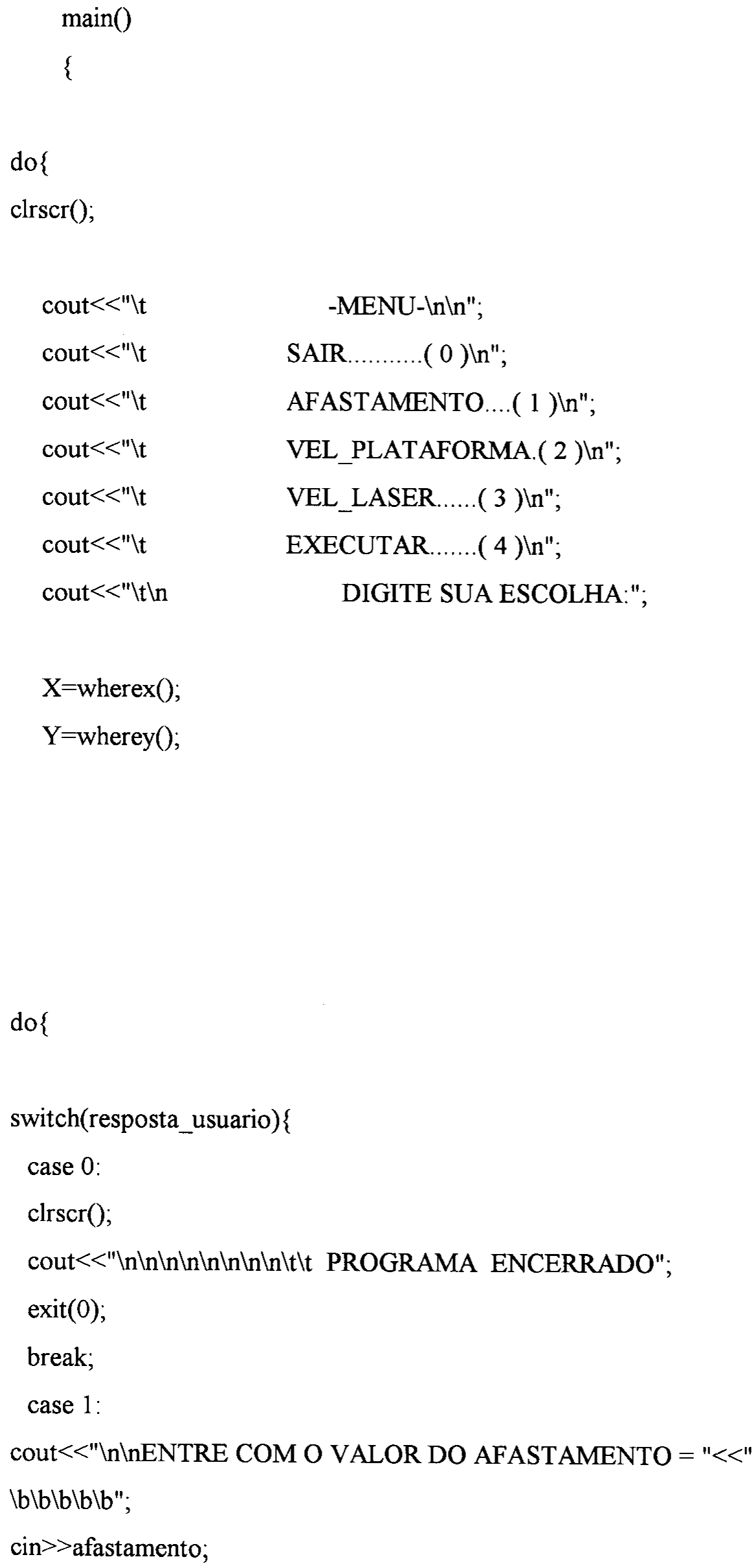

do \{

switch(resposta_usuario) \{

case 0

clrscr();

cout $<<" \ln \backslash n \ln \ln \backslash n \ln \ln \ln |t| t$ PROGRAMA ENCERRADO";

$\operatorname{exit}(0)$;

break;

case 1

cout $<<" \backslash n \backslash n E N T R E$ COM O VALOR DO AFASTAMENTO $="<<"$

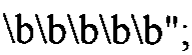

cin>>afastamento; 
break;

case 2:

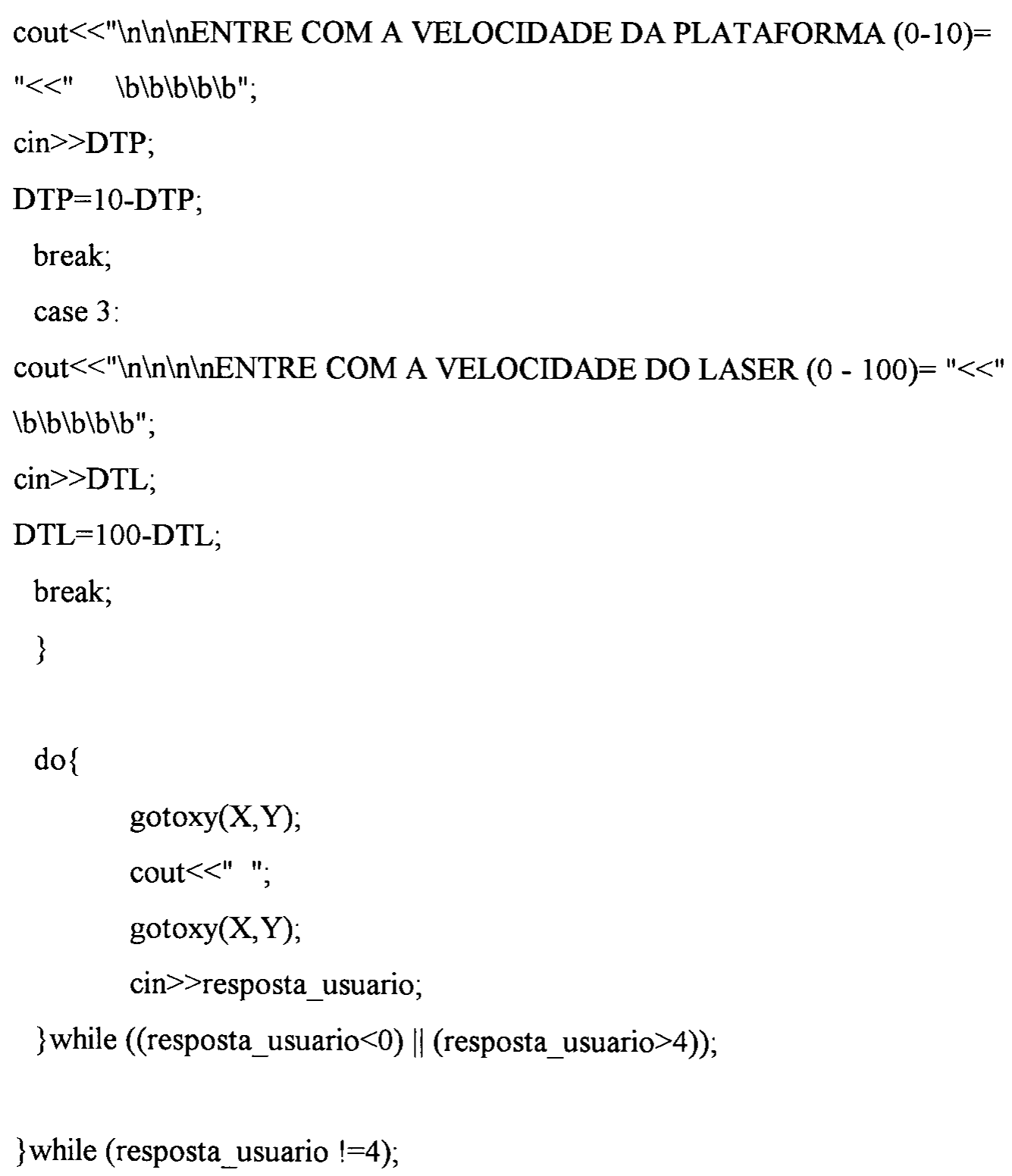


switch (ch) \{

case ' $\mathrm{N}$ ':

$\mathrm{CASO}=4$;

break;

case ' $\mathrm{X}$ ':

$\mathrm{CASO}=1$;

break;

case ' $\mathrm{D}$ ':

$\mathrm{CASO}=2$;

break;

case ' $\mathrm{C}$ ':

nc++;

$\mathrm{ij}=-1$;

$\mathrm{CASO}=3$;

break;

case ' 0 ':

vl++;

vlf=vl;

valor $[\mathrm{vl}]=0$;

break;

case '1':

vl++;

vlf=vl;

valor[vl] $=1$;

break;

case ' 2 ': 


$$
\begin{aligned}
& \text { vl++; } \\
& \text { vlf-vl; }
\end{aligned}
$$

valor $[\mathrm{vl}]=2$;

break;

case '3':

$\mathrm{vl++}$;

vlf=vl;

valor $[\mathrm{vl}]=3$;

break;

case ' 4 ':

vl++;

vlf-vl;

valor $[\mathrm{vl}]=4$;

break;

case ' 5 ':

$\mathrm{vl++}$;

vlf-vl;

valor $[\mathrm{vl}]=5$;

break;

case ' 6 ':

vl++;

$\mathrm{vlf}=\mathrm{vl}$;

valor $[\mathrm{vl}]=6$;

break;

case '7':

$\mathrm{vl++}$;

vlf-vl;

valor $[\mathrm{vl}]=7$;

break; 
case ' 8 ':

$\mathrm{vl++}$;

vlf=vl;

valor $[\mathrm{vl}]=8$;

break;

case ' 9 ':

$\mathrm{vl++}$;

vlf=vl;

valor $[\mathrm{vl}]=9$;

break;

case ",:

for(vl=vlf;vl>0;vl--)

VALOR $=$ VALOR + valor $[\mathrm{vl}] *$ pow $10(\mathrm{vlf}-\mathrm{vl}) ;$

$\mathrm{i}=\mathrm{VALOR}$;

for $(\mathrm{vl}=1 ; \mathrm{vl}<=\mathrm{vlf} ; \mathrm{vl}++)$

valor $[\mathrm{vl}]=0$;

$\mathrm{VALOR}=0$;

$\mathrm{vl}=0$;

vlf $=0$;

break;

case ')':

for(vl=vlf;vl $>0 ; \mathrm{vl}--)$

$\mathrm{VALOR}=\mathrm{VALOR}+$ valor$[\mathrm{vl}] *$ powl0(vlf-vl);

switch (CASO) \{

case 1 :

$\mathrm{I}=\mathrm{J}=\mathrm{VALOR}+3$;

ajuste $=1024-\mathrm{I} / 2$;

$\mathrm{M}=$ new int*[I]; 


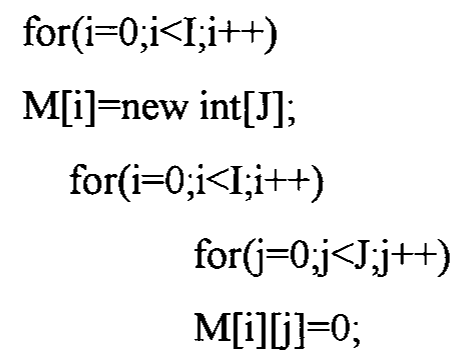

VALOR $=0$;

$\mathrm{vl}=0$;

vlf $=0$;

$\mathrm{CASO}=0$;

break;

case 2:

espessura $=$ VALOR;

VALOR $=0$;

$\mathrm{vl}=0$;

vlf $=0$;

$\mathrm{CASO}=0$;

break;

case 3:

camada=VALOR;

VALOR $=0$;

$\mathrm{vl}=0$;

vlf $=0$;

$\mathrm{CASO}=0$;

break;

case 4 :

$\mathrm{NC}=\mathrm{VALOR}$;

$\mathrm{CBi}=$ new int ${ }^{*}[\mathrm{NC}]$;

$\mathrm{CBj}=$ new int $*[\mathrm{NC}]$;

for $\left(\mathrm{nc}=0 ; \mathrm{nc}<\mathrm{NC} ; \mathrm{nc}^{++}\right)\{$ 
$\mathrm{CBi}[\mathrm{nc}]=$ new int $[1000]$;

$\mathrm{CBj}[\mathrm{nc}]=$ new int $[1000]$;

\}

$\mathrm{nc}=-1$;

VALOR $=0$;

$\mathrm{vl}=0$;

vlf $=0$;

$\mathrm{CASO}=0$;

break;

default :

$\mathrm{j}=\mathrm{VALOR}$;

ij++;

$\mathrm{CBi}[\mathrm{nc}][\mathrm{ij}]=\mathrm{i}$;

$\mathrm{CBj}[\mathrm{nc}][\mathrm{ij}]=\mathrm{j}$;

$\mathrm{NPC}[\mathrm{nc}]=\mathrm{ij}$;

VALOR $=0$;

$\mathrm{vl}=0$;

vlf $=0$;

$\mathrm{CASO}=0$;

break;

break;

\}

\}

minha_entrada.close();

initgraph(\&gdriver,\&gmode,"'");

errorcode=graphresult $($ );

if(errorcode != grOk)\{

printf("ERRO DE FUNCAO GRAFICA:\%sIn",grapherrormsg(errorcode));

printf("PRECIONE QUALQUER TECLA PARA PARAR:"); 


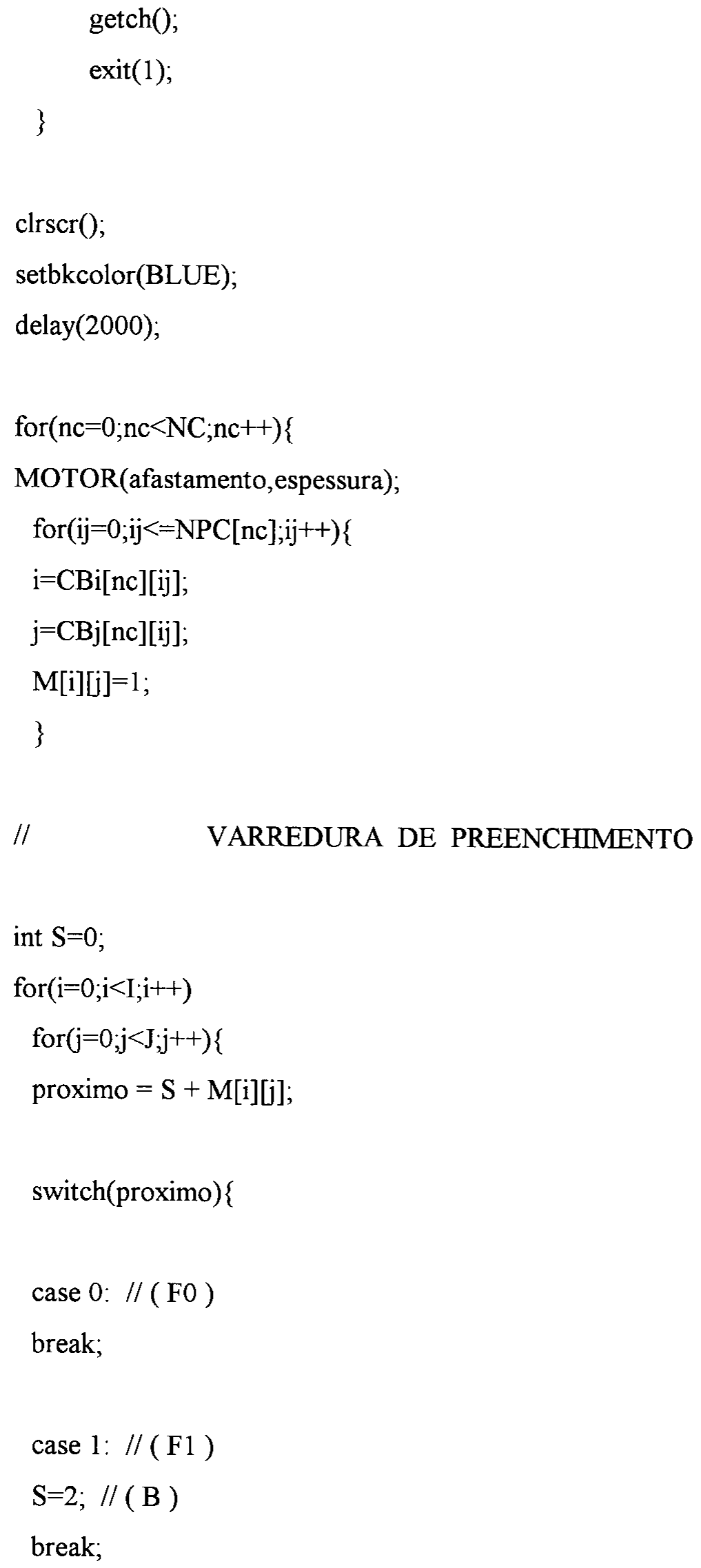




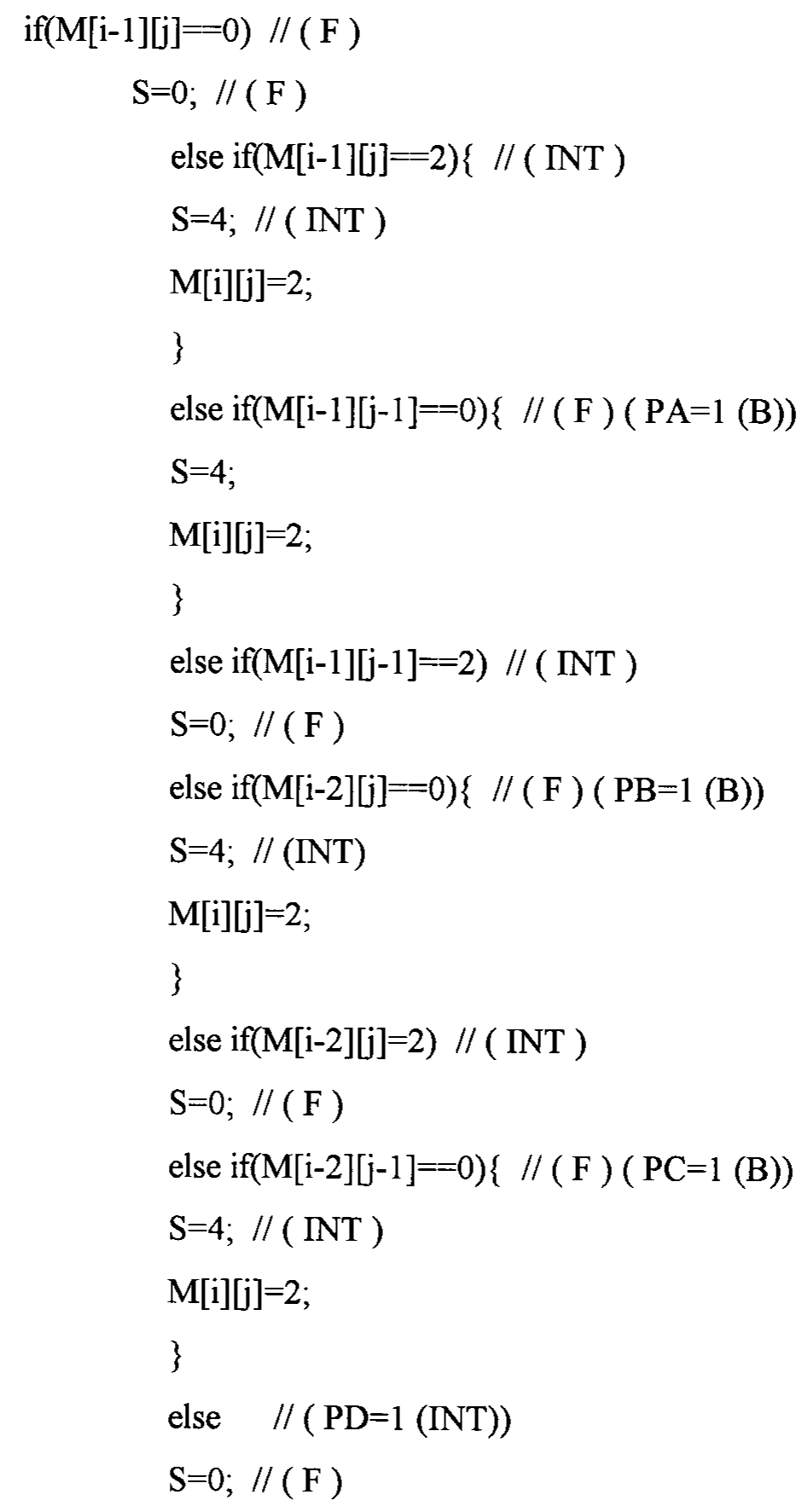

break;

case 3:

break;

case 4: // ( INT )

$\mathrm{M}[\mathrm{i}][\mathrm{i}]=2$;

break; 
case $5: / /(\mathrm{B})$

$\mathrm{S}=2$;

break;

\}

\}

cout $<<" \backslash \mathrm{a} "$;

$\operatorname{clrscr}()$;

cout $<<" \backslash n \backslash n \backslash n \backslash n \backslash n \backslash n \backslash n \backslash n \backslash n \backslash n \backslash n \backslash n \backslash n \backslash n \backslash n \backslash n \backslash n \backslash n \backslash n \backslash n \backslash n \backslash n \backslash n \backslash n \backslash n C A M A D A$

$"<<\mathrm{nc}+1<<" / "<<\mathrm{NC}$;

//

VARREDURA DE SAIDA

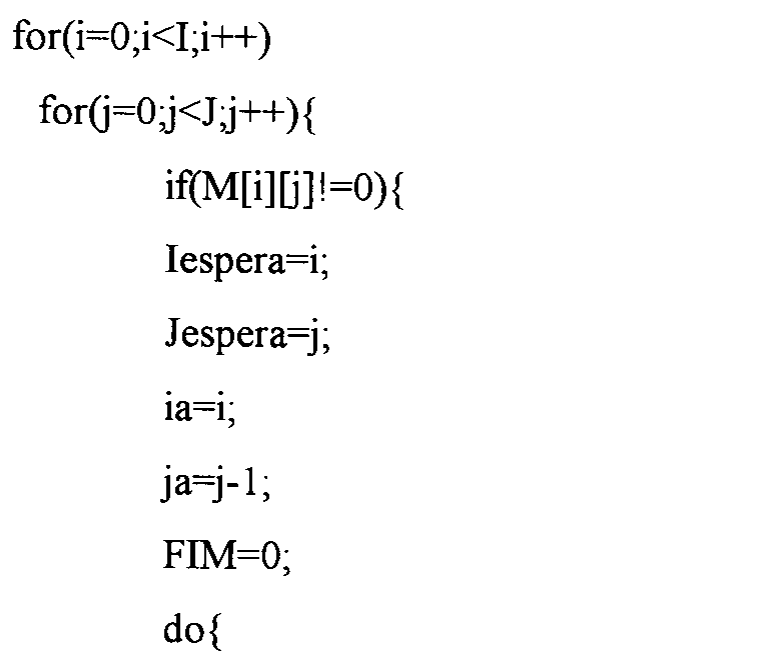

DELTA $=(i-i a)-3 *(j-j a)$;

switch(DELTA)\{

case 1:

$\mathrm{i} 1=\mathrm{i} 2=\mathrm{i} 3=\mathrm{i} 5=\mathrm{i}+1$;

$\mathrm{i} 4=\mathrm{i} 6=\mathrm{i}$;

i $7=\mathrm{i}-1$;

$\mathrm{i} 8=\mathrm{i}+2$; 
$\mathrm{j} 1=\mathrm{j}+1$;

$\mathrm{j} 2=\mathrm{j} 8=\mathrm{j}$;

$j 3=j 4=j+2$;

$\mathrm{j} 5=\mathrm{j} 6=\mathrm{j} 7=\mathrm{j}-1$;

$\mathrm{A}=1$;

break;

case -1 :

$\mathrm{i} 1=\mathrm{i} 2=\mathrm{i} 3=\mathrm{i} 5=\mathrm{i}-1$;

$\mathrm{i} 4=\mathrm{i} 6=\mathrm{i}$;

$\mathrm{i} 7=\mathrm{i}+1$;

$\mathrm{i} 8=\mathrm{i}-2$;

$\mathrm{j} 1=\mathrm{j}-1$;

$\mathrm{j} 2=\mathrm{j} 8=\mathrm{j}$;

$\mathrm{j} 3=\mathrm{j} 4=\mathrm{j}-2$;

$\mathrm{j} 5=\mathrm{j} 6=\mathrm{j} 7=\mathrm{j}+1$;

$\mathrm{A}=1$;

break;

case -4 :

$\mathrm{i} 1=\mathrm{i} 2=\mathrm{i} 3=\mathrm{i} 4=\mathrm{i}-1$;

$\mathrm{i} 5=\mathrm{i}$;

$\mathrm{i} 6=\mathrm{i} 7=\mathrm{i}+1$;

$\mathrm{j} 1=\mathrm{j} 7=\mathrm{j}$;

$j 2=j 5=j 6=j+1$;

$\mathrm{j} 3=\mathrm{j}-1$;

$\mathrm{j} 4=\mathrm{j}-2$;

$\mathrm{A}=0$;

break;

case 4:

$\mathrm{i} 1=\mathrm{i} 2=\mathrm{i} 3=\mathrm{i} 4=\mathrm{i}+1$;

$\mathrm{i} 5=\mathrm{i}$; 
$\mathrm{i} 6=\mathrm{i} 7=\mathrm{i}-1$;

$\mathrm{j} 1=\mathrm{j} 7=\mathrm{j}$;

$\mathrm{j} 2=\mathrm{j} 5=\mathrm{j} 6=\mathrm{j}-1$;

$\mathrm{j} 3=\mathrm{j}+1$;

$\mathrm{j} 4=\mathrm{j}+2$;

$\mathrm{A}=0$;

break;

case -3 :

$\mathrm{i} 1=\mathrm{i}-1$;

$\mathrm{i} 2=\mathrm{i} 8=\mathrm{i}$;

i3 $=\mathrm{i} 4=\mathrm{i}-2$;

i $5=\mathrm{i} 6=\mathrm{i} 7=\mathrm{i}+1$;

$\mathrm{j} 1=\mathrm{j} 2=\mathrm{j} 3=\mathrm{j} 5=\mathrm{j}+1$;

$\mathrm{j} 4=\mathrm{j} 6=\mathrm{j}$;

$\mathrm{j} 7=\mathrm{j}-1$;

$\mathrm{j} 8=\mathrm{j}+2$;

$\mathrm{A}=1$;

break;

case 3 :

$\mathrm{i} 1=\mathrm{i}+1$;

$\mathrm{i} 2=\mathrm{i} 8=\mathrm{i}$;

$\mathrm{i} 3=\mathrm{i} 4=\mathrm{i}+2$;

$\mathrm{i} 5=\mathrm{i} 6=\mathrm{i} 7=\mathrm{i}-1$

$\mathrm{j} 1=\mathrm{j} 2=\mathrm{j} 3=\mathrm{j} 5=\mathrm{j}-1$;

$\mathrm{j} 4=\mathrm{j} 6=\mathrm{j}$;

$\mathrm{j} 7=\mathrm{j}+\mathrm{l}$;

$\mathrm{j} 8=\mathrm{j}-2$;

$\mathrm{A}=1$;

break;

case -2 : 
$\mathrm{i} 1=\mathrm{i} 7=\mathrm{i}$;

$\mathrm{i} 2=\mathrm{i} 5=\mathrm{i} 6=\mathrm{i}+1$;

$\mathrm{i} 3=\mathrm{i}-1$;

$\mathrm{i} 4=\mathrm{i}-2$;

$\mathrm{j} 1=\mathrm{j} 2=\mathrm{j} 3=\mathrm{j} 4=\mathrm{j}+1$;

$\mathrm{j} 5=\mathrm{j}$;

$j 6=j 7=j-1$;

$\mathrm{A}=0$;

break;

case 2:

i1 $=\mathrm{i} 7=\mathrm{i}$;

$\mathrm{i} 2=\mathrm{i} 5=\mathrm{i} 6=\mathrm{i}-1$;

$\mathrm{i} 3=\mathrm{i}+1$;

$\mathrm{i} 4=\mathrm{i}+2$;

$\mathrm{j} 1=\mathrm{j} 2=\mathrm{j} 3=\mathrm{j} 4=\mathrm{j}-1$;

$\mathrm{j} 5=\mathrm{j}$;

$\mathrm{j} 6=\mathrm{j} 7=\mathrm{j}+1$;

$\mathrm{A}=0$;

break;

\}

if $((\mathrm{M}[\mathrm{i} 1][\mathrm{j} 1]==0) \& \&(\mathrm{M}[\mathrm{i} 2][\mathrm{j} 2] !=0))\{$

$\mathrm{M}[\mathrm{i} 2][\mathrm{j} 2]=0$;

putpixel(i2,j2,cor);

defletores(i2,j2);

ia $=i$;

$\mathrm{ja}=\mathrm{j}$;

$\mathrm{i}=\mathrm{i} 2$;

$\mathrm{j}=\mathrm{j} 2$;

\}

else if $((M[i 3][j 3]==0) \& \&(M[i 1][j 1] !=0))\{$

$\mathrm{M}[\mathrm{i1}][\mathrm{j} 1]=0$;

putpixel(i1,j1,cor); 
defletores(i1,j1);

$\mathrm{ia}=\mathrm{i}$;

$\mathrm{ja}=\mathrm{j}$;

$\mathrm{i}=\mathrm{i} 1$;

$j=j 1$;

\}

else if $((M[i 4][j 4]==0) \& \&(M[i 3][j 3] !=0))\{$

$$
\text { if }(A==1)\{
$$

$M[i 2][j 2]=0$;

putpixel(i2,j2,cor);

defletores(i2,j2);

$\mathrm{M}[\mathrm{i1}][\mathrm{j} 1]=0$;

putpixel(i1,j1,cor);

defletores(i1,j1);

$\mathrm{M}[\mathrm{i} 3][\mathrm{j} 3]=0$;

putpixel(i3,j3,cor);

defletores $(\mathrm{i} 3, \mathrm{j} 3)$;

ia $=\mathrm{i} 1$;

$\mathrm{ja}=\mathrm{j} 1$;

$\mathrm{i}=\mathrm{i}$;

$\mathrm{j}=\mathrm{j} 3$;

\}

else\{

$\mathrm{M}[\mathrm{i} 3][\mathrm{j} 3]=0$;

putpixel(i3,j3,cor);

defletores $(\mathrm{i} 3, \mathrm{j} 3)$;

$\mathrm{ia}=\mathrm{i}$;

$\mathrm{ja}=\mathrm{j}$;

$\mathrm{i}=\mathrm{i} 3$;

$j=j$;

\}

\}

else if(M[i4][j4]!=0)\{ 


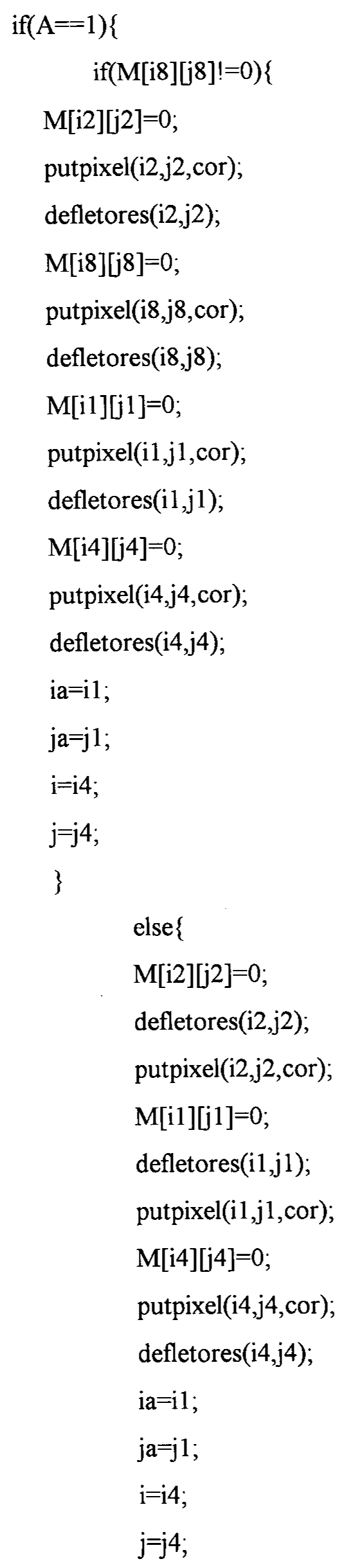


else\{

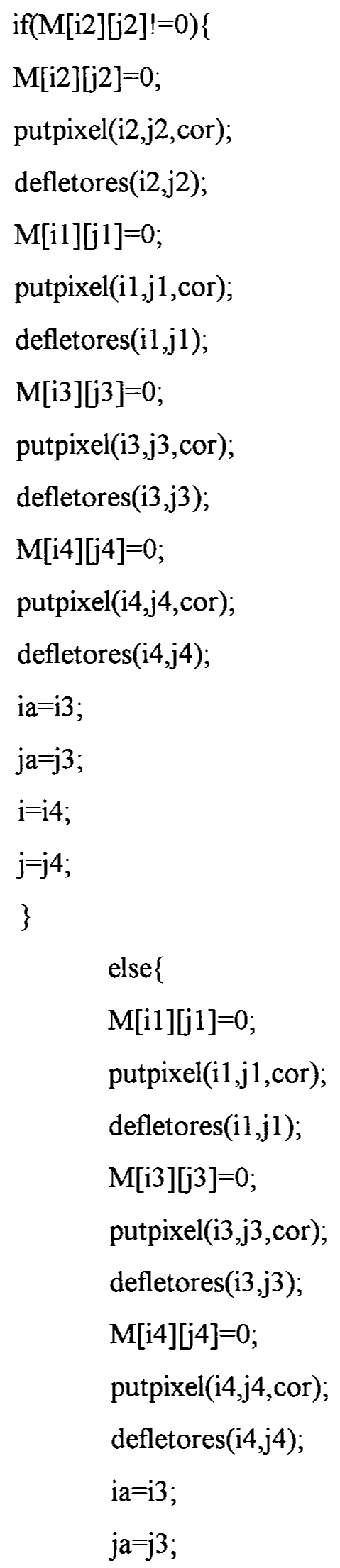




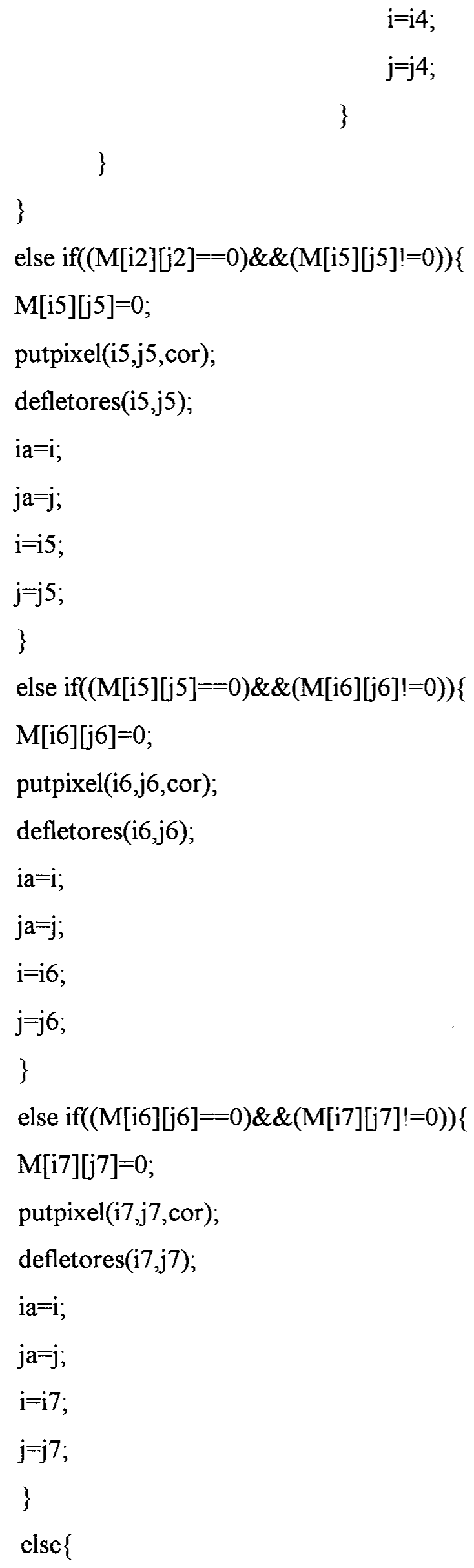


$M[i][j]=0$;

putpixel(i,j,cor);

defletores $(\mathrm{i}, \mathrm{j})$;

FIM=1;

$\mathrm{i}=$ Iespera;

$\mathrm{j}=$ Jespera;

\}

\} while(FIM==0);

\}

\}

\}

for $(\mathrm{i}=0 ; \mathrm{i}<\mathrm{I} ; \mathrm{i}++)$

$\operatorname{delete}(\mathrm{M}[\mathrm{i}])$;

for $\left(\mathrm{nc}=0 ; \mathrm{nc}<\mathrm{NC} ; \mathrm{nc}^{++}\right)\{$

$\operatorname{delete}(\mathrm{CBi}[\mathrm{nc}])$;

delete(CBj[nc]);

\}

cout $<<"$ PRECIONE QUALQUER TECLA PARA CONTINUAR";

getch();

closegraph();

\}while $(\mathrm{i}=\mathrm{i})$;

return(0);

\} 